Nevada

Environmental

Management

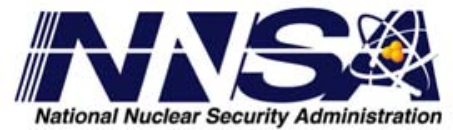

Operations Activity

\title{
Corrective Action Investigation Plan for Corrective Action Unit 550: Smoky Contamination Area Nevada National Security Site, Nevada
}

Controlled Copy No.:

Revision No.: 0

May 2012

Approved for public release; further dissemination unlimited.

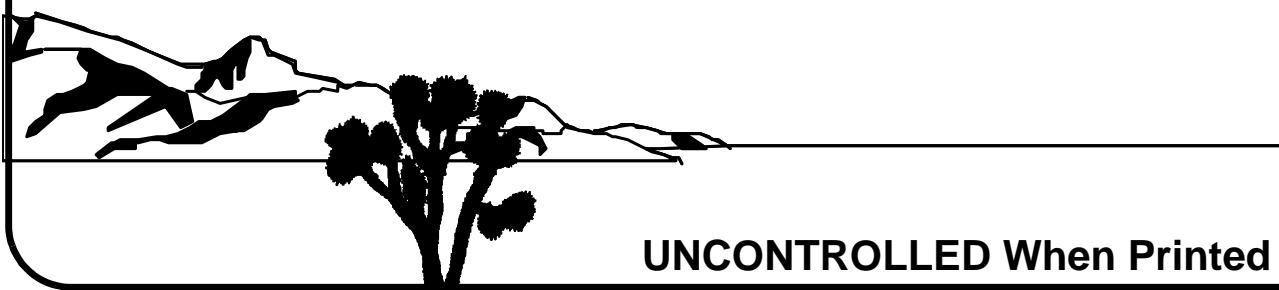


Available for sale to the public from:

U.S. Department of Commerce

National Technical Information Service

5301 Shawnee Road

Alexandria, VA 22312

Telephone: 800.553.6847

Fax: 703.605.6900

E-mail: orders@ntis.gov

Online Ordering: http://www.ntis.gov/help/ordermethods.aspx

Available electronically at http://www.osti.gov/bridge

Available for a processing fee to U.S. Department of Energy and its contractors, in paper, from:

U.S. Department of Energy

Office of Scientific and Technical Information

P.O. Box 62

Oak Ridge, TN 37831-0062

Phone: 865.576.8401

Fax: 865.576.5728

Email: reports@adonis.osti.gov

Reference herein to any specific commercial product, process, or service by trade name, trademark, manufacturer, or otherwise, does not necessarily constitute or imply its endorsement, recommendation, or favoring by the United States Government or any agency thereof or its contractors or subcontractors. 


\title{
CORRECTIVE ACTION INVESTIGATION PLAN FOR CORRECTIVE ACTION UNIT 550: SMOKY CONTAMINATION AREA NEVADA NATIONAL SECURITY SITE, NEVADA
}

\author{
U.S. Department of Energy, National Nuclear Security Administration \\ Nevada Site Office \\ Las Vegas, Nevada
}

Controlled Copy No.:

Revision No.: 0

May 2012

Approved for public release; further dissemination unlimited.

Reviewed and determined to be UNCLASSIFIED.
Derivative Classifier:_Joseph P. Johnston/N-1 CO
Signature: $\frac{1 \mathrm{~s} / \text { Joseph P. Johnston }}{\text { (Name/persenaljentifind position title) }}$
Date:




\section{CORRECTIVE ACTION INVESTIGATION PLAN FOR CORRECTIVE ACTION UNIT 550: SMOKY CONTAMINATION AREA NEVADA NATIONAL SECURITY SITE, NEVADA}

\footnotetext{
Approved by: /S/ Robert F. Boehlecke

for Kevin J. Cabble

Date:

Soils Activity Lead
}

\footnotetext{
Approved by: /s/ Robert F. Boehlecke Date: $5 / 9 / 12$

Robert F. Boehlecke

Environmental Management Operations

Activity Manager
} 


\section{Table of Contents}

List of Figures . $\mathrm{v}$

List of Tables . vii

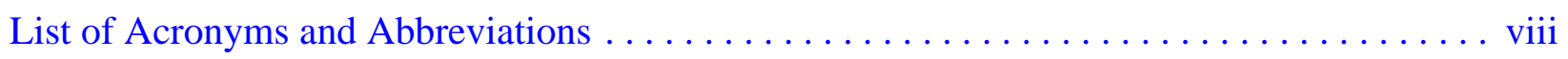

Executive Summary . . . . . . . . . . . . . . . . . . . . . . ES-1

$1.0 \quad$ Introduction. . . . . . . . . . . . . . . . . . . . . . . 1

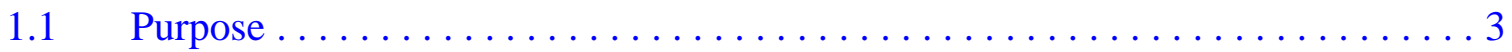

1.1.1 CAU 550 History and Description . . . . . . . . . . . . . . . 3

1.1 .2 Data Quality Objective Summary $\ldots \ldots \ldots \ldots \ldots \ldots \ldots \ldots \ldots$

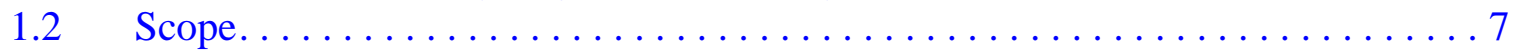

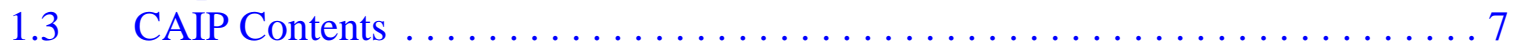

$2.0 \quad$ Facility Description. . . . . . . . . . . . . . . $9 \ldots \ldots \ldots \ldots \ldots \ldots$

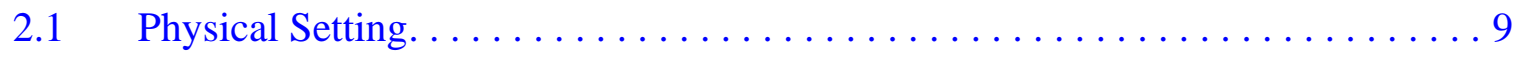

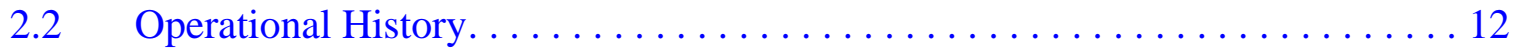

2.2.1 Study Group 1, Atmospheric Test . . . . . . . . . . . . . . 15

2.2.2 Study Group 2, Safety Experiments . . . . . . . . . . . . . . 17

2.2 .3 Study Group 3, Washes . . . . . . . . . . . . . . . . . . 17

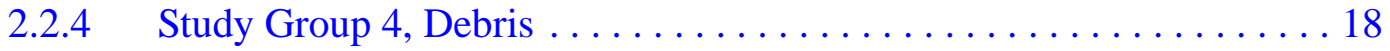

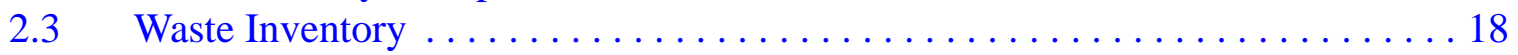

2.3.1 Study Group 1, Atmospheric Test . . . . . . . . . . . . . . . 18

2.3.2 Study Group 2, Safety Experiments . . . . . . . . . . . . . . . 19

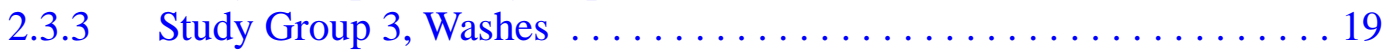

2.3 .4 Study Group 4, Debris . . . . . . . . . . . . . . . . . 19

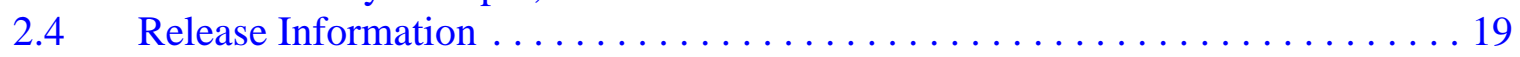

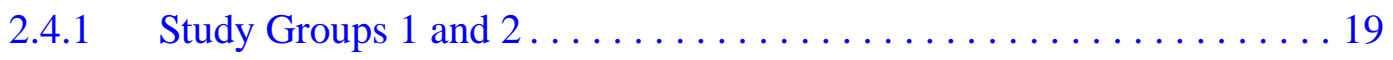

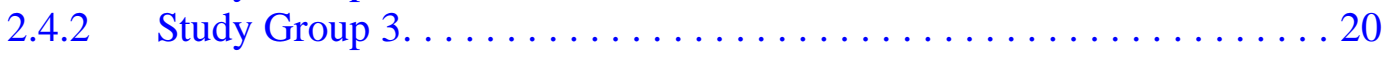

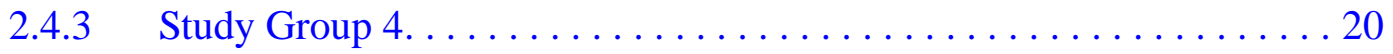

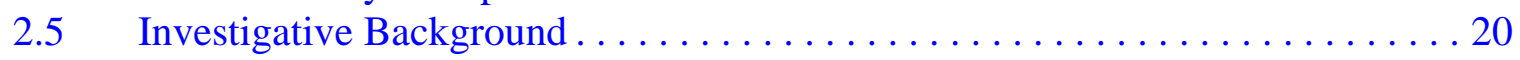

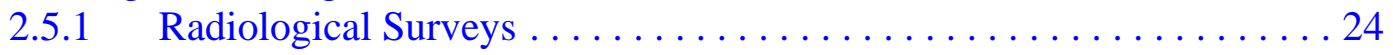

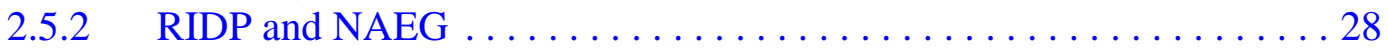

2.5.3 CAU 550 Preliminary Investigation. . . . . . . . . . . . . . . . 29

2.5.4 National Environmental Policy Act . . . . . . . . . . . . . 32

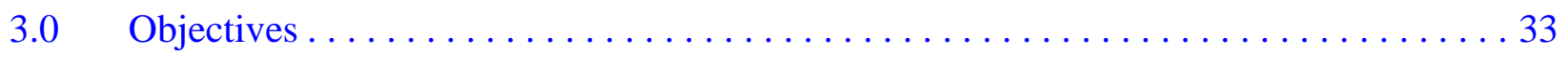

3.1 Conceptual Site Model . . . . . . . . . . . . . . . . . . . 33

3.1.1 Land-Use and Exposure Scenarios. . . . . . . . . . . . . 33

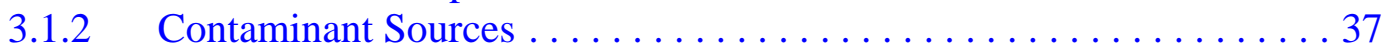

3.1.3 Release Mechanisms . . . . . . . . . . . . . . . . . 37

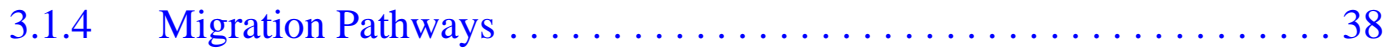

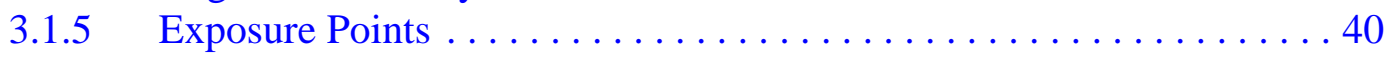




\section{Table of Contents (Continued)}

3.1.6 Exposure Routes. ......................... 40

3.1.7 Additional Information....................... 40

3.2 Contaminants of Potential Concern . . . . . . . . . . . . . . . . . . . . . . . . . . 40

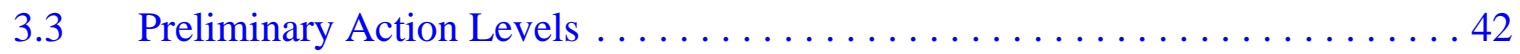

3.3.1 Chemical PALs............................... 45

3.3.2 Radionuclide PALs............................. 45

3.4 DQO Process Discussion ........................... 46

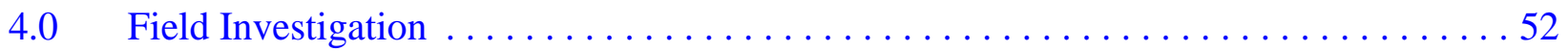

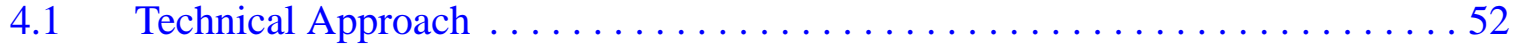

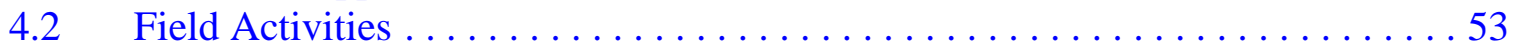

4.2.1 Site Preparation Activities . . . . . . . . . . . . . . . . 53

4.2.2 Sample Location Selection.......................... 54

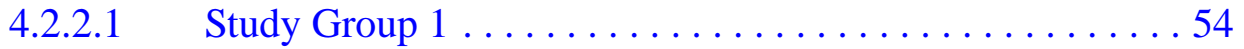

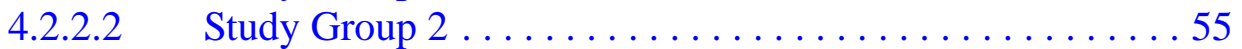

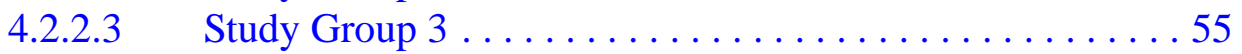

4.2.2.4 Study Group $4 \ldots \ldots \ldots \ldots \ldots \ldots \ldots \ldots \ldots \ldots \ldots \ldots \ldots \ldots$

4.2.3 Sample Collection ........................... 57

4.2.4 Sample Management $\ldots \ldots \ldots \ldots \ldots \ldots \ldots \ldots \ldots \ldots \ldots$

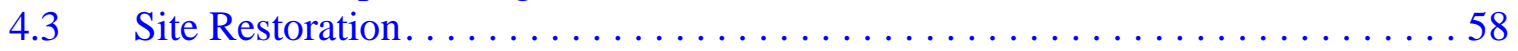

$5.0 \quad$ Waste Management....................................... 59

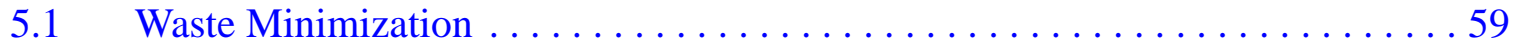

$5.2 \quad$ Potential Waste Streams . . . . . . . . . . . . . . . . . . . . . . . 60

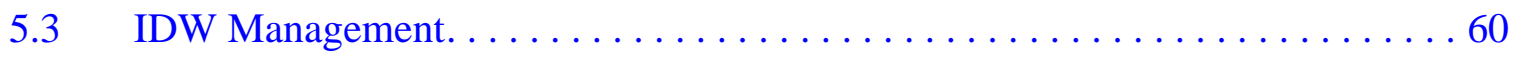

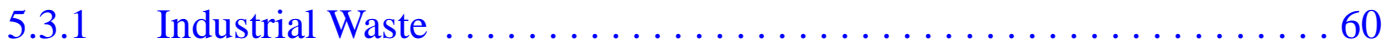

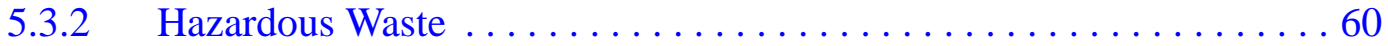

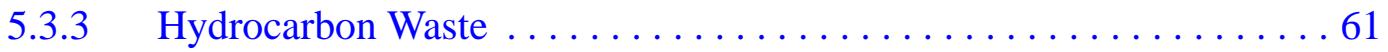

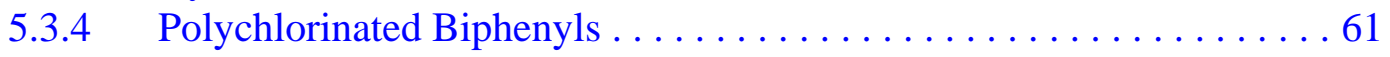

5.3.5 Low-Level Waste .............................. 61

5.3.6 Mixed Low-Level Waste .......................... 61

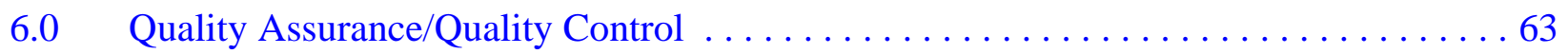

$6.1 \quad$ QC Sampling Activities ................................. 64

$6.2 \quad$ Laboratory/Analytical QA . . . . . . . . . . . . . . . . . . . . . . . 65

6.2.1 Data Validation................................... 65

6.2 .2 Data Quality Indicators......................... 65

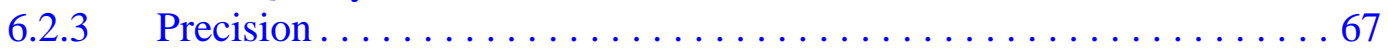

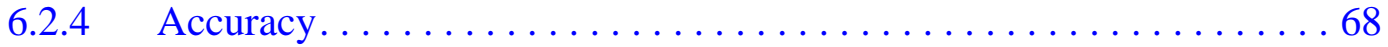

6.2 .5 Representativeness ...........................69 69

6.2 .6 Completeness ............................... 69 


\section{Table of Contents (Continued)}

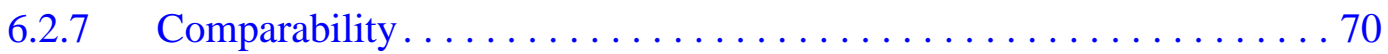

$6.2 .8 \quad$ Sensitivity ............................... 70

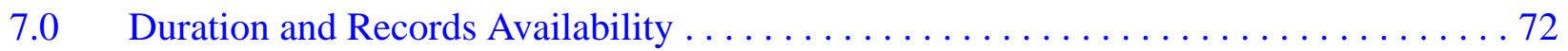

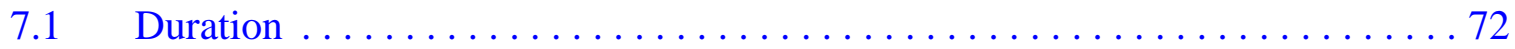

$7.2 \quad$ Records Availability . . . . . . . . . . . . . . . . . . . . . . . . . 72

$8.0 \quad$ References..................................... 73

\section{Appendix A - Data Quality Objectives}

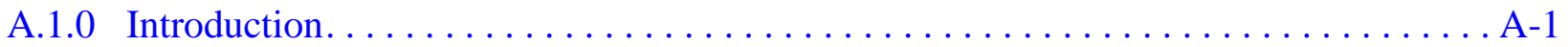

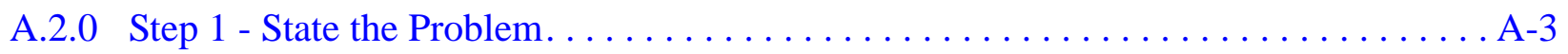

A.2.1 Planning Team Members $\ldots \ldots \ldots \ldots \ldots \ldots \ldots \ldots \ldots \ldots \ldots \ldots \ldots \ldots \ldots \ldots$

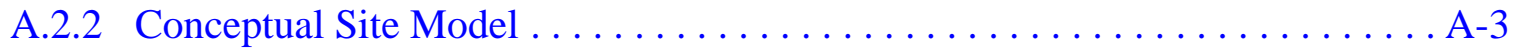

A.2.2.1 Release Sources ........................... A-5

A.2.2.2 Potential Contaminants. ...................... A-9

A.2.2.3 Contaminant Characteristics...................... A-9

A.2.2.4 Site Characteristics ........................ A-13

A.2.2.5 Migration Pathways and Transport Mechanisms ............. A-14

A.2.2.6 Exposure Scenarios . . . . . . . . . . . . . . . . . . . . A-15

A.3.0 Step 2 - Identify the Goal of the Study ....................... A-17

A.3.1 Decision Statements . . . . . . . . . . . . . . . . . . . . . . . A

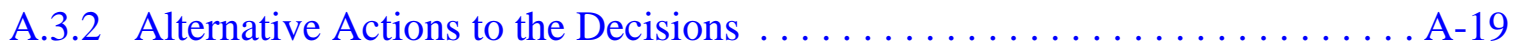

A.3.2.1 Alternative Actions to Decision I. . . . . . . . . . . . . A-19

A.3.2.2 Alternative Actions to Decision II . . . . . . . . . . . . . A-19

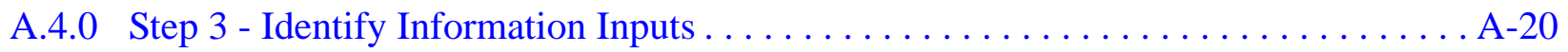

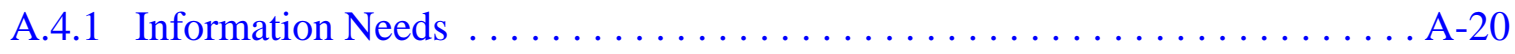

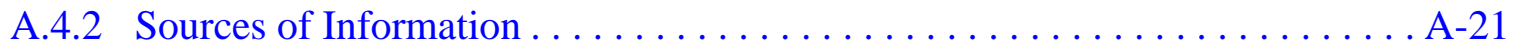

A.4.2.1 Sample Locations .......................... A-21

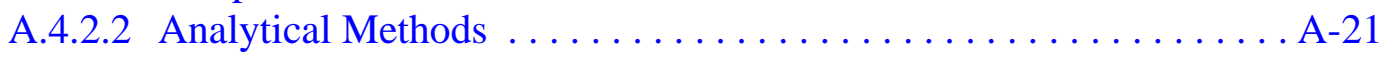

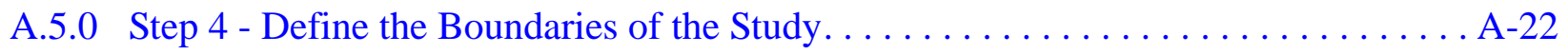

A.5.1 Target Populations of Interest . . . . . . . . . . . . . . . . . . . . A-22

A.5.2 Spatial Boundaries .............................. A-22

A.5.3 Practical Constraints ............................... A-23

A.5.4 Define the Sampling Units . . . . . . . . . . . . . . . . . . . A-23

A.6.0 Step 5 - Develop the Analytic Approach . . . . . . . . . . . . . . . . . . . . A-24 


\section{Table of Contents (Continued)}

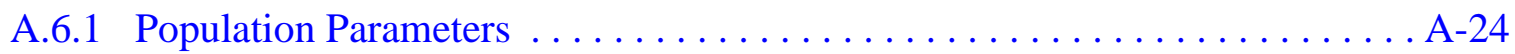

A.6.1.1 Judgmental Sampling Design...................... A-24

A.6.1.2 Probabilistic Sampling Design ................... A-24

A.6.2 Action Levels ................................. A-25

A.6.2.1 Chemical PALs............................. A-26

A.6.2.2 Radionuclide PALs......................... A-27

A.6.3 Decision Rules . . . . . . . . . . . . . . . . . . . . . . . . A-28

A.7.0 Step 6 - Specify Performance or Acceptance Criteria $\ldots \ldots \ldots \ldots \ldots \ldots \ldots$ A-30

A.7.1 Decision Hypotheses. . . . . . . . . . . . . . . . . . . . . . . . A-30

A.7.2 False Negative Decision Error $\ldots \ldots \ldots \ldots \ldots \ldots \ldots \ldots \ldots \ldots \ldots$ A-30

A.7.2.1 False Negative Decision Error

for Judgmental Sampling ...................... A-31

A.7.2.2 False Negative Decision Error

for Probabilistic Sampling ...................... A-32

A.7.3 False Positive Decision Error $\ldots \ldots \ldots \ldots \ldots \ldots \ldots \ldots \ldots \ldots \ldots \ldots \ldots \ldots$

A.8.0 Step 7 - Develop the Plan for Obtaining Data $\ldots \ldots \ldots \ldots \ldots \ldots \ldots \ldots \ldots$ A-34

A.8.1 Primary Releases Sample Location Selection and Sampling . . . . . . . . . . A-34

A.8.1.1 Study Group 1 Sample Plot and TLD Locations ............ A-34

A.8.1.2 Study Group 2 Sample Plot and TLD Locations .............. A-36

A.8.1.3 Sampling of Sample Plots $\ldots \ldots \ldots \ldots \ldots \ldots \ldots \ldots \ldots$ A-36

A.8.1.4 External Dose Sampling...................... A-40

A.8.2 Sampling for Other Releases $\ldots \ldots \ldots \ldots \ldots \ldots \ldots \ldots \ldots \ldots \ldots$ A -42

A.8.2.1 Study Group 3 Sample and TLD Locations ............... A-43

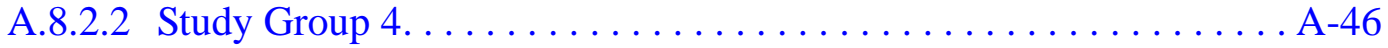

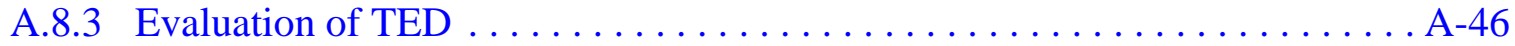

A.8.4 Establishment of Final Corrective Action Boundary . . . . . . . . . . . A-47

A.9.0 References...................................... A 48

\section{Attachment A-1 - Derivation of Residual Radioactive Material Guidelines} for Radionuclides in Soil

\section{Appendix B - Project Organization}

B.1.0 Project Organization . . . . . . . . . . . . . . . . . . . . .

Appendix C - Nevada Division of Environmental Protection Comments 


\section{List of Figures}

Number

1-1 CAU 550, CAS Location Map . .............................. 2

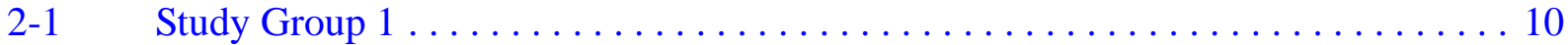

$2-2 \quad$ Study Group $2 \ldots \ldots \ldots \ldots \ldots \ldots \ldots \ldots \ldots \ldots \ldots \ldots \ldots \ldots \ldots \ldots \ldots \ldots \ldots$

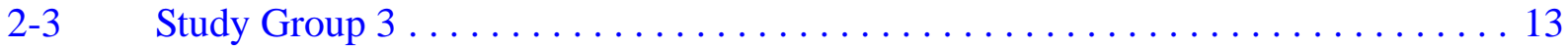

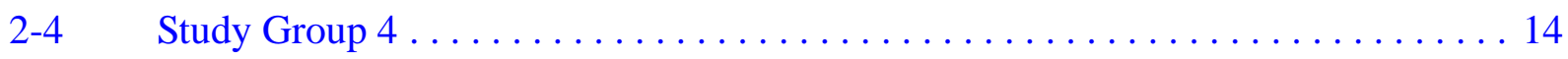

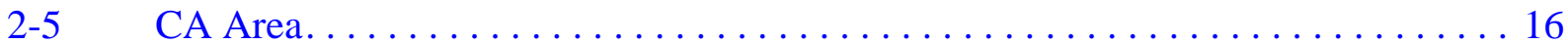

2-6 Gross Count 1994 Flyover............................... 21

2-7 Man-Made Radiation 1994 Flyover ............................ 22

2-8 Americium 1994 Flyover ................................. 23

2-9 CAU 550 RIDP In Situ Data .............................. 27

2-10 Ground-Based PRM-470 Survey. ......................... 30

2-11 Ground-Based FIDLER Survey $\ldots \ldots \ldots \ldots \ldots \ldots \ldots \ldots \ldots \ldots \ldots \ldots \ldots \ldots \ldots$

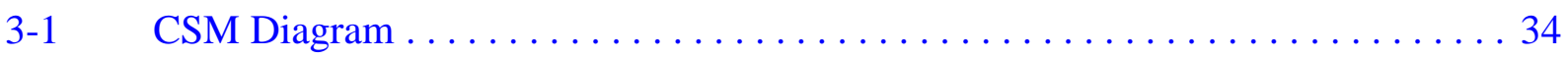

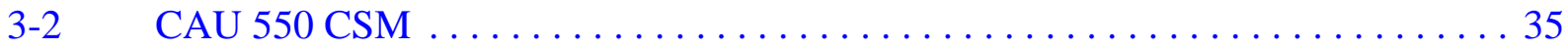

3-3 Risk-Based Corrective Action Decision Process ................... 44

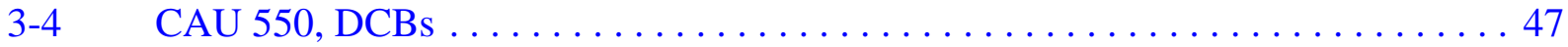

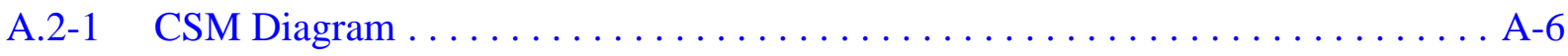

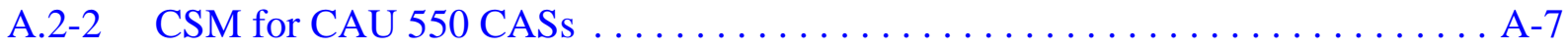

A.8-1 Sample Layout for Study Group $1 \ldots \ldots \ldots \ldots \ldots \ldots \ldots \ldots \ldots \ldots \ldots \ldots \ldots$ 


\section{List of Figures (Continued)}

Number

Title

Page

A.8-2 Sample Layout for Study Group $2 \ldots \ldots \ldots \ldots \ldots \ldots \ldots \ldots \ldots \ldots \ldots$ A $\ldots \ldots \ldots$

A.8-3 Example Sample Plot $\ldots \ldots \ldots \ldots \ldots \ldots \ldots \ldots \ldots \ldots \ldots \ldots \ldots \ldots \ldots \ldots$

A.8-4 Background TLD Layout $\ldots \ldots \ldots \ldots \ldots \ldots \ldots \ldots \ldots \ldots \ldots \ldots \ldots \ldots \ldots$

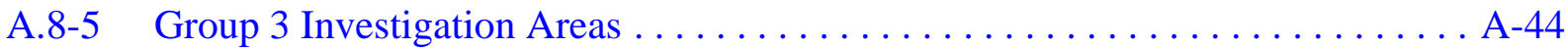




\section{List of Tables}

Number

Title

Page

2-1 Rainfall and PET Information for Yucca Flat. . . . . . . . . . . . . 15

2-2 Comparison of Radiation Survey Methods. . . . . . . . . . . . . . . . 25

3-1 Analytical Methods. .......................... 41

3-2 Analytes Reported by Analytical Methods...................... 42

3-3 RRMG Values......................... 46

3-4 Analytical Requirements for Radionuclides for CAU $550 \ldots \ldots \ldots \ldots \ldots$

3-5 Analytical Requirements for Chemicals for CAU $550 \ldots \ldots \ldots \ldots \ldots \ldots$

6-1 Laboratory and Analytical Performance Criteria

for CAU 550 DQIs . . . . . . . . . . . . . . . . . . . . 66

A.2-1 CSM Description of Elements for Each CAU 550 Group . . . . . . . . . . . . . A-4

A.2-2 Contaminants of Potential Concern $\ldots \ldots \ldots \ldots \ldots \ldots \ldots \ldots \ldots \ldots$. . . . . . . .

A.2-3 Analytical Methods. .......................... A-10

A.2-4 Analytes Reported by Analytical Methods. . . . . . . . . . . . . . . . . A-12

A.2-5 Vertical Migration Potential through the Vadose

of the Major Radionuclide Contaminants. . . . . . . . . . . . . A-13

A.2-6 Land-Use and Exposure Scenarios . . . . . . . . . . . . . A-16

A.6-1 RRMG Values. . . . . . . . . . . . . . . . . . . . 


\section{List of Acronyms and Abbreviations}

Ac

Ag

agl

Am

ASTM

bgs

BJY

CA

CAA

CADD

CAI

CAIP

CAS

CAU

CED

CERCLA

CFR

$\mathrm{cm}$

$\mathrm{cm}^{3} / \mathrm{cm}^{3}$

$\mathrm{Cm}$

Co

COC

COPC

cps

Cs

CSM
Actinium

Silver

Above ground level

Americium

ASTM International

Below ground surface

Buster Jangle Y

Contamination area

Corrective action alternative

Corrective action decision document

Corrective action investigation

Corrective action investigation plan

Corrective action site

Corrective action unit

Committed effective dose

Comprehensive Environmental Response, Compensation, and Liability Act

Code of Federal Regulations

Centimeter

Cubic centimeters per cubic centimeter

Curium

Cobalt

Contaminant of concern

Contaminant of potential concern

Counts per second

Cesium

Conceptual site model 


\section{List of Acronyms and Abbreviations (Continued)}

CZ Contamination zone

DCB Default contamination boundary

DOE U.S. Department of Energy

DQI Data quality indicator

DQO Data quality objective

EPA U.S. Environmental Protection Agency

$\mathrm{Eu} \quad$ Europium

FAL Final action level

FFACO Federal Facility Agreement and Consent Order

FIDLER Field instrument for the detection of low-energy radiation

FSL Field-screening level

FSR Field-screening result

$\mathrm{ft} \quad$ Foot

GPS Global Positioning System

GWS Gamma walkover survey

g/yr Grams per year

GZ Ground zero

HCA High contamination area

HWAA Hazardous waste accumulation area

ICRP International Commission on Radiological Protection

IDW Investigation-derived waste

in. Inch

in./yr Inches per year

K Potassium

$\mathrm{K}_{\mathrm{d}} \quad$ Sorption coefficient

keV Kiloelectron volt 


\section{List of Acronyms and Abbreviations (Continued)}

\begin{tabular}{|c|c|}
\hline kt & Kiloton \\
\hline LCS & Laboratory control sample \\
\hline $\mathrm{m}$ & Meter \\
\hline $\mathrm{m}^{2}$ & Square meter \\
\hline $\mathrm{m} / \mathrm{yr}$ & Meters per year \\
\hline MDC & Minimum detectable concentration \\
\hline mg/day & Milligrams per day \\
\hline mi & Mile \\
\hline $\mathrm{mL} / \mathrm{g}$ & Milliliters per gram \\
\hline $\mathrm{mm} / \mathrm{yr}$ & Millimeters per year \\
\hline mrem & Millirem \\
\hline mrem/IA-yr & Millirem per Industrial Area year \\
\hline mrem/OA-yr & Millirem per Occasional Use Area year \\
\hline mrem/RW-yr & Millirem per Remote Work Area year \\
\hline $\mathrm{mrem} / \mathrm{yr}$ & Millirem per year \\
\hline MS & Matrix spike \\
\hline MSD & Matrix spike duplicate \\
\hline NAC & Nevada Administrative Code \\
\hline NAD & North American Datum \\
\hline NAEG & Nevada Applied Ecology Group \\
\hline $\mathrm{Nb}$ & Niobium \\
\hline ND & Normalized difference \\
\hline NDEP & Nevada Division of Environmental Protection \\
\hline NEPA & National Environmental Policy Act \\
\hline N-I & Navarro-Intera, LLC \\
\hline NNSA/NSO & $\begin{array}{l}\text { U.S. Department of Energy, National Nuclear Security Administration } \\
\text { Nevada Site Office }\end{array}$ \\
\hline
\end{tabular}




\section{List of Acronyms and Abbreviations (Continued)}

\begin{tabular}{|c|c|}
\hline NNSS & Nevada National Security Site \\
\hline NNSSWAC & Nevada National Security Site Waste Acceptance Criteria \\
\hline NRDS & Nuclear Rocket Development Station \\
\hline NTS & Nevada Test Site \\
\hline PAL & Preliminary action level \\
\hline $\mathrm{Pb}$ & Lead \\
\hline PCB & Polychlorinated biphenyl \\
\hline $\mathrm{pCi} / \mathrm{g}$ & Picocuries per gram \\
\hline PET & Potential evapotranspiration \\
\hline PPE & Personal protective equipment \\
\hline PSM & Potential source material \\
\hline $\mathrm{Pu}$ & Plutonium \\
\hline QA & Quality assurance \\
\hline QAPP & Quality Assurance Project Plan \\
\hline QC & Quality control \\
\hline RBCA & Risk-based corrective action \\
\hline RBSL & Risk-based screening level \\
\hline RCRA & Resource Conservation and Recovery Act \\
\hline REOP & Real Estate/Operations Permit \\
\hline RESRAD & Residual Radioactive \\
\hline RIDP & Radionuclide Inventory and Distribution Program \\
\hline $\mathrm{RL}$ & Reporting limit \\
\hline RMA & Radioactive material area \\
\hline RPD & Relative percent difference \\
\hline RRMG & Residual radioactive material guideline \\
\hline RWMS & Radioactive waste management site \\
\hline
\end{tabular}




\section{List of Acronyms and Abbreviations (Continued)}

$\mathrm{Sr}$

SSTL

SVOC

TCLP

TED

Th

$\mathrm{Tl}$

TLD

$\mathrm{TPH}$

TSCA

$\mathrm{U}$

UCL

UTM

VOC

$\mu \mathrm{Ci} / \mathrm{g}$

$\mu \mathrm{R} / \mathrm{hr}$

$\% \mathrm{R}$
Strontium

Site-specific target level

Semivolatile organic compound

Toxicity Characteristic Leaching Procedure

Total effective dose

Thorium

Thallium

Thermoluminescent dosimeter

Total petroleum hydrocarbons

Toxic Substances Control Act

Uranium

Upper confidence limit

Universal Transverse Mercator

Volatile organic compound

Microcuries per gram

Microroentgens per hour

Percent recovery 


\section{Executive Summary}

Corrective Action Unit (CAU) 550 is located in Areas 7, 8, and 10 of the Nevada National Security Site, which is approximately 65 miles northwest of Las Vegas, Nevada. CAU 550, Smoky Contamination Area, comprises 19 corrective action sites (CASs). Based on process knowledge of the releases associated with the nuclear tests and radiological survey information about the location and shape of the resulting contamination plumes, it was determined that some of the CAS releases are co-located and will be investigated as study groups. This document describes the planned investigation of the following CASs (by study group):

\section{- Study Group 1, Atmospheric Test}

- CAS 08-23-04, Atmospheric Test Site T-2C

\section{- $\quad$ Study Group 2, Safety Experiments}

- CAS 08-23-03, Atmospheric Test Site T-8B

- CAS 08-23-06, Atmospheric Test Site T-8A

- CAS 08-23-07, Atmospheric Test Site T-8C

\section{- Study Group 3, Washes}

- Potential stormwater migration of contaminants from CASs

\section{- Study Group 4, Debris}

- CAS 08-01-01, Storage Tank

- CAS 08-22-05, Drum

- CAS 08-22-07, Drum

- CAS 08-22-08, Drums (3)

- CAS 08-22-09, Drum

- CAS 08-24-03, Battery

- CAS 08-24-04, Battery

- CAS 08-24-07, Batteries (3)

- CAS 08-24-08, Batteries (3)

- CAS 08-26-01, Lead Bricks (200)

- CAS 10-22-17, Buckets (3)

- CAS 10-22-18, Gas Block/Drum

- CAS 10-22-19, Drum; Stains

- CAS 10-22-20, Drum

- CAS 10-24-10, Battery 
These sites are being investigated because existing information on the nature and extent of potential contamination is insufficient to evaluate and recommend corrective action alternatives (CAAs). Additional information will be obtained by conducting a corrective action investigation before evaluating CAAs and selecting the appropriate corrective action for each study group. The results of the field investigation will support a defensible evaluation of viable CAAs that will be presented in the Corrective Action Decision Document.

The sites will be investigated based on the data quality objectives (DQOs) developed on January 31, 2012, by representatives of the Nevada Division of Environmental Protection and the U.S. Department of Energy (DOE), National Nuclear Security Administration Nevada Site Office. The DQO process was used to identify and define the type, amount, and quality of data needed to develop and evaluate appropriate corrective actions for CAU 550.

The potential contamination sources associated with the study groups are from nuclear testing activities conducted at CAU 550. The DQO process resulted in an assumption that the total effective dose (TED) within the default contamination boundary of CAU 550 exceeds the final action level and requires corrective action. The presence and nature of contamination outside the default contamination boundary at CAU 550 will be evaluated based on information collected from a field investigation. Radiological contamination will be evaluated based on a comparison of the TED at sample locations to the dose-based final action level. The TED will be calculated as the total of separate estimates of internal and external dose. Results from the analysis of soil samples will be used to calculate internal radiological dose. Thermoluminescent dosimeters placed at the center of each sample location will be used to measure external radiological dose.

Appendix A provides a detailed discussion of the DQO methodology and the DQOs specific to each group of CASs.

This Corrective Action Investigation Plan has been developed in accordance with the Federal Facility Agreement and Consent Order that was agreed to by the State of Nevada; DOE, Environmental Management; U.S. Department of Defense; and DOE, Legacy Management. Under the Federal Facility Agreement and Consent Order, this Corrective Action Investigation Plan will be submitted to the Nevada Division of Environmental Protection for approval. Fieldwork will be conducted after the plan is then approved. 


\subsection{Introduction}

This Corrective Action Investigation Plan (CAIP) contains project-specific information, including facility descriptions, environmental sample collection objectives, and criteria for conducting site investigation activities at Corrective Action Unit (CAU) 550: Smoky Contamination Area, Nevada National Security Site (NNSS), Nevada.

This CAIP has been developed in accordance with the Federal Facility Agreement and Consent Order (FFACO) (1996, as amended) that was agreed to by the State of Nevada; U.S. Department of Energy (DOE), Environmental Management; U.S. Department of Defense; and DOE, Legacy Management.

CAU 550 is located in Areas 7, 8, and 10 of the NNSS (formerly the Nevada Test Site [NTS]), which is approximately 65 miles (mi) northwest of Las Vegas, Nevada. CAU 550 comprises 19 corrective action sites (CASs), which are shown on Figure 1-1. The CASs are sorted into the following study groups based on release potential and technical similarities:

\section{- Study Group 1, Atmospheric Test}

- 08-23-04, Atmospheric Test Site T-2C

\section{- Study Group 2, Safety Experiments}

- 08-23-03, Atmospheric Test Site T-8B

- 08-23-06, Atmospheric Test Site T-8A

- 08-23-07, Atmospheric Test Site T-8C

\section{- Study Group 3, Washes}

- This group consists of certain areas that are outside the test area but related to the overall site. These are drainage channels (called "washes" in this document) that cut through the site and a fenced "depositional area” south of Circle Road.

\section{- Study Group 4, Debris}

- 08-01-01, Storage Tank

- 08-22-05, Drum

- 08-22-07, Drum

- 08-22-08, Drums (3)

- 08-22-09, Drum

- 08-24-03, Battery 


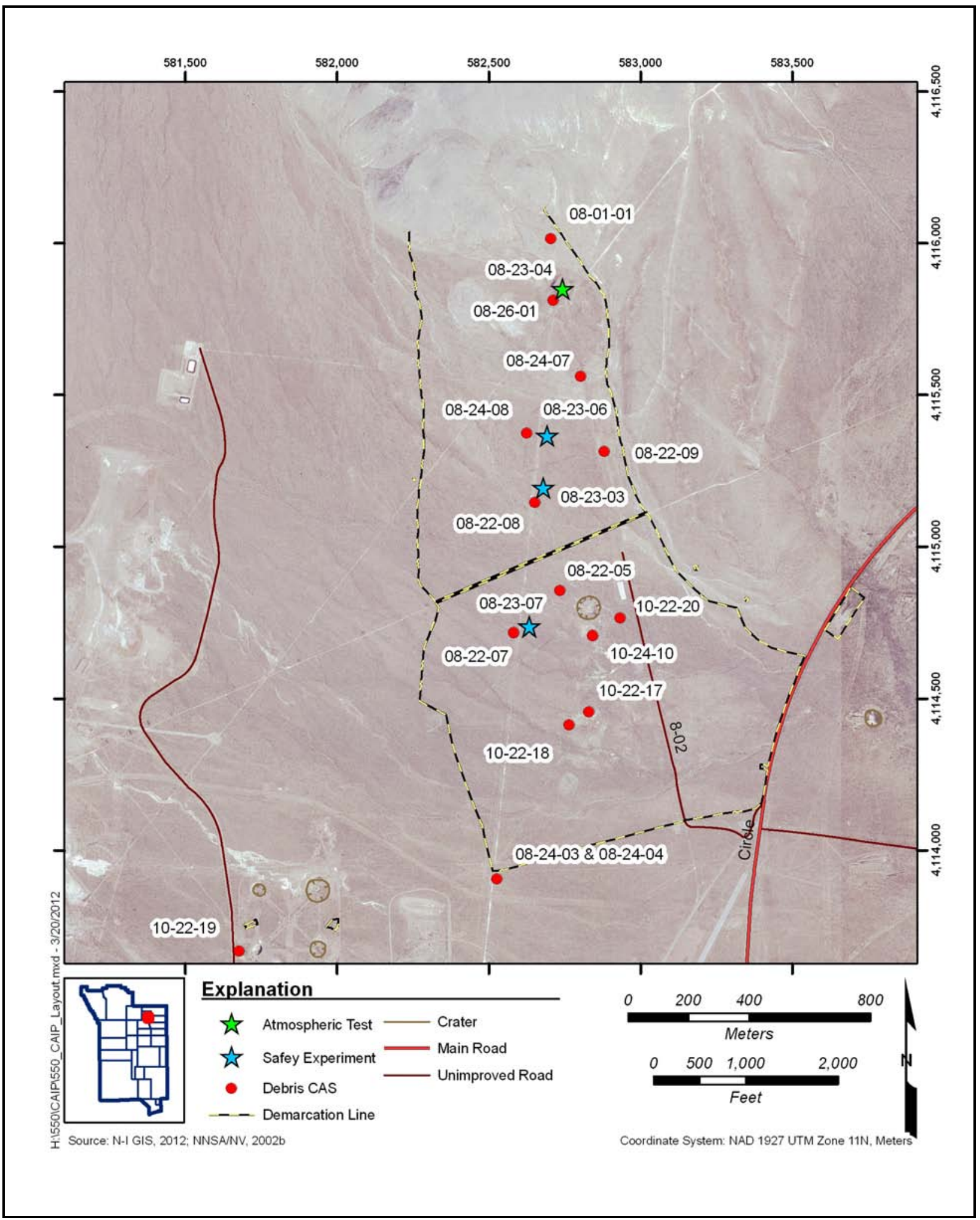

Figure 1-1 CAU 550, CAS Location Map 
- 08-24-04, Battery

- 08-24-07, Batteries (3)

- 08-24-08, Batteries (3)

- 08-26-01, Lead Bricks (200)

- 10-22-17, Buckets (3)

- 10-22-18, Gas Block/Drum

- 10-22-19, Drum; Stains

- 10-22-20, Drum

- 10-24-10, Battery

The corrective action investigation (CAI) will include field inspections, radiological surveys, sampling of environmental media, analysis of samples, and assessment of investigation results. Data will be obtained to support corrective action alternative (CAA) evaluations and waste management decisions.

\subsection{Purpose}

The CASs in CAU 550 are being investigated because hazardous and/or radioactive contaminants may be present in concentrations that exceed risk-based corrective action (RBCA) levels. Existing information on the nature and extent of potential contamination is insufficient to evaluate and recommend CAAs for the CASs. Additional information will be generated by conducting a CAI before evaluating and selecting CAAs.

\subsubsection{CAU 550 History and Description}

CAU 550, Smoky Contamination Area, is located in Areas 7, 8, and 10. The name was derived from the T-2c "Smoky" atmospheric test, which was the first test conducted in this area. The 19 CASs consist of one weapons-related atmospheric tower test (Smoky), three tower safety experiments, six drum sites, five battery sites, a bucket site, a storage tank site, a gas block site, and a lead brick site. The CAU 550 sites are related to nuclear testing conducted in the Yucca Flat area.

Smoky (CAS 08-23-04) was a weapons-related tower test (conducted as a part of Operation Plumbbob) that had a yield of 44 kilotons (kt) and was detonated on August 31, 1957, from a 700-foot (ft) tower (DOE/NV, 2000a). Smoky was also used to study the blast effects produced on missiles, vehicles, and unmanned tanks. In the 1960s, two armored personnel carriers and a small aircraft, both unrelated to the original tests, were brought to the area for training purposes (NNSA/NSO, 2005). The 
two armored personnel carriers and a small aircraft remain at the site in addition to hundreds of tower pieces (steel beams and other hardware) surrounding the Smoky GZ.

The three safety experiments were conducted as part of Operation Hardtack II (DOE/NV, 2000a):

- T-8A (CAS 08-23-06), also called Oberon, was a zero-yield safety experiment detonated from a tower at $25 \mathrm{ft}$ above ground level (agl) on October 22, 1958.

- T-8B (CAS 08-23-03), also called Ceres, was a safety experiment with yield of 0.7 tons detonated from a tower at $25 \mathrm{ft}$ agl on October 26, 1958.

- T-8C (CAS 08-23-07), also called Titania, was a safety experiment with yield of 0.2 tons detonated from a tower at $25 \mathrm{ft}$ agl on October 30, 1958.

Debris related to testing operations was left on site. This debris is addressed in 15 CASs, and consists of the six drum sites, five battery sites, a bucket site, a storage tank site, a gas block site, and a lead brick site.

To facilitate the investigation, the 19 CASs have been grouped into the 4 study groups. The rationale for study group consolidation and operational histories for each CAU 550 study group is detailed in Section 2.0.

\subsubsection{Data Quality Objective Summary}

The study groups will be investigated based on data quality objectives (DQOs) developed by representatives of the Nevada Division of Environmental Protection (NDEP) and the DOE, National Nuclear Security Administration Nevada Site Office (NNSA/NSO). The DQOs are used to identify and define the type, amount, and quality of data needed to develop and evaluate appropriate corrective actions for CAU 550. This CAIP describes the investigative approach developed to collect the necessary data identified in the DQO process. Discussions of the DQO methodology and the DQOs specific to the study groups are presented in Appendix A. A summary of the DQO process is provided below. 
The DQO problem statement for CAU 550 is as follows: "Existing information on the nature and extent of potential contamination is insufficient to evaluate and recommend CAAs for the CASs in CAU 550.” To address this problem, resolution of the following decision statements is required:

- Decision I. "Is any contaminant of concern (COC) associated with the CAS present in environmental media?” For judgmental sampling decisions, any contaminant associated with a CAS that is present at concentrations exceeding its corresponding final action level (FAL) will be defined as a COC. For probabilistic sampling decisions, any contaminant for which the 95 percent upper confidence limit (UCL) of the mean exceeds its corresponding FAL will be defined as a COC. A COC may also be defined as a contaminant that, in combination with other like contaminants, is determined to jointly pose an unacceptable risk based on a multiple constituent analysis (NNSA/NSO, 2012b).

- Decision II. “Is sufficient information available to evaluate potential CAAs?” Sufficient information is defined to include to following:

- The lateral and vertical extent of COC contamination

- The information needed to predict potential remediation waste types and volumes

- Any other information needed to evaluate the feasibility of remediation alternatives

A corrective action will be determined for any site containing a COC. The evaluation of the need for corrective action will include the potential for wastes that are present at the site to cause the future contamination of site environmental media if the wastes were to be released (see Section 3.4).

The informational inputs and data needs to resolve the problem statement and the decision statements were generated as part of the DQO process for this CAU and are documented in Appendix A. The information necessary to resolve the DQO decisions will be generated for each CAU 550 study group by collecting and analyzing samples generated during a field investigation. The presence of a COC will be determined by collecting and analyzing samples following these two criteria:

- To make a judgmental sampling decision, samples must be collected in areas most likely to contain a COC.

- To make a probabilistic sampling decision, samples must be collected from unbiased locations that represent contamination within the sampling unit (see Section A.5.4). 
The DQOs for CAU 550 defined the following release scenarios to appropriately address the different types of releases that may be present at the study groups:

- Primary releases. This release category is specific to the atmospheric deposition of radionuclide contamination onto the soil surface that has not been displaced through excavation or migration. The contamination associated with the primary releases is limited to the top 5 centimeters $(\mathrm{cm})$ of soil. Atmospheric releases of radionuclides that have been distributed at the NNSS from nuclear testing have been found to be concentrated in the upper $5 \mathrm{~cm}$ of undisturbed soil (McArthur and Kordas, 1983 and 1985; Gilbert et al., 1977;

Tamura, 1977). Therefore, for the purposes of this CAIP, surface is defined as the upper $5 \mathrm{~cm}$ of soil.

- Other releases. This release category includes any radionuclide contamination from test activities that is not atmospheric deposition of radionuclides. This includes radionuclide contaminants that were initially deposited onto the soil surface (as in the primary release category) but have been displaced through subsequent activities. This category also includes radionuclides that were deposited under mechanisms other than atmospheric deposition (such as radionuclides being driven into the soil by high explosives at each of the ground zero [GZ] areas). This includes any other chemical or radiological contamination that may be discovered during the investigation through the identification of biasing factors that are not a part of a previously identified release.

As shown in the conceptual site model (CSM) in Section 3.1, it is assumed that surface contamination exceeding the FAL is present within any area exceeding the criteria for a high contamination area (HCA). Portions of the radiologically posted areas at Study Groups 1 and 2 (see Section A.2.2.1) exceed HCA criteria and will be defined as default contamination boundaries (DCBs) (see Section 3.4).

The primary releases and other releases will be investigated outside the DCBs. Investigation of primary releases will be accomplished through measurements of surface soil radioactivity using a combination of judgmental and probabilistic sampling schemes. Investigation of other releases will be accomplished using a judgmental sampling scheme at depths dependent upon the nature of the release. 


\subsection{Scope}

To generate information needed to resolve the decision statements identified in the DQO process, the scope of the CAI for CAU 550 includes the following activities:

- Move surface debris and/or materials, as needed, to facilitate sampling.

- Conduct radiological surveys.

- Perform field screening.

- Measure in situ external dose rates using thermoluminescent dosimeters (TLDs) or other dose-measurement devices.

- Collect and submit environmental samples for laboratory analysis to determine whether any COC is present.

- Collect and submit environmental samples for laboratory analysis to determine the nature and extent of any COCs that are present.

- Collect samples of waste material, if present, to determine the potential for a release to result in contamination exceeding FALs.

- Collect samples of potential remediation wastes, if present.

- Collect quality control (QC) samples.

Contamination of environmental media originating from activities not identified in the CSM of any study group will not be considered as part of this CAU unless the CSM and the DQOs are modified to include the release. If not included in the CSM, contamination originating from these sources will not be considered for sample location selection and/or will not be considered COCs. If such contamination is present, the contamination will be identified as part of another CAS (either new or existing).

\subsection{CAIP Contents}

Section 1.0 presents the purpose and scope of this CAIP, while Section 2.0 provides background information about CAU 550. Objectives of the investigation, including the CSM, are presented in Section 3.0. Field investigation and sampling activities are discussed in Section 4.0, and waste management issues for this project are discussed in Section 5.0. General field and laboratory quality 
assurance (QA) (including collection of QA samples) is presented in Section 6.0 and in the Industrial Sites Quality Assurance Project Plan (QAPP) (NNSA/NV, 2002a). The project schedule and records availability are discussed in Section 7.0. Section 8.0 provides a list of references.

Appendix A provides a detailed discussion of the DQO methodology and the DQOs specific to each study group, while Appendix B contains information on the project organization. Appendix C contains NDEP comments on the draft version of this document. 


\subsection{Facility Description}

CAU 550 comprises 19 CASs that were grouped together based on the geographical location of the sites. The CASs and physical portions of the overall site have been further consolidated into 4 study groups based on release potential and technical similarities (the atmospheric test vs. the safety experiments, debris CASs, the wash study group).

\subsection{Physical Setting}

General background information pertaining to topography, geology, hydrogeology, and climatology is provided for these specific areas of the NNSS region in the Geologic Map of the Nevada Test Site, Southern Nevada (Frizzell and Shulters, 1990); CERCLA Preliminary Assessment of DOE's Nevada Operations Office Nuclear Weapons Testing Areas (DRI, 1988); Final Environmental Impact Statement, Nevada Test Site, Nye County, Nevada (ERDA, 1977); and the Final Environmental Impact Statement for the Nevada Test Site and Off-Site Locations in the State of Nevada (DOE/NV, 1996).

CAU 550 is located within the southern portion of Area 8 and northern portions of Areas 7 and 10, in the Yucca Flat Hydrographic Area of the NNSS. Yucca Flat is a closed basin that is slowly being filled with alluvial deposits eroding from the surrounding mountains (Laczniak et al., 1996).

Local topography around CAU 550 is relatively flat, with distinct hills to the north and a moderate slope towards the southeast. A contamination area (CA) fence presently surrounds the majority of the CAU. See Figures 2-1 through 2-4 for the general layout and an overview of the study groups areas. Some of the ground was cleared during pre-test installations, but vegetation has grown back and is now relatively uniform across the CAU. The general direction of precipitation runoff flow from CAU 550 is to the southeast into a series of ephemeral channels that generally flow to the south into the Yucca Flat dry lake.

Several washes cut through the CA with general flow-direction to the southeast. These washes (included in Study Group 3) coalesce into a wash system that intermittently transports sediment across the south-southeastern boundary of the site into a depression on the east side of Circle Road, an abandoned borrow pit (BN, 2004). Sediment has also been deposited in sediment accumulation areas 


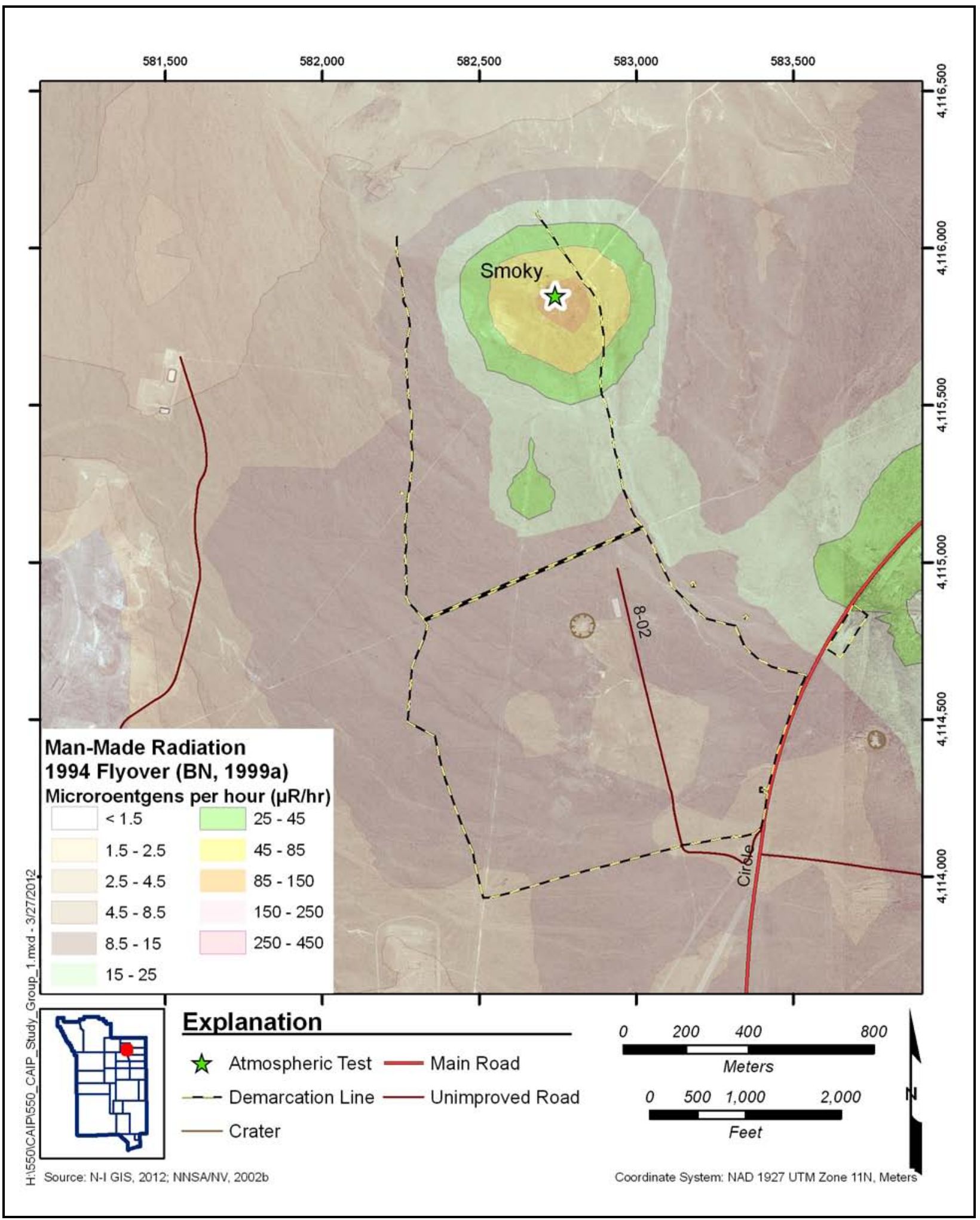

Figure 2-1

Study Group 1 


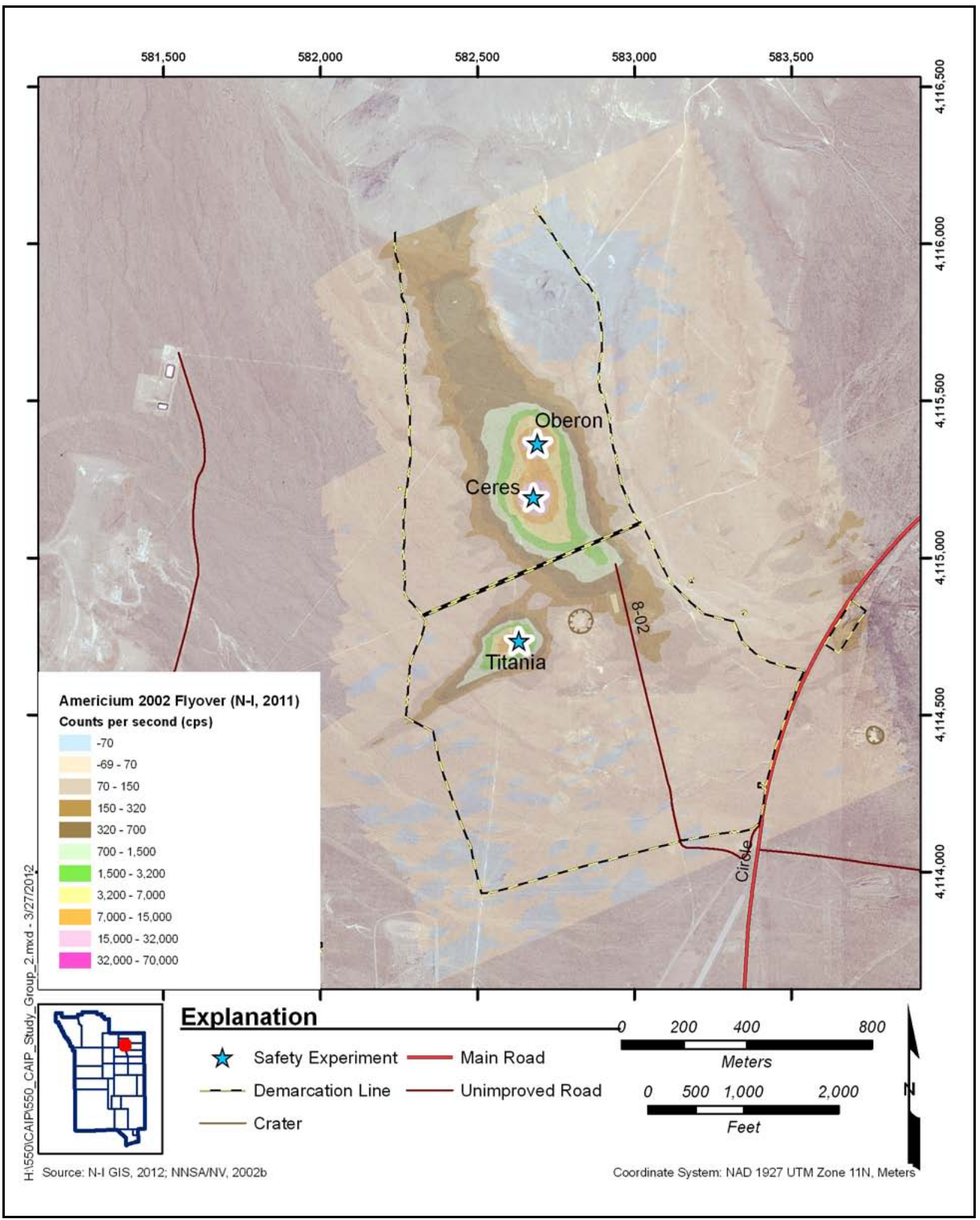

Figure 2-2

Study Group 2 
throughout the channels up gradient from Circle Road. Within this document, the borrow pit area will be referred to as the “depositional area” and is included within Study Group 3. See Figure 2-3 for an overview of the Study Group 3 (Washes) area.

The Study Group 4 (Debris) sites are mostly positioned within the CA, with 3 CASs outside the fenced CA boundaries. The approximate debris CAS locations are presented on Figure 2-4.

Two underground tests (U10b and U10n) resulted in two craters in a portion of the site south of the Study Groups 1 and 2 GZs.

Average annual potential evapotranspiration (PET) has been estimated for the Area 3 Radioactive Waste Management Site (RWMS) as 156.7 cm (61.7 inches [in.]). Rainfall and PET data for the Buster Jangle Y (BJY) rain gauge location near CAU 550 are presented in Table 2-1.

The direction of groundwater flow in the northwestern section of Yucca Flat generally is northeast to southwest. Within the overlying alluvial and volcanic aquifers, lateral groundwater flow occurs from the margins to the center of the basin and downward into the carbonate aquifer (Laczniak et al., 1996). The measured groundwater depth in the U-8d borehole was 649 meters $(\mathrm{m})(2,128 \mathrm{ft})$ below ground surface (bgs) (N-I, 2010). The thickness of the unsaturated zone extends to more than $600 \mathrm{ft}$ bgs (Hevesi et al., 2003).

\subsection{Operational History}

CAU 550 is a complex site due to the multiple tests conducted there. Aerial radiation data indicate one GZ area at T-2C (Smoky) and three distinct GZs for the plutonium safety experiment tests (T-8A, T-8B, and T-8C). The present CA fence was constructed in 1998 to enclose the safety experiment test GZs using soil-based removable contamination data. The original CA was split into north and south sections, to allow access for powerline maintenance along a narrow road. Clean fill was brought in and spread across the road, and then the road was radiologically downgraded from a CA to no posting. The site also has scattered metal debris outside the CAs in the wash area to the east. Aerial and ground radiation survey data indicate extensive alpha migration to the north from the original test plumes and to the south from water erosion down washes (DOE/NV, 2000b). The north CA is open at the northern end because it was not practical to fence the extremely steep area north of 


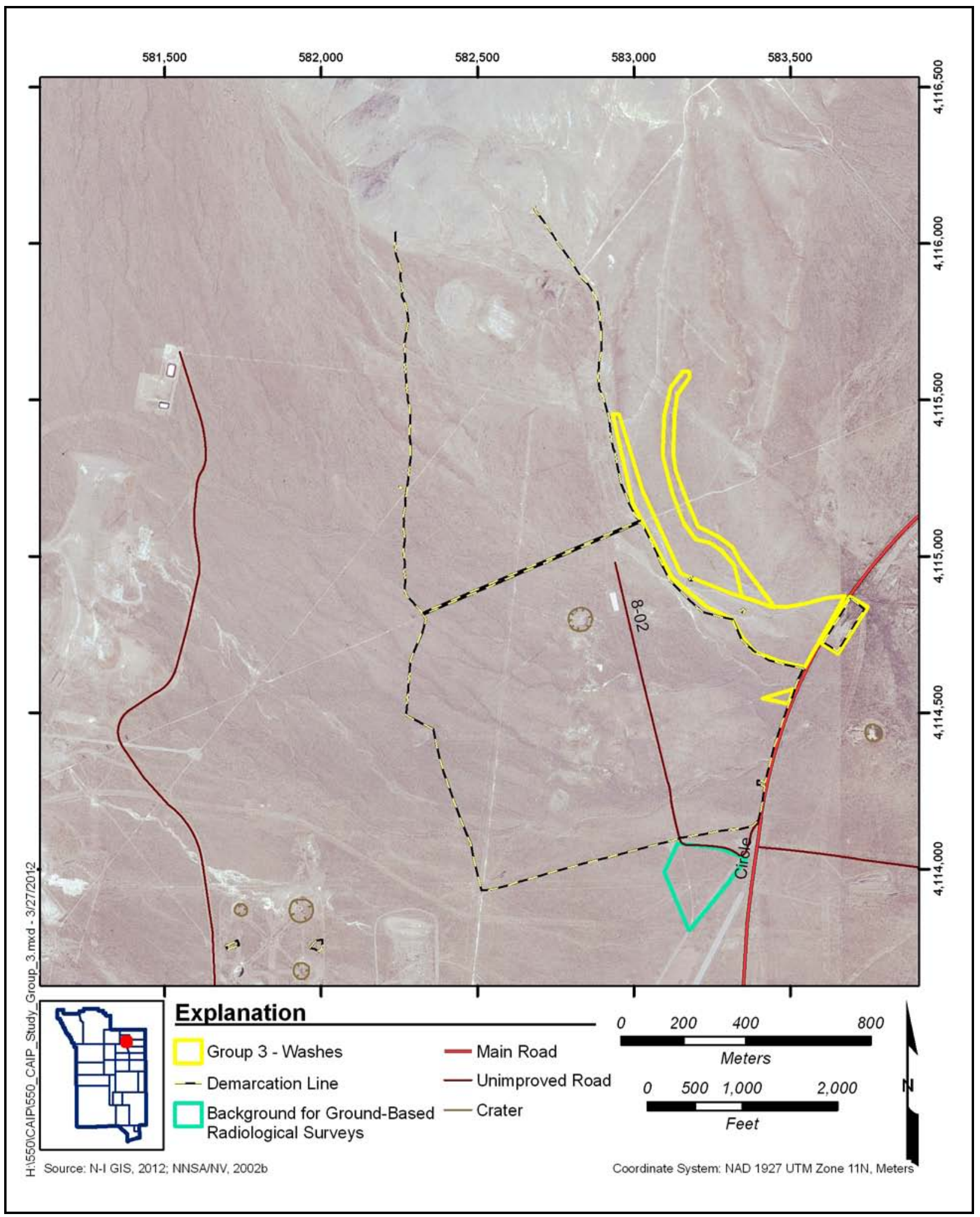

Figure 2-3

Study Group 3 


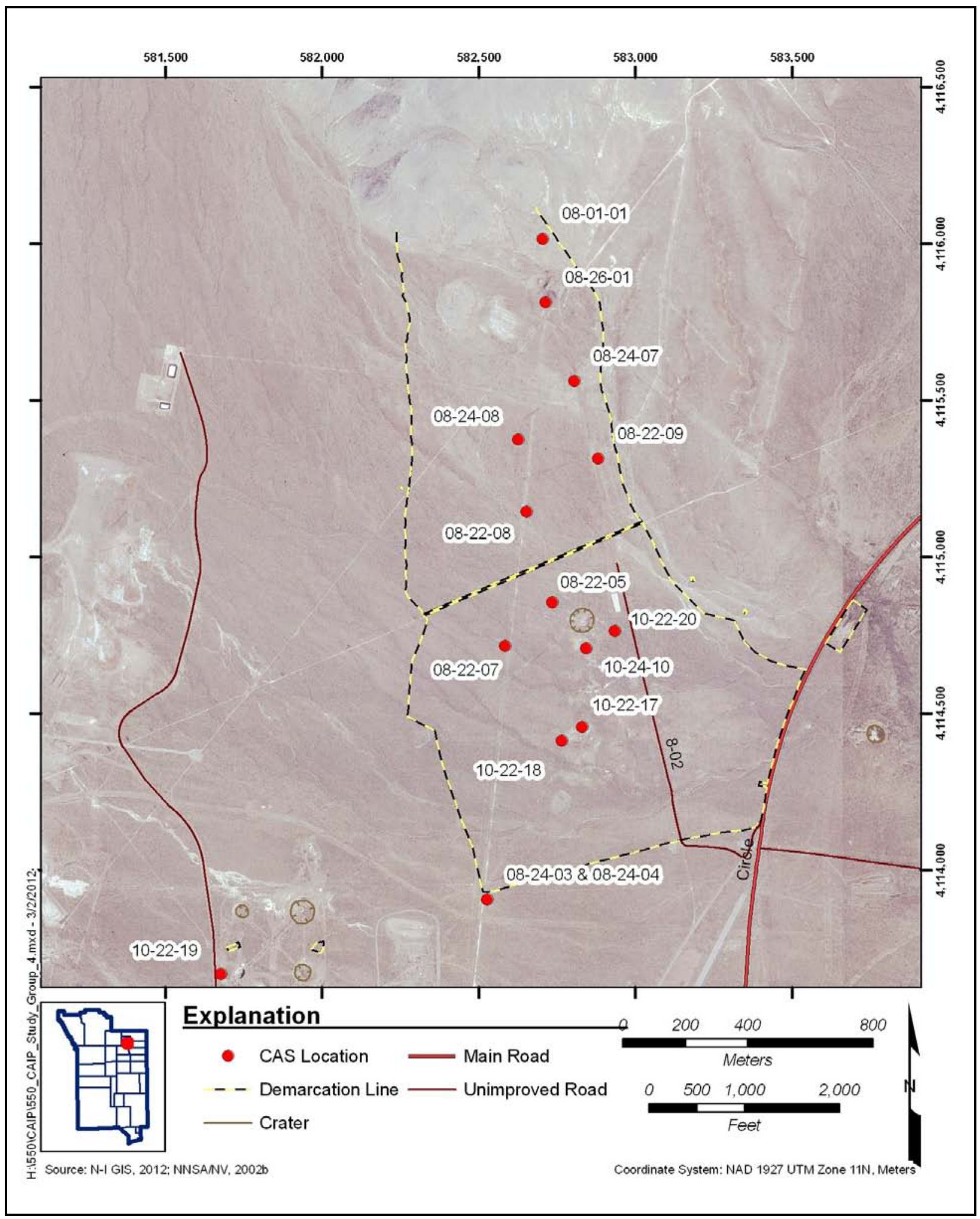

Figure 2-4

Study Group 4 
Table 2-1

Rainfall and PET Information for Yucca Flat

\begin{tabular}{|c|c|c|}
\hline & $\begin{array}{c}\text { Area 3 PET } \\
\text { (cm) }\end{array}$ & $\begin{array}{c}\text { BJY } \\
\text { Precipitation } \\
\text { (cm) }\end{array}$ \\
\hline \hline Minimum & 150.2 & 3.8 \\
\hline Maximum & 160.8 & 37.4 \\
\hline Mean & 156.7 & 15.9 \\
\hline $95 \%$ UCL & 159.6 & 18.8 \\
\hline
\end{tabular}

Source: ARL/SORD, 2011; Yucel, 2009

the site. Demarcation activities were conducted in 2002 (BN, 2002), and the present-day fenced CA is presented in Figure 2-5.

The following subsections provide a description of the use and history of each study group in CAU 550 that may have resulted in releases of contaminants to the environment. The group-specific summaries are designed to describe the current definition of each study group and document all significant, known activities.

\subsubsection{Study Group 1, Atmospheric Test}

This study group is defined as the release of contaminants associated with the Smoky weapons-related tower test. The test was conducted at Test Site T-2C at a height of $700 \mathrm{ft}$ agl. Smoky was a 44-kt-yield test conducted as part of Operation Plumbbob on August 31, 1957 (DOE/NV, 2000a). The surface contamination was released to the atmosphere in an annular pattern around GZ (BN, 1999a). See Figure 2-1 for the fallout pattern.

During construction of the Smoky test area, gamma-emitting fission product fallout from the Diablo Area T-2B test (detonated July 15, 1957) southwest of the Smoky test was detected in the tower area (DOE/NV, 2000a). It was determined necessary to decontaminate the asphalt and desert surfaces at Smoky to a perimeter approximately $500 \mathrm{ft}$ outward from the base of the Smoky tower. The contaminated soil and asphalt was scraped off and was "removed to a location where contamination was not undesirable and at a distance sufficient to prevent the material from being a continued source of radiation in the decontaminated area.” The decontamination was completed on July 29, 1957 


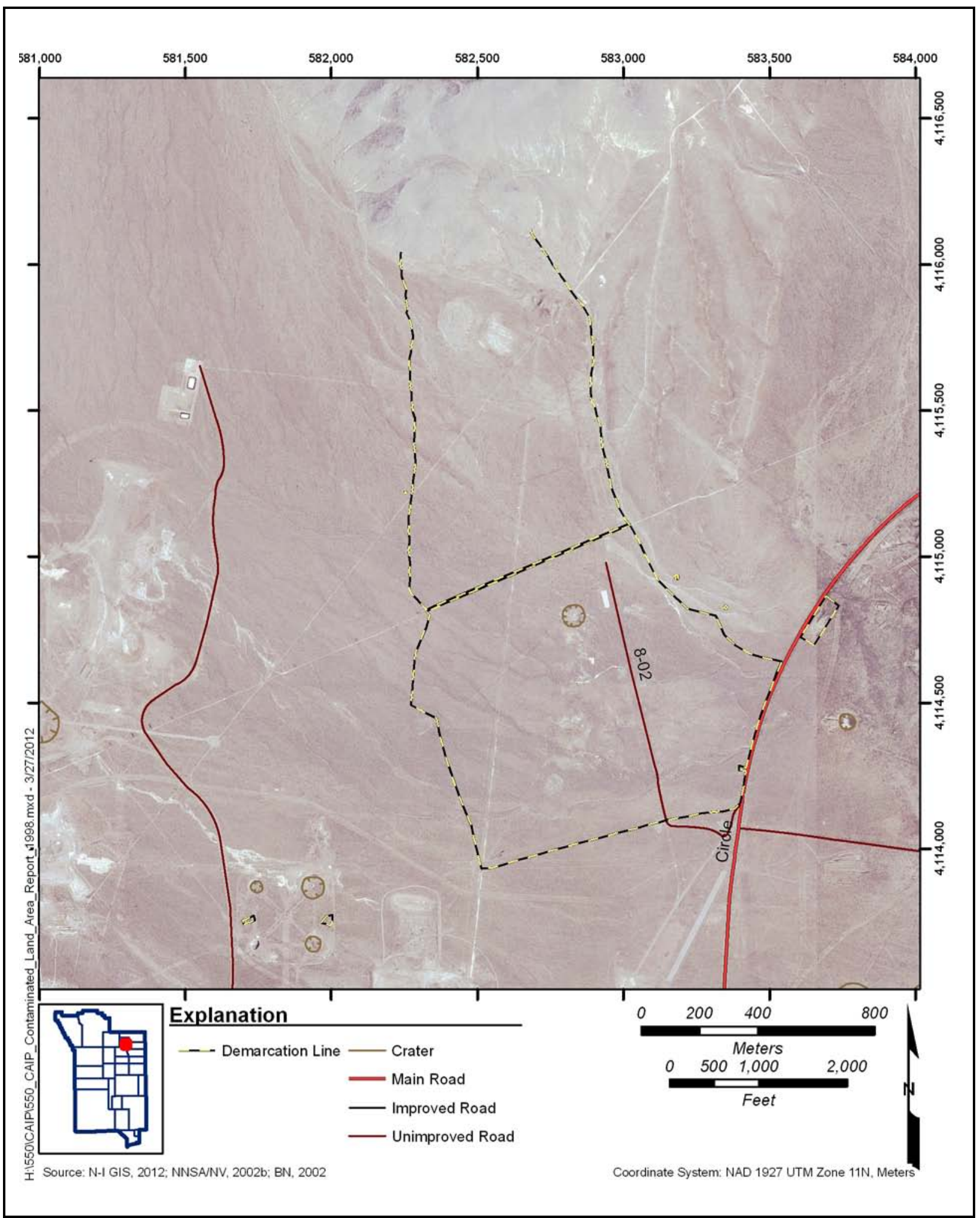

Figure 2-5

CA Area 
(REECO, 1957). The document did not provide any information as to where the soil and asphalt was placed.

The majority of the objects placed around the Smoky tower for weapons-effects studies were removed after the detonation (NNSA/NSO, 2005). Historical operations records were reviewed, and no post-test cleanup was mentioned or documented.

\subsubsection{Study Group 2, Safety Experiments}

This study group is defined as the release of contaminants associated with the three safety experiments (DOE/NV, 2000a):

- T-8A, the Oberon source (CAS 08-23-06), was a zero-yield safety experiment detonated from a tower at $25 \mathrm{ft}$ agl on October 22, 1958.

- $\quad$ T-8B, the Ceres source (CAS 08-23-03), was a safety experiment with yield of 0.7 tons detonated from a tower at $25 \mathrm{ft}$ agl on October 26, 1958.

- T-8C, the Titania source (CAS 08-23-07), was a safety experiment with yield of 0.2 tons detonated from a tower at $25 \mathrm{ft}$ agl on October 30, 1958.

During the general time period after the experiments, the measured activity related to the three safety experiments was determined to be limited to within a few hundred feet of the GZs (AEC, 1958).

See Figure 2-2 for the fallout pattern. Historical operations records were reviewed, and no post-test cleanup was mentioned or documented.

\subsubsection{Study Group 3, Washes}

Study Group 3 is defined as the translocation of contamination in washes leaving the CA and in a depositional area across Circle Road. Construction of Circle Road modified the natural drainage by creating a small check dam. The road intercepts flow from the channel and the resulting reduction in stream gradient causes the flow to spread laterally. In the past, Circle Road has impounded potentially contaminated sediment on the upstream side. In 1994, it was documented that flood events may result in the overtopping of Circle Road by channel flow and subsequent deposition of sediment on the road (BN, 2004). See Figure 2-3 for the study group areas. 


\subsubsection{Study Group 4, Debris}

Study Group 4 is defined as the release of contaminants from drums, buckets, a storage tank, batteries, lead bricks, and other items. The debris CASs are listed in Section 1.0 and are shown on Figure 2-4.

The debris associated with this study group was initially identified in the Nevada Test Site Inventory of Inactive and Abandoned Facilities and Waste Sites (REECo, 1991a). Historical documentation states that the housekeeping procedures required that all drums, batteries, and lead bricks be surveyed for radiation, and any contents be sampled before removal. Those items that did not pass the field screening were to be left in place. Documentation states that empty drums passing the survey were to be transported to onsite disposal locations (Shaw, 2003).

There are uncertainties related to the debris CASs within this study group; mainly, it is uncertain which items were removed and which were left in place. Many debris items were identified during the 2011 preliminary investigation phase. The presence or absence of the specific items will be determined during the CAI. Additional stained soil and debris may be identified during the site characterization activities and will be investigated as appropriate.

\subsection{Waste Inventory}

Available documentation, interviews with former site employees, process knowledge, and general historical NNSS practices were used to identify wastes that may be present. Potential waste types may include investigation-derived waste (IDW), decontamination liquids, and soils. Potential waste streams include sanitary waste, hydrocarbon waste, Resource Conservation and Recovery Act (RCRA) hazardous waste, radioactive waste, and mixed waste. The potential wastes specific to each study group are listed in the following subsections.

\subsubsection{Study Group 1, Atmospheric Test}

Solid waste items identified in Study Group 1 include a large mound of charcoal, electrical panels, metal parts from the tower elevator, and abandoned tower parts (e.g., dimensional steel members, cables, and tie-down parts). 


\subsubsection{Study Group 2, Safety Experiments}

Solid waste items identified in Study Group 2 include the two armored personnel carriers and an aircraft.

\subsubsection{Study Group 3, Washes}

Solid waste items identified in Study Group 3 include a small amount of miscellaneous trailer parts, electrical panels, metal parts from the Smoky tower elevator, and abandoned tower parts (e.g., dimensional steel members, cables, tie-down parts).

\subsubsection{Study Group 4, Debris}

Solid waste items identified in Study Group 4 include metal drums and buckets, lead-acid batteries, a metal storage tank, a gas block, and lead bricks.

\subsection{Release Information}

The releases of contamination to Study Groups 1 through 4 are directly or indirectly associated with the Smoky, Oberon, Ceres, and Titania nuclear tests. The investigation of specific releases at CAU 550 will depend upon the nature of these releases. Therefore, the releases have been categorized into one of the two release scenarios defined in Section 1.1.2.

Exposure routes to receptors include ingestion and inhalation of radionuclides in surface soil (internal exposure). Site workers may also be exposed to direct radiation by performing activities in proximity to radiologically contaminated materials (i.e., external dose).

The following subsections contain group-specific descriptions of known or suspected releases associated with CAU 550.

\subsubsection{Study Groups 1 and 2}

The primary release at Study Groups 1 and 2 includes the atmospheric deposition of radioactive contamination onto the surface soils from atmospheric nuclear tests conducted within these study groups. The initial release of radionuclides from the tests was distributed in roughly concentric 
patterns on the ground surface, exhibiting a pattern of surface contamination that is generally decreasing in concentration with increasing distance from the release locations. This is illustrated in the 1994 aerial radiological surveys showing the gross count and man-made signatures of the Smoky release (Figures 2-6 and 2-7) (BN, 1999a); and the 1994 and 2002 aerial radiological surveys showing the americium (Am)-241 signature of the Oberon, Ceres, and Titania plumes (BN, 1999a; N-I, 2011) (Figures 2-8 and 2-2).

\subsubsection{Study Group 3}

The subsequent migration of radioactivity associated with deposition under the primary release scenario is identified as an other release. This may occur as a result of sheet and gully erosion from post-test stormwater runoff. Study Group 3 addresses releases related to potential contaminant migration along both lateral and vertical pathways. Contaminants may move across soil surfaces and accumulate in washes and depositional areas. Contaminants may also migrate vertically into subsurface soils.

\subsubsection{Study Group 4}

Other releases may include potential releases from lead-acid batteries, lead bricks, spills, wastes, or debris from activities conducted at the Smoky site.

The drum, storage tank, and bucket sites may have released radiological or chemical contamination from any remaining contents or residue. The battery sites and the lead brick site contain exposed lead that is assumed to have the potential to release contamination to the surrounding surface and subsurface soil.

\subsection{Investigative Background}

All previous investigation data are assessed in the planning phase as biasing information for selecting appropriate sampling locations. A variety of different radiation surveys were conducted in the CAU 550 area. These include aerial and ground-based surveys. Table 2-2 lists the method descriptions for the different radiation surveys conducted within the area of CAU 550. This table includes advantages, limitations, spatial and spectral resolutions, measurement dates, and applied 


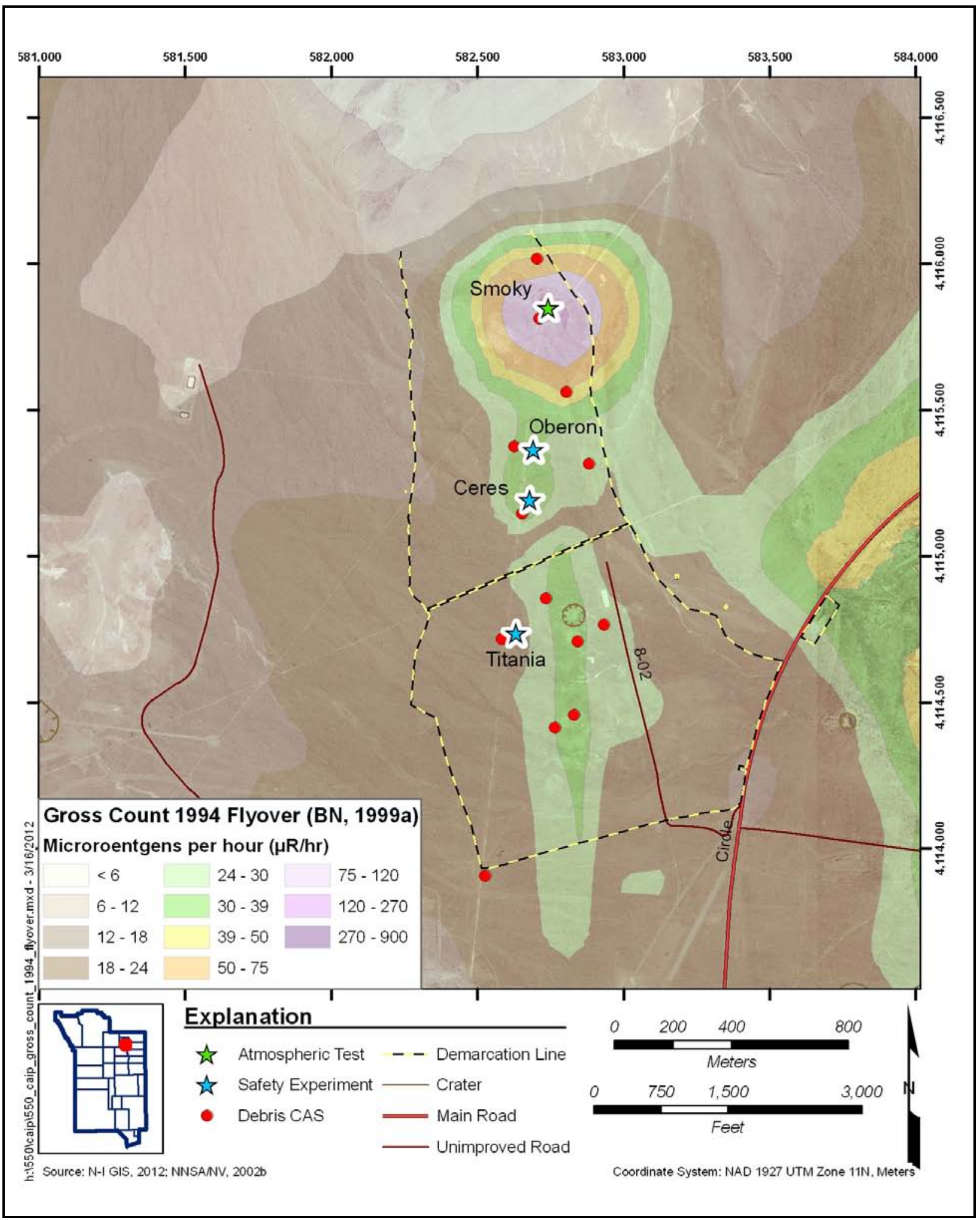

Figure 2-6

Gross Count 1994 Flyover 


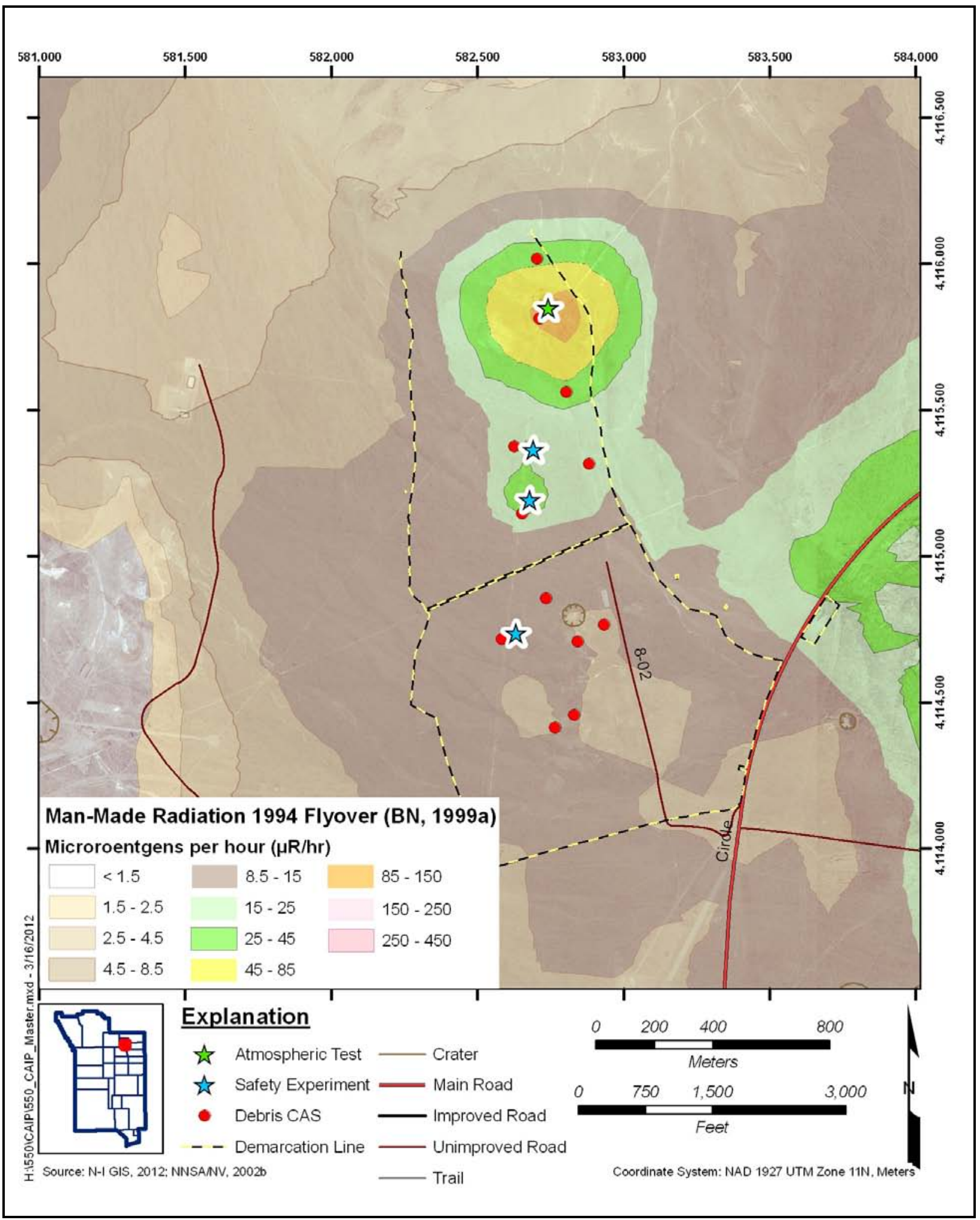

Figure 2-7

Man-Made Radiation 1994 Flyover 


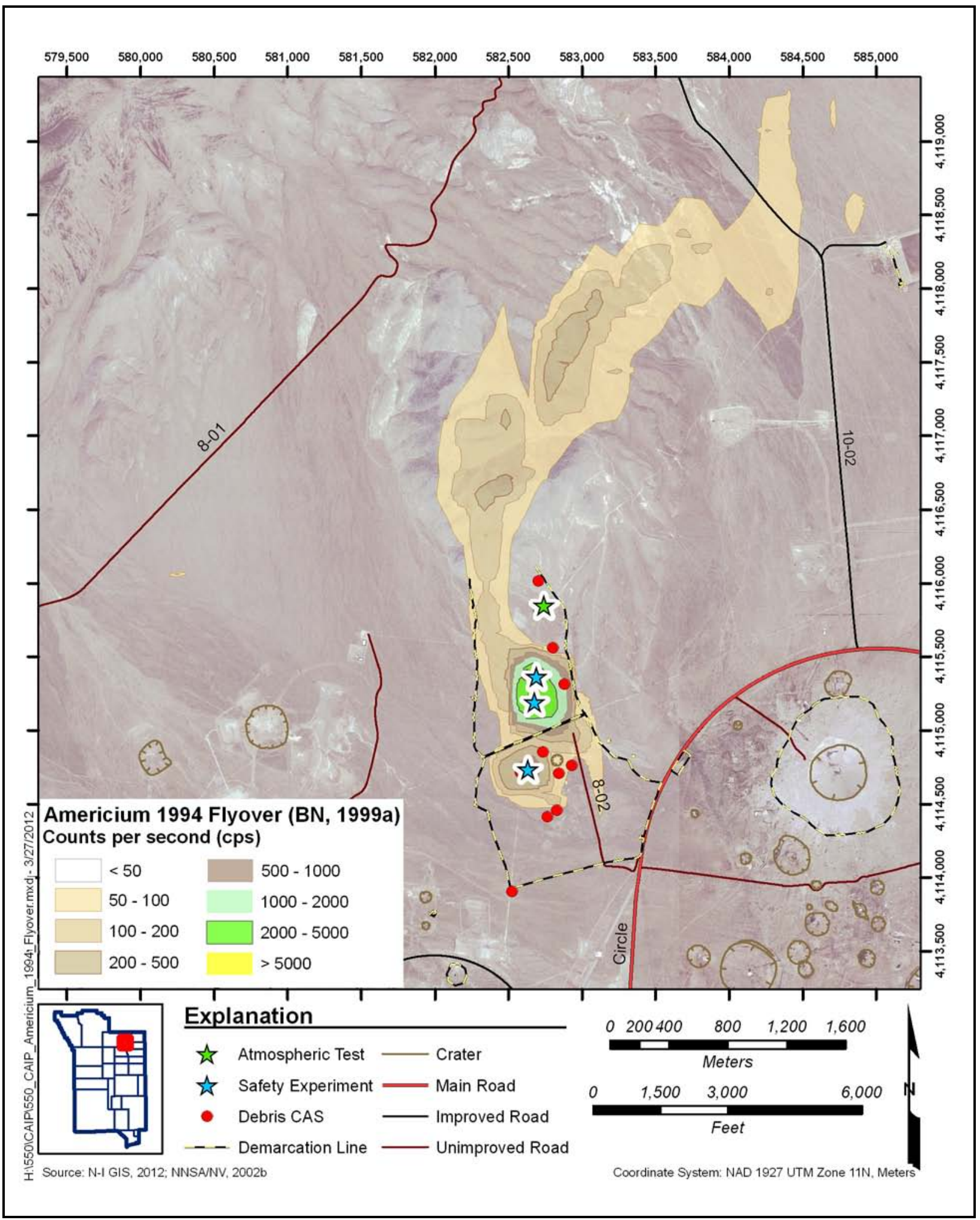

Figure 2-8

Americium 1994 Flyover 
use as a comparison of the radiation survey methods. Details of the surveys are discussed in Sections 2.5.1 and 2.5.3.

These data are not considered to be decision quality and are not used in making corrective action decisions. However, the radiation surveys will be evaluated for use in defining corrective action boundaries in the investigation report. For defining corrective action boundaries, the radiation surveys will be used only in terms of defining a relative spatial distribution of contamination. This relative spatial distribution will be correlated to measured dose (decision quality) to define the shape of the areas that require corrective action.

The aerial radiation surveys provided spectral information that was used to differentiate specific isotopic signatures. This allowed the separate mapping of Am-241 contamination, man-made gamma activity, and gross gamma activity within the surveyed areas.

The radionuclide activity in this area is due to a combination of fission products (primarily high-energy gamma radiation) and unfissioned nuclear material (primarily low-energy gamma, beta, and alpha radiation). The sources of these radiation types are not necessarily co-located.

The Radionuclide Inventory and Distribution Program (RIDP) conducted an investigation from 1981 through 1986 that estimated the inventory of man-made radionuclides at the NNSS through in situ gamma spectroscopy (McArthur and Mead, 1987). These RIDP data were decay-corrected to estimate levels of plutonium across CAU 550 as shown on Figure 2-9 and discussed in Section 2.5.2. More detailed discussions of these investigations are found in Appendix A.

\subsubsection{Radiological Surveys}

All previous investigation data are assessed in the planning phase as biasing information used in selecting appropriate sampling locations. Several aerial and ground-based radiological surveys were conducted from 1994 to 2011. The 2011 results are discussed in more detail in Section 2.5.3. Each survey method has unique spatial and spectral characteristics that contribute to the data's utility as biasing information. Aerial radiological surveys conducted at the NNSS in 1994, 1997, and 2002 provide coverage of the entire site at discrete energies. These flyover data were processed to produce gross count, man-made contamination, and americium concentration data layers (BN, 1999a and b; 
Table 2-2

Page 25 of 79

\section{Comparison of Radiation Survey Methods}

(Page 1 of 2)

\begin{tabular}{|c|c|c|c|c|c|}
\hline & KIWI & FIDLER & PRM-470 & $\begin{array}{l}\text { Aerial Radiological } \\
\text { Survey }(200 \mathrm{ft} \text { agl) }\end{array}$ & $\begin{array}{l}\text { Aerial Radiological } \\
\text { Survey (50 ft agl) }\end{array}$ \\
\hline $\begin{array}{c}\text { Method } \\
\text { Description } \\
\text { Summary }\end{array}$ & $\begin{array}{l}\text { Ground-based, sodium iodide } \\
\text { gamma spectroscopy unit }\end{array}$ & $\begin{array}{l}\text { Ground-based instrument that } \\
\text { detects low-energy } \\
\text { gamma emissions }\end{array}$ & $\begin{array}{l}\text { Ground-based organic plastic } \\
\text { scintillator instrument that } \\
\text { detects gamma emissions }\end{array}$ & $\begin{array}{l}\text { Helicopter-mounted } \\
\text { thallium-activated sodium } \\
\text { iodide, gamma-ray } \\
\text { scintillation detectors }\end{array}$ & $\begin{array}{l}\text { Helicopter-mounted } \\
\text { thallium-activated sodium } \\
\text { iodide, gamma-ray } \\
\text { scintillation detectors }\end{array}$ \\
\hline $\begin{array}{l}\text { Advantages } \\
\text { and Limitations }\end{array}$ & $\begin{array}{l}\text { Advantages: Can } \\
\text { post-process data to identify } \\
\text { specific gamma-emitting } \\
\text { radionuclides of interest } \\
\text { Limitations: Detector mounted } \\
\text { on a vehicle, may have issues } \\
\text { with terrain and a } \\
\text { higher potential } \\
\text { for contamination }\end{array}$ & $\begin{array}{l}\text { Advantages: Lightweight } \\
\text { hand-held instrument } \\
\text { designed to see low-energy } \\
\text { gamma emissions } \\
\text { Limitations: Does not } \\
\text { discriminate between low } \\
\text { energy gamma emissions } \\
\text { from different isotopes }\end{array}$ & $\begin{array}{l}\text { Advantages: Lightweight } \\
\text { hand-held instrument that } \\
\text { detects gamma emissions } \\
\\
\text { Limitations: Does not } \\
\text { distinguish between the } \\
\text { radionuclides emitting the } \\
\text { gamma emissions }\end{array}$ & $\begin{array}{l}\text { Advantages: Gives a wide } \\
\text { area of view (as opposed to } \\
\text { ground-based surveys); can } \\
\text { survey large areas quickly } \\
\text { Limitations: Because it is } \\
\text { elevated and moving at a fast } \\
\text { rate, does not distinguish } \\
\text { small localized areas of } \\
\text { contamination or materials } \\
\text { that are contaminated }\end{array}$ & $\begin{array}{l}\text { Advantages: Gives a wide } \\
\text { area of view (as opposed to } \\
\text { ground-based surveys); can } \\
\text { survey large areas quickly } \\
\text { Limitations: Because it is } \\
\text { elevated and moving at a fast } \\
\text { rate, does not distinguish } \\
\text { small localized areas of } \\
\text { contamination or materials } \\
\text { that are contaminated }\end{array}$ \\
\hline $\begin{array}{c}\text { Spatial } \\
\text { Resolution }\end{array}$ & $\begin{array}{l}\text { Mounted } \sim 2.5 \mathrm{ft} \mathrm{agl} \text {; stationary } \\
\text { KIWI has an Am- } 241 \text { footprint } \\
\text { of } \sim 3 \mathrm{~m} \text { wide and } 1.2 \mathrm{~m} \text { long; } \\
\text { travelling at } 5 \text { miles per hour, } \\
\text { the footprint for each } \\
1 \text {-second measurement is } \\
\sim 3 \mathrm{~m} \text { wide by } 3.4 \mathrm{~m} \text { long }\end{array}$ & $\begin{array}{l}\text { Held at } \sim 6 \text { in. agl, has a small } \\
\text { field of view }\end{array}$ & $\begin{array}{l}\text { Held at } \sim 1 \mathrm{~m} \text { agl, has a small } \\
\text { field of view }\end{array}$ & $\begin{array}{l}\text { Altitude: } 60 \mathrm{~m} \\
\text { Line Spacing: } 150 \mathrm{~m} \\
\text { 120-m diameter window }\end{array}$ & $\begin{array}{l}\text { Altitude: } 15 \mathrm{~m} \\
\text { Line Spacing: } 23 \mathrm{~m} \\
\text { 30-m diameter window }\end{array}$ \\
\hline $\begin{array}{c}\text { Spectral } \\
\text { Resolution }\end{array}$ & 28 to $4,000 \mathrm{keV}$ & 10 to $100 \mathrm{keV}$ & All gamma emitters & 38 to $3,026 \mathrm{keV}$ & 38 to $3,026 \mathrm{keV}$ \\
\hline $\begin{array}{l}\text { Measurement } \\
\text { Date }\end{array}$ & 2002 & 08/2011 and 09/2011 & 08/2011 and 09/2011 & 12/1994 & $1997 / 2002$ \\
\hline
\end{tabular}


Table 2-2

Page 26 of 79

\section{Comparison of Radiation Survey Methods}

(Page 2 of 2)

\begin{tabular}{|c|c|c|c|c|c|}
\hline & KIWI & FIDLER & PRM-470 & $\begin{array}{l}\text { Aerial Radiological } \\
\text { Survey ( } 200 \mathrm{ft} \text { agl) }\end{array}$ & $\begin{array}{l}\text { Aerial Radiological } \\
\text { Survey (50 ft agl) }\end{array}$ \\
\hline $\begin{array}{l}\text { Applied } \\
\text { Use }\end{array}$ & $\begin{array}{l}\text { Processed for energies in the } \\
57-\text { to } 70-k e V \text { range (Am-241) } \\
\text { relative to the } 38 \text { - to } 50-k e V \\
\text { and } 70-\text { to } 82-k e V \text { background } \\
\text { windows; used to identify } \\
\text { Am-241 contamination as } \\
\text { an indicator of } \\
\text { plutonium contamination }\end{array}$ & $\begin{array}{l}\text { Energies in the } 59-k e V \text { range, } \\
\text { which are indicative of } \\
\text { Am- } 241 \text { or other } \\
\text { higher-energy emitters; used } \\
\text { to identify Am- } 241 \\
\text { contamination as an indicator } \\
\text { of plutonium contamination }\end{array}$ & $\begin{array}{l}\text { Nondiscriminatory gamma } \\
\text { count used to identify } \\
\text { contamination from } \\
\text { nuclear testing }\end{array}$ & $\begin{array}{l}\text { For Am-241: Processed for } \\
\text { energies in the } 57-\text { to } 70-k e V \\
\text { range (Am-241) relative to the } \\
38-\text { to } 50-k e V \text { and } 70-\text { to } \\
82-k e V \text { background windows. } \\
\text { Used to identify Am-241 } \\
\text { contamination as an indicator } \\
\text { of plutonium contamination. } \\
\text { For man-made: Processed for } \\
\text { energies in the 38- to } \\
1,294-k e V \text { window relative to } \\
\text { the } 1,394-\text { to } 3,026-k e V \\
\text { background window. Used to } \\
\text { identify contamination from } \\
\text { nuclear testing. }\end{array}$ & $\begin{array}{l}\text { For Am-241: Processed for } \\
\text { energies in the } 57-\text { to } 70-k e V \\
\text { range }(\mathrm{Am}-241) \text { relative to the } \\
\text { 38- to } 50-\mathrm{keV} \text { and } 70 \text { - to } \\
82-\mathrm{keV} \text { background windows. } \\
\text { Used to identify Am-241 } \\
\text { contamination as an indicator } \\
\text { of plutonium contamination. } \\
\text { For man-made: Processed for } \\
\text { energies in the 38- to } \\
1,294-k e V \text { window relative to } \\
\text { the } 1,394-\text { to } 3,026-k e V \\
\text { background window. Used to } \\
\text { identify contamination from } \\
\text { nuclear testing. }\end{array}$ \\
\hline
\end{tabular}

FIDLER = Field instrument for the detection of low-energy radiation

keV $=$ Kiloelectron volt

Source: N-I, 2011; N-I GIS, 2012; BN, 1999b; Riedhauser, 1999; Buchheit and Marianno, 2005; TSA Systems, 2005 


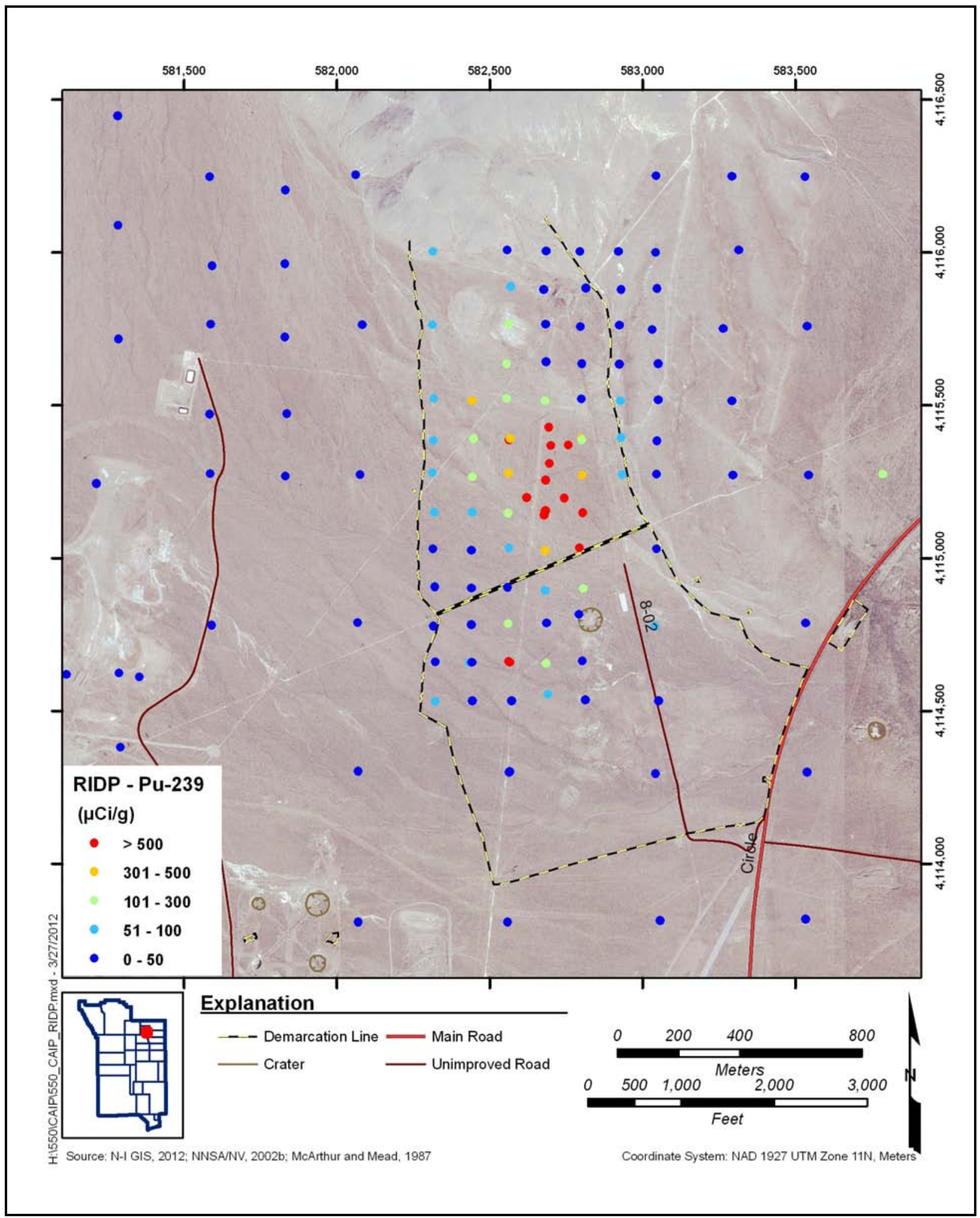

Figure 2-9

CAU 550 RIDP In Situ Data 
N-I, 2011). In addition, a ground-based system called a KIWI (same spectral capabilities as the flyover data) was used to survey the roads and other limited areas of the site in 2002. The KIWI data do not provide site-wide coverage but were processed for depiction of the americium concentration (N-I, 2011).

Each of the four study groups has unique characteristics that result in certain survey data being of optimal use for biasing information. Study Group 1 is related to a high-yield test that resulted in the deposition of cesium, europium, and other fission-related contaminants. For this study group, gross gamma and man-made spectra are of the greatest use in delineating the spatial distribution of contaminants. Therefore, the 1994 man-made flyover survey was used as biasing information in projecting sample locations for Study Group 1 (see Section A.8.1).

Study Group 2 represents a series of safety shots that were negligible-low yield and are characterized by a heterogeneous distribution of americium- and plutonium-related contaminants. The 2002 KIWI data exhibited strong americium signatures just north of the proposed DCB and were therefore used to bias the potential location of the sample plot for this area (see Section A.8.2) (N-I, 2011). In the southwestern part of the DCB, KIWI data are not available, but the 2002 flyover data show a plume of americium extending outside the DCB. The potential location of the sample plot in this area was biased using the 2002 flyover americium data (see Section A.8.2).

Study Group 3, other release areas, consists of washes where secondary concentrations of radiological contaminants are of concern, and a man-made soil accumulation area located adjacent to the east side of Circle Road. The aerial surveys did not provide the resolution necessary for effective biasing of the sample location; therefore, ground-based radiological surveys were conducted over these areas. Both the FIDLER and the PRM-470 surveys indicated that the highest instrument readings were located in the man-made soil accumulation area. The sample location is depicted in Figure A.8-5.

\subsubsection{RIDP and NAEG}

As part of an effort to assess the implications of contamination on future uses of the NNSS, the RIDP was established in 1981 to make a comprehensive survey of the important man-made radionuclides of NNSS origin in the surface soil at the site (McArthur and Mead, 1987). Data collected for the RIDP and by the Nevada Applied Ecology Group (NAEG) in the 1980s allowed for estimates of surface soil 
inventories throughout the NNSS. The RIDP estimated the inventory through in situ soil

measurements by gamma spectroscopy and limited confirmatory soil sampling (McArthur and Mead, 1987; Gray et al., 2007). Desert Research Institute reported in situ gamma spectroscopy measurements for Area 8, which included the CAU 550 area (McArthur and Mead, 1987). Although the RIDP data present a general distribution of contamination, there is not sufficient resolution for biasing sample locations within CAU 550. The RIDP in situ measurements for plutonium (Pu)-239 within the boundaries of CAU 550 are shown in Figure 2-9.

\subsubsection{CAU 550 Preliminary Investigation}

In 2011, a preliminary field investigation was completed within the majority of the CAU 550 Study Groups 1, 2, 3, and 4 areas. This effort included limited visual surveys as a result of access limitations due to radiological exposure. During the visual survey, some batteries and lead bricks were identified, but an assessment of the Study Group 4 (Debris) sites was not performed (i.e., the presence or absence of the debris items or site conditions at CAS locations was not ascertained).

Ground-based gamma walkover surveys (GWSs) were also completed within Study Groups 1, 2, and 3 during the 2011 preliminary field investigation. These GWSs provide high spatial resolution coverage over much of the site using two different instruments, one which measures gross gamma count (PRM-470) and the other (FIDLER) which uses a more narrow spectral window to help identify americium contamination. The FIDLER was used within Study Groups 1, 2, and 3; but primarily at Study Groups 2 and 3, where plutonium was identified as a potential contaminant. The PRM-470 instrument was used at Study Groups 1 and 3, and within limited areas at Study Group 2. Figures 2-10 and 2-11 show the results of the ground-based radiological survey from the PRM-470 and FIDLER radiological instruments, respectively.

The other previous investigation that impinges on CAU 550 is CAU 367, Sedan. The overlapping plume to the southeast of Smoky crossing Circle Road is presented in Figure 2-1. 


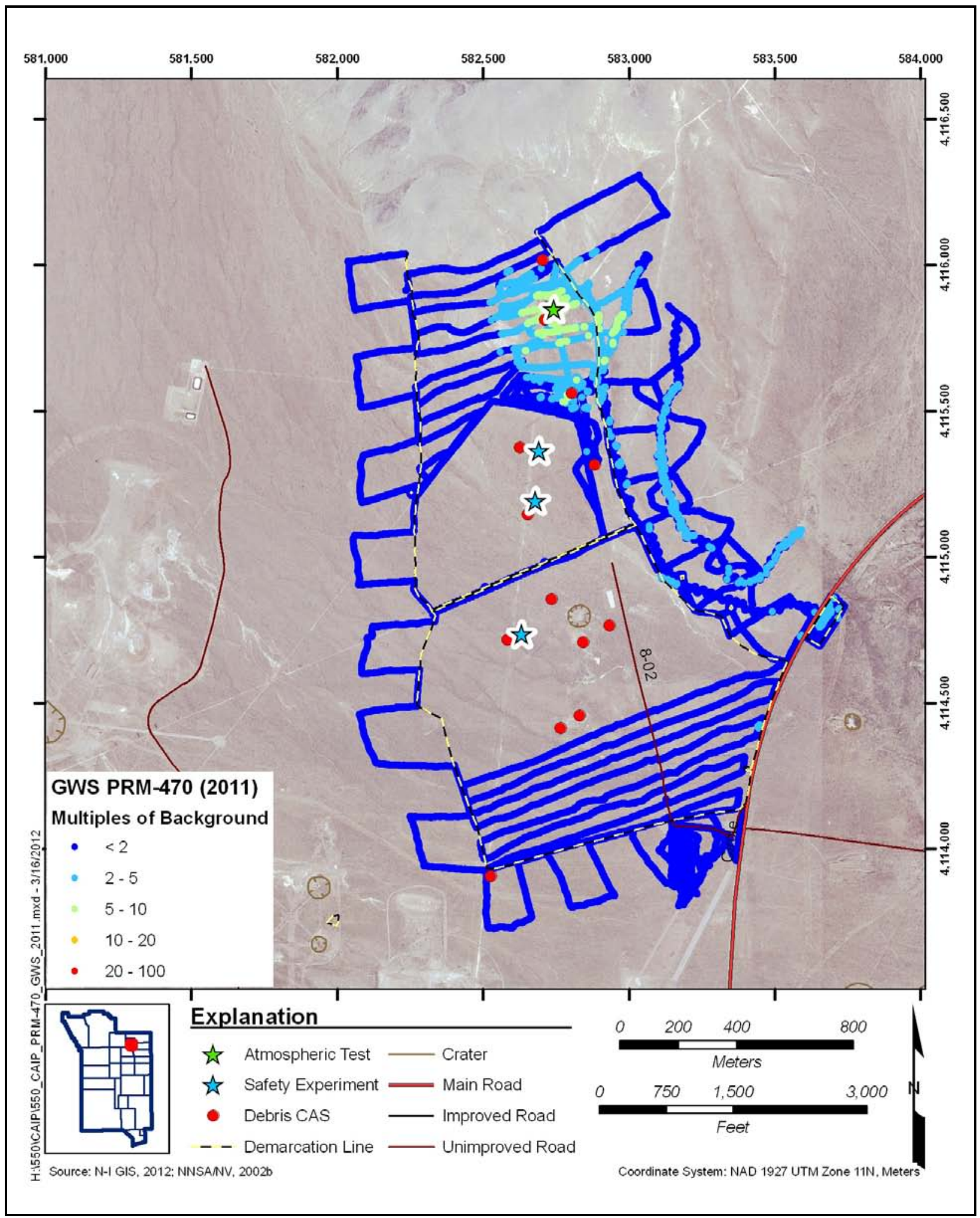

Figure 2-10

Ground-Based PRM-470 Survey 


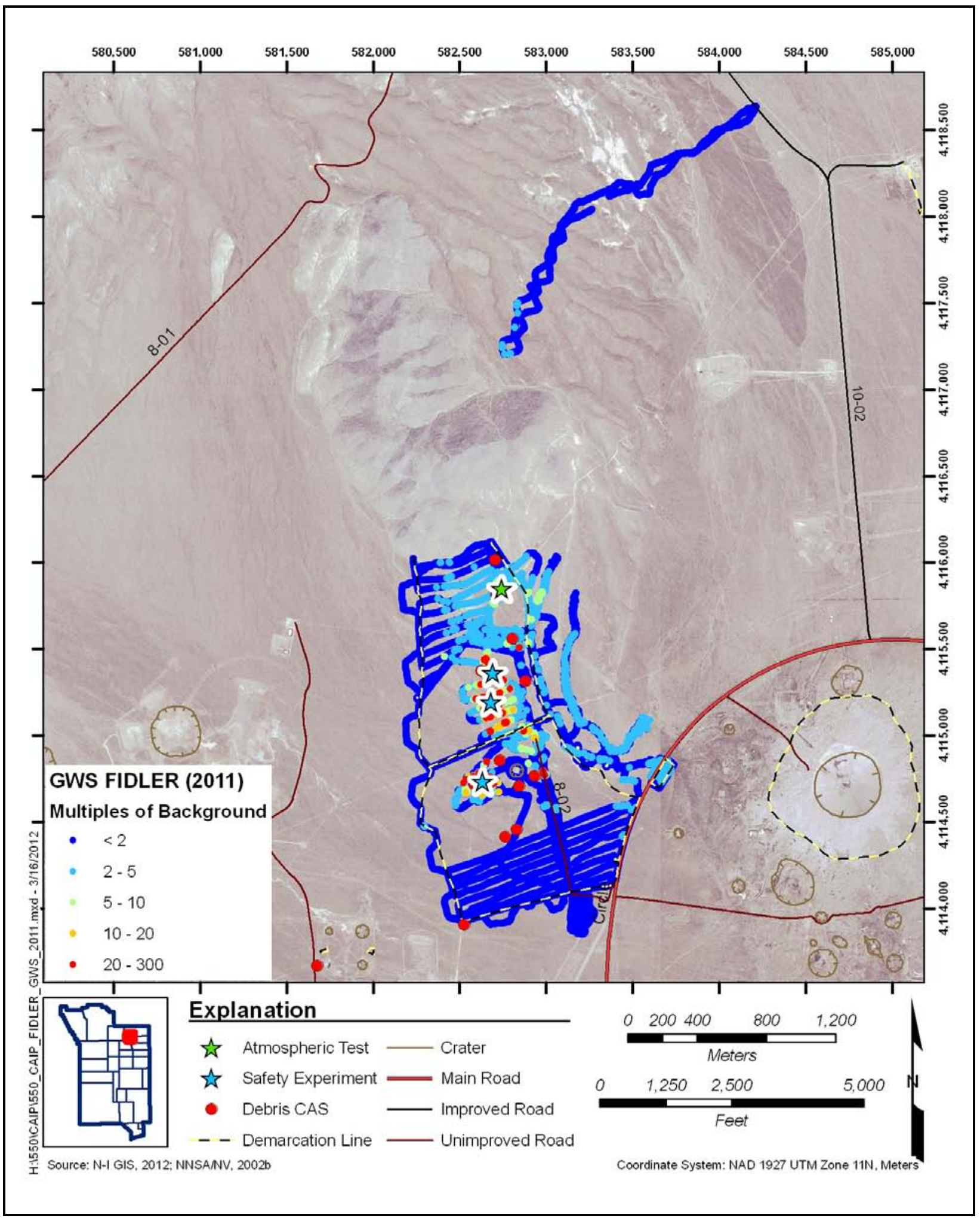

Figure 2-11

Ground-Based FIDLER Survey 


\subsubsection{National Environmental Policy Act}

The Final Environmental Impact Statement for the Nevada Test Site and Off-Site Locations in the State of Nevada (DOE/NV, 1996) includes site investigation activities such as those proposed for CAU 550. In accordance with the NNSA/NSO National Environmental Policy Act (NEPA) Compliance Program, a NEPA checklist will be completed before beginning site investigation activities at CAU 550. This checklist requires NNSA/NSO project personnel to evaluate their proposed project activities against a list of potential impacts that include, but are not limited to, air quality, chemical use, waste generation, noise level, and land use. Completion of the checklist results in a determination of the appropriate level of NEPA documentation by the NNSA/NSO NEPA Compliance Officer. This will be accomplished before mobilization for the field investigation. 


\subsection{Objectives}

This section presents an overview of the DQOs for CAU 550 and formulation of the CSM. Also presented is a summary listing of the contaminants of potential concern (COPCs), the preliminary action levels (PALs), and the process used to establish FALs. Additional details and figures depicting the CSM are located in Appendix A.

\subsection{Conceptual Site Model}

The CSM describes the most probable scenario for current conditions at each site and defines the assumptions that are the basis for identifying the future land use, contaminant sources, release mechanisms, migration pathways, exposure points, and exposure routes. The CSM was used to develop appropriate sampling strategies and data collection methods. The CSM was developed for CAU 550 using information from the physical setting, potential contaminant sources, release information, historical background information, knowledge from similar sites, and physical and chemical properties of the potentially affected media and COPCs. Figure 3-1 depicts a representation of the conceptual pathways to receptors from CAU 550 sources. Figure 3-2 depicts a graphical representation of the CSM. If evidence of contamination that is not consistent with the presented CSM is identified during investigation activities, the situation will be reviewed, the CSM will be revised, the DQOs will be reassessed, and a recommendation will be made as to how best to proceed. In such cases, decision makers listed in Section A.2.1 will be notified and given the opportunity to comment on and/or concur with the recommendation.

The following sections discuss future land use and the identification of exposure pathways (i.e., combination of source, release, migration, exposure point, and receptor exposure route) for CAU 550.

\subsubsection{Land-Use and Exposure Scenarios}

Land-use zones where the CAU 550 study groups are located dictate future land use, and restrict current and future land use to nonresidential (i.e., industrial) activities. 


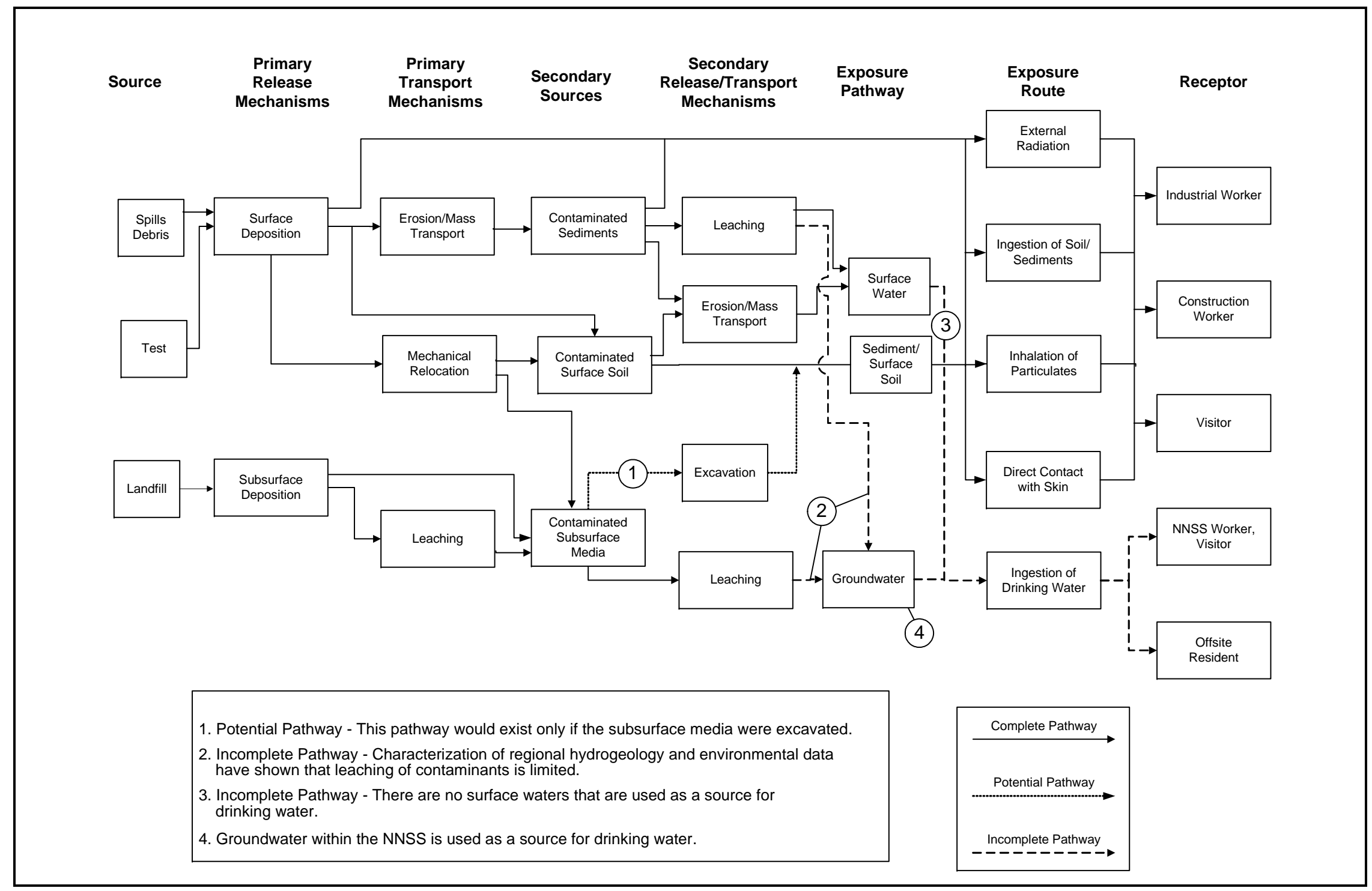

\section{Figure 3-1}

CSM Diagram

\section{UNCONTROLLED When Printed}




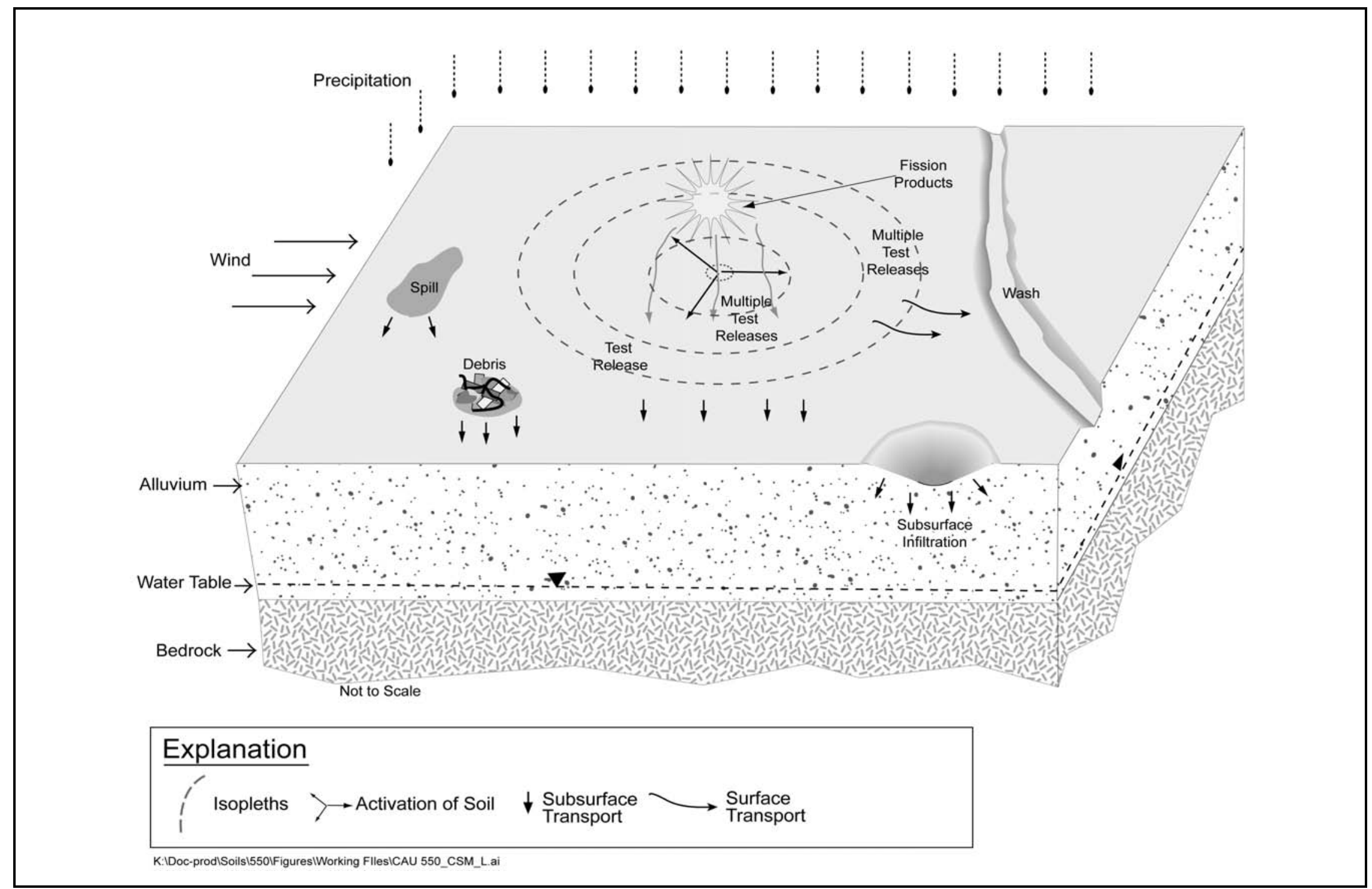

Figure 3-2

CAU 550 CSM 
The CAU 550 site is located in the land-use zone described as "Nuclear Test Zone” within the NNSS.

This area is reserved for dynamic experiments, hydrodynamic tests, and underground nuclear weapons and weapons-effects tests. This zone includes compatible defense and nondefense research, development, and testing activities (DOE/NV, 1998).

Exposure scenarios for the CAU 550 study groups have been categorized into the following three types based on current and projected future land uses:

- Industrial Area. This scenario addresses exposure to industrial workers exposed daily to contaminants in soil during an average workday. This scenario assumes that this is the regular assigned work area for the worker who will be on the site for an entire career (250 days per year, 8 hours per day, for 25 years). The total effective dose (TED) calculated using this exposure scenario is the TED an industrial worker receives during 2,000 hours of annual exposure to site contaminants and is expressed in terms of millirem per Industrial Area year (mrem/IA-yr).

- $\quad$ Remote Work Area. This exposure scenario assumes noncontinuous work activities at a site. This scenario addresses exposure to industrial workers exposed to contaminants in soil during a portion of an average workday. This scenario assumes that this is an area where the worker regularly visits but is not an assigned work area where the worker spends an entire workday. A site worker under this scenario is assumed to be on the site for an equivalent of 336 hours (or 42 days) per year for an entire career (25 years). The TED calculated using this exposure scenario is the TED a remote area worker receives during 336 hours of annual exposure to site radioactivity and is expressed in terms of millirem per Remote Work Area Year (mrem/RW-yr).

- Occasional Use Area. This exposure scenario assumes occasional work activities at a site. This scenario addresses exposure to industrial workers who are not assigned to the area as a regular worksite but may occasionally use the site. This scenario assumes that this is an area where the worker does not regularly visit but may occasionally use for short-term activities. A site worker under this scenario is assumed to be on the site for an equivalent of 80 hours (or 10 days) per year for 5 years. The TED calculated using this exposure scenario is the TED an occasional use area worker receives during 80 hours of annual exposure to site radioactivity and is expressed in terms of millirem per Occasional Use Area year (mrem/OU-yr).

The CAU 550 land-use zone and exposure scenario are based on current and future land use at the NNSS. CAU 550 is a remote location without any site improvements and where no regular work is performed. There is still the possibility, however, that site workers could occupy these locations on an 
occasional and temporary basis such as a military exercise. Therefore, this site is classified as an Occasional Use Area.

\subsubsection{Contaminant Sources}

The contamination sources for CAU 550 study groups are releases of radiological contamination to the atmosphere and soil as a result of nuclear tests (safety experiments and the weapons-related tests). The atmospheric detonations irradiated the surrounding soil with neutrons, causing the activation of some elements in the soil (primarily europium [Eu]-152 and -154). Fission fragments were deposited in an annular pattern around GZs. Radionuclides with a low melting point (e.g., iodine) traveled significant distances before condensing and falling out of the plume, while those with higher melting points (e.g., cesium) condensed earlier and were deposited closer to respective GZs. The nuclear fuel that did not fission (e.g., uranium [U]-235) has a very high melting point and is generally found very near to GZ. Different mixtures of radionuclides may be present at these release sites based on the varying composition of the nuclear source material used in the test devices and the type of test (safety or weapons related). Contamination on the soil surface may be sources for future migration.

Other sources of contamination include radionuclides deposited by injection into native materials, spills, wastes, and debris. Debris itself can present a source of contamination. During the preliminary investigations at the CAU, lead-acid batteries and lead bricks were identified. The batteries and lead bricks may release lead to the soil. No stained soil was identified during preliminary investigations, but stained soil and debris may be identified during site characterization activities and will be investigated as appropriate.

\subsubsection{Release Mechanisms}

Release mechanism for the primary releases at Study Group 1 was the detonation of a nuclear device at a tower-height elevation of $700 \mathrm{ft}$. This released fission products and unfissioned nuclear fuel, as well as neutron activation of soil and debris. The weapons-effect related test (Study Group 1) released mainly fission products. The safety-related experiments (Study Group 2) dispersed nuclear device components using high explosives. 
The distribution of surface contamination from Study Group 1 is that surface deposition of contaminants from the Smoky test occurred mainly concentric with the GZ with a small bias toward the prevailing wind direction (north) at the time of detonation. The distribution of surface contamination from the three safety experiments tests is concentric with the individual GZs, with surface deposition of contaminants from the Titania test skewed towards the southwest, likely due to wind direction (from the northeast) at the time of detonation. However, due to the close proximity of the Oberon and Ceres GZs and quantities of deposition, the plume images indicate overlapping releases of contamination in the center area (see Figure A.8-2).

Release mechanisms for the releases at Study Group 4 are spills and leaks onto surface soils from equipment, discarded debris, or stored materials. Materials stored in containers may have leaked or have been spilled.

\subsubsection{Migration Pathways}

Surface migration pathways for CAU 550 Study Group 3 include the lateral migration of potential contaminants across surface soils into washes transecting the site since the original deposition. The washes entering and leaving these areas are generally dry but are subject to infrequent stormwater flows. These stormwater flow events provide an intermittent mechanism for both vertical (infiltration) and lateral transport of contaminants. Contaminated sediments entrained by these stormwater events would be carried by the streamflow to locations where the flowing water loses energy and the sediments drop out. These locations are readily identified as sedimentation areas. The area near CAU 550 drains into an intertwined wash system located east and southeast of the site that flows towards Circle Road, and into the Study Group 3 depositional area and Yucca Flat Dry Lake. Other migration pathways for contamination from the site include wind-borne material and material displaced from roads in the vicinity (e.g., moved during road maintenance).

Contaminants may also be moved through mechanical disturbance due to maintenance or construction activities at the site. Specifically, this can include activities such as removal of surface contamination through scraping or grading and construction and maintenance of roadways (e.g., shoulder grading of Circle Road) and also cleanup activities along Circle Road. 
Migration is influenced by physical and chemical characteristics of the contaminants and media. Contaminant characteristics include, but are not limited to, solubility, density, and adsorption potential. Media characteristics include permeability, porosity, water-holding capacity, sorting, chemical composition, and organic content. In general, contaminants with low solubility, high affinity for media, and high density can be expected to be found relatively close to release points. Contaminants with high solubility, low affinity for media, and low density can be expected to be found farther from release points. These factors affect the migration pathways and potential exposure points for the contaminants in the various media under consideration.

Infiltration and percolation of precipitation serve as driving forces for downward migration of contaminants. However, due to high PET (annual PET at the Area 3 RWMS has been estimated at 61.7 in. [Shott et al., 1997]) and limited precipitation at Station BJY (6.26 inches per year [in./yr] [ARL/SORD, 2011]), percolation of infiltrated precipitation at the NNSS does not provide a significant mechanism for vertical migration of contaminants to groundwater (DOE/NV, 1992).

Subsurface migration pathways at CAU 550 are expected to be predominately vertical, although spills or leaks at the ground surface may also have limited lateral migration before infiltration. The depth of infiltration (shape of the subsurface contaminant plume) will be dependent upon the type, volume, and duration of the discharge as well as the presence of relatively impermeable layers that could modify vertical or lateral transport pathways, both on the ground surface (e.g., concrete) and in the subsurface (e.g., caliche layers).

For surface contamination to reach the water table, the contaminants would have to be dissolved in infiltrating precipitation and then be transported through the vadose alluvium that extends the entire unsaturated thickness of $488 \mathrm{~m}$ at ER-3-2.

The vertical penetration distance of infiltrating precipitation in 1,000 years would be the groundwater recharge rate (in millimeters per year $[\mathrm{mm} / \mathrm{yr}]$ ) divided by the volumetric moisture content (cubic centimeters per cubic centimeter $\left[\mathrm{cm}^{3} / \mathrm{cm}^{3}\right]$ ) of the subsurface vadose alluvium times 1,000 years. The groundwater recharge rate in the vicinity of CAU 550 has been estimated to range from less than $0.1 \mathrm{~mm} / \mathrm{yr}$ to $2.5 \mathrm{~mm} / \mathrm{yr}$ based on regional infiltration studies (SNJV, 2006). The moisture content observed in the subsurface alluvium in shallow boreholes near the Area 3 RWMS indicates moisture contents in the range of 0.05 to 0.1 (Kwicklis et al., 2006). Based on these 
observations, penetration distances of infiltrating precipitation may be as much as $50 \mathrm{~m}$ in 1,000 years (using the maximum groundwater recharge rate of $2.5 \mathrm{~mm} / \mathrm{yr}$ and the minimum moisture content of 0.05).

\subsubsection{Exposure Points}

Exposure points for the CSM are expected to be areas of surface contamination where visitors and site workers may come in contact with contaminated surface soil. Subsurface exposure points may exist if construction workers come in contact with contaminated media during excavation activities.

\subsubsection{Exposure Routes}

Exposure routes to site workers include ingestion and inhalation from disturbance of, or direct contact with, contaminated media. Site workers may also be exposed to direct ionizing radiation by performing activities in proximity to radioactive materials.

\subsubsection{Additional Information}

Information concerning topography, geology, climatic conditions, hydrogeology, floodplains, and infrastructure at the CAU 550 study groups is presented in Section 2.1 as it pertains to the investigation. This information has been addressed in the CSM and will be considered during the evaluation of CAAs, as applicable. Climatic and site conditions (e.g., surface and subsurface soil descriptions) as well as specific structure descriptions will be recorded during the CAI. Areas of erosion and deposition within the washes will be qualitatively evaluated to provide additional information on potential offsite migration of contamination. Movement of ephemeral stream channels may be identified based on a comparison of historical photographs and visual observations where erosion and deposition have occurred within the washes.

\subsection{Contaminants of Potential Concern}

Based on the releases identified in Section 2.4, the COPCs for CAU 550 are defined as lead; U-234, -235, -238; Pu-238, -239/240, -241; Eu-152, -154, -155; cesium (Cs)-137; and Am-241. These COPCs will be reported by the analytical methods identified in Table 3-1 for Decision I 
Table 3-1

Analytical Methods

\begin{tabular}{|c|c|c|c|c|}
\hline Analytical Method & $\begin{array}{l}\text { Study } \\
\text { Group } 1\end{array}$ & $\begin{array}{c}\text { Study } \\
\text { Group } 2\end{array}$ & $\begin{array}{c}\text { Study } \\
\text { Group } 3\end{array}$ & $\begin{array}{c}\text { Study } \\
\text { Group } 4^{a}\end{array}$ \\
\hline \multicolumn{5}{|c|}{ Organic COPCs } \\
\hline PCBs & -- & -- & -- & $x$ \\
\hline SVOCs & -- & -- & -- & $x$ \\
\hline VOCs & -- & -- & -- & $x$ \\
\hline \multicolumn{5}{|c|}{ Inorganic COPCs } \\
\hline RCRA Metals & -- & -- & -- & $x$ \\
\hline Total Beryllium & -- & -- & -- & $x$ \\
\hline \multicolumn{5}{|c|}{ Radionuclide COPCs } \\
\hline Gamma Spectroscopy & $x$ & $x$ & $x$ & $x^{b}$ \\
\hline Isotopic U & $x$ & $x$ & $x$ & -- \\
\hline Isotopic Pu & $x$ & $x$ & $x$ & -- \\
\hline Isotopic Am & $x$ & $x$ & $x$ & -- \\
\hline
\end{tabular}

${ }^{a}$ The analytical methods may be required based on the nature of the potential release.

${ }^{\mathrm{b}}$ Results of gamma analysis will be used to determine whether further isotopic analysis is warranted.

$\mathrm{PCB}=$ Polychlorinated biphenyl

SVOC $=$ Semivolatile organic compound

VOC $=$ Volatile organic compound

$$
\begin{aligned}
& X=\text { Required analytical method } \\
& --=\text { Not required }
\end{aligned}
$$

environmental samples taken at each of the CASs. The analytes reported for each analytical method are listed in Table 3-2.

The list of COPCs is intended to encompass all contaminants reasonably expected at each site that could contribute to a dose or risk that exceed an action level. These COPCs were identified during the planning process through the review of site history, process knowledge, personal interviews, past investigation efforts (where available), and inferred activities associated with the CASs and other releases (including those that may be discovered during the investigation). Other specific COPCs (and subsequently the analyses requested) will be determined for discovered potential releases based on the nature of the potential release (e.g., hydrocarbon stain, lead bricks). 
Table 3-2

Analytes Reported by Analytical Methods

\begin{tabular}{|c|c|c|c|c|c|c|}
\hline \multicolumn{2}{|c|}{ VOCs } & \multicolumn{2}{|c|}{ SVOCs } & PCBs & Metals & Radionuclides \\
\hline $\begin{array}{l}\text { 1,1,1,2-Tetrachloroethane } \\
\text { 1,1,1-Trichloroethane } \\
\text { 1,1,2,2-Tetrachloroethane } \\
\text { 1,1,2-Trichloroethane } \\
\text { 1,1-Dichloroethane } \\
\text { 1,1-Dichloroethene } \\
\text { 1,2,4-Trichlorobenzene } \\
\text { 1,2,4-Trimethylbenzene } \\
\text { 1,2-Dibromo-3-chloropropane } \\
\text { 1,2-Dichlorobenzene } \\
\text { 1,2-Dichloroethane } \\
\text { 1,2-Dichloropropane } \\
\text { 1,3,5-Trimethylbenzene } \\
\text { 1,3-Dichlorobenzene } \\
\text { 1,4-Dichlorobenzene } \\
\text { 1,4-Dioxane } \\
\text { 2-Butanone } \\
\text { 2-Chlorotoluene } \\
\text { 2-Hexanone } \\
\text { 4-Isopropyltoluene } \\
\text { 4-Methyl-2-pentanone } \\
\text { Acetone } \\
\text { Acetonitrile } \\
\text { Allyl chloride } \\
\text { Benzene } \\
\text { Bromodichloromethane } \\
\text { Bromoform } \\
\text { Bromomethane } \\
\text { Carbon disulfide }\end{array}$ & $\begin{array}{l}\text { Carbon tetrachloride } \\
\text { Chlorobenzene } \\
\text { Chloroethane } \\
\text { Chloroform } \\
\text { Chloromethane } \\
\text { Chloroprene } \\
\text { cis-1,2-Dichloroethene } \\
\text { Dibromochloromethane } \\
\text { Dichlorodifluoromethane } \\
\text { Ethyl methacrylate } \\
\text { Ethylbenzene } \\
\text { Isobutyl alcohol } \\
\text { Isopropylbenzene } \\
\text { Methacrylonitrile } \\
\text { Methyl methacrylate } \\
\text { Methylene chloride } \\
\text { n-Butylbenzene } \\
\text { n-Propylbenzene } \\
\text { sec-Butylbenzene } \\
\text { Styrene } \\
\text { tert-Butylbenzene } \\
\text { Tetrachloroethene } \\
\text { Toluene } \\
\text { Total xylenes } \\
\text { Trichloroethene } \\
\text { Trichlorofluoromethane } \\
\text { Vinyl acetate } \\
\text { Vinyl chloride }\end{array}$ & $\begin{array}{l}\text { 2,3,4,6-Tetrachlorophenol } \\
\text { 2,4,5-Trichlorophenol } \\
\text { 2,4,6-Trichlorophenol } \\
\text { 2,4-Dimethylphenol } \\
\text { 2,4-Dinitrotoluene } \\
\text { 2-Chlorophenol } \\
\text { 2-Methylnaphthalene } \\
\text { 2-Methylphenol } \\
\text { 2-Nitrophenol } \\
\text { 3-Methylphenol }{ }^{a} \text { (m-cresol) } \\
\text { 4-Methylphenol }{ }^{a} \text { (p-cresol) } \\
\text { 4-Chloroaniline } \\
\text { 4-Nitrophenol } \\
\text { Acenaphthene } \\
\text { Acenaphthylene } \\
\text { Aniline } \\
\text { Anthracene } \\
\text { Benzo(a)anthracene } \\
\text { Benzo(a)pyrene } \\
\text { Benzo(b)fluoranthene } \\
\text { Benzo(g,h,i)perylene } \\
\text { Benzo(k)fluoranthene } \\
\text { Benzoic acid } \\
\text { Benzyl alcohol } \\
\text { Bis(2-ethylhexyl)phthalate } \\
\text { Butyl benzyl phthalate } \\
\text { Carbazole } \\
\text { Chrysene } \\
\text { Di-n-butyl phthalate }\end{array}$ & $\begin{array}{l}\text { Di-n-octyl phthalate } \\
\text { Dibenzo(a,h)anthracene } \\
\text { Dibenzofuran } \\
\text { Diethyl phthalate } \\
\text { Dimethyl phthalate } \\
\text { Fluoranthene } \\
\text { Fluorene } \\
\text { Hexachlorobenzene } \\
\text { Hexachlorobutadiene } \\
\text { Hexachloroethane } \\
\text { Indeno(1,2,3-cd)pyrene } \\
\text { n-Nitroso-di-n-propylamine } \\
\text { Naphthalene } \\
\text { Nitrobenzene } \\
\text { Pentachlorophenol } \\
\text { Phenanthrene } \\
\text { Phenol } \\
\text { Pyrene } \\
\text { Pyridine }\end{array}$ & $\begin{array}{l}\text { Aroclor } 1016 \\
\text { Aroclor } 1221 \\
\text { Aroclor } 1232 \\
\text { Aroclor } 1242 \\
\text { Aroclor } 1248 \\
\text { Aroclor } 1254 \\
\text { Aroclor } 1260 \\
\text { Aroclor } 1268\end{array}$ & \begin{tabular}{|l} 
Arsenic \\
Barium \\
Beryllium \\
Cadmium \\
Chromium \\
Lead \\
Mercury \\
Selenium \\
Silver
\end{tabular} & \begin{tabular}{|l} 
Isotopic Analyses \\
Am-241 \\
Pu-238 \\
Pu-239/240 \\
U-234 \\
U-235 \\
U-238 \\
\\
\\
Gamma-Emitting \\
Ac-228 \\
Am-241 \\
Co-60 \\
Cs-137 \\
Eu-152 \\
Eu-154 \\
Eu-155 \\
K-40 \\
Nb-94 \\
Pb-212 \\
Pb-214 \\
Th-234 \\
TI-208 \\
U-235
\end{tabular} \\
\hline
\end{tabular}

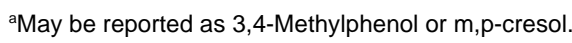

$\begin{array}{ll}\mathrm{Ac}=\text { Actinium } & \mathrm{Pb}=\text { Lead } \\ \mathrm{Co}=\text { Cobalt } & \mathrm{Sr}=\text { Strontium } \\ \mathrm{K}=\text { Potassium } & \mathrm{Th}=\text { Thorium } \\ \mathrm{Nb}=\text { Niobium } & \mathrm{Tl}=\text { Thallium }\end{array}$

\subsection{Preliminary Action Levels}

The PALs presented in this section are to be used for site screening purposes. They are not necessarily intended to be used as cleanup action levels or FALs. However, they are useful in screening out contaminants that are not present in sufficient concentrations to warrant further evaluation, therefore streamlining the consideration of remedial alternatives. The RBCA process used to establish FALs is described in the Soils Risk-Based Corrective Action Evaluation Process (NNSA/NSO, 2012b). This process conforms with Nevada Administrative Code (NAC) 445A.227, which lists the requirements for sites with soil contamination (NAC, 2008a). For the evaluation of corrective actions, NAC 445A.22705 (NAC, 2008b) requires the use of ASTM International (ASTM) Method E1739 
(ASTM, 1995) to "conduct an evaluation of the site, based on the risk it poses to public health and the environment, to determine the necessary remediation standards or to establish that corrective action is not necessary.” For the evaluation of corrective actions, the FALs are established as the necessary remedial standard.

This RBCA process, summarized in Figure 3-3, defines three tiers (or levels) of evaluation involving increasingly sophisticated analyses:

- Tier 1 evaluation. Sample results from source areas (highest concentrations) are compared to action levels based on generic (non-site-specific) conditions (i.e., the PALs established in the CAIP). The FALs may then be established as the Tier 1 action levels, or the FALs may be calculated using a Tier 2 evaluation.

- Tier 2 evaluation. Conducted by calculating Tier 2 site-specific target levels (SSTLs) using site-specific information as inputs to the same or similar methodology used to calculate Tier 1 action levels. The Tier 2 SSTLs are then compared to individual sample results from reasonable points of exposure (as opposed to the source areas as is done in Tier 1) on a point-by-point basis. Results from total petroleum hydrocarbons (TPH) analyses will not be used for risk-based decisions under Tier 2 or Tier 3. Rather, the individual chemical constituents of diesel reported from VOC and SVOC analyses will be compared to the SSTLs.

- Tier 3 evaluation. Conducted by calculating Tier 3 SSTLs on the basis of more sophisticated risk analyses using methodologies described in Method E1739 that consider site-, pathway-, and receptor-specific parameters.

This RBCA process includes a provision for conducting an interim remedial action if necessary and appropriate. The decision to conduct an interim action may be made at any time during the investigation and at any level (tier) of analysis. Concurrence of the decision makers listed in Section A.2.1 will be obtained before any interim action is implemented. Evaluation of DQO decisions will be based on conditions at the site after any interim actions are completed. Any interim actions conducted will be reported in the corrective action decision document (CADD).

If, after implementation of corrective actions, contamination remains in place that is less than the site-specific exposure scenario based FAL but exceeds 25 millirem per year (mrem/yr) based on the Industrial Area exposure scenario, an administrative use restriction will be implemented to prevent future industrial use of the area. For this reason, contamination at all sites will be evaluated against industrial exposure scenario based PALs and site-specific exposure scenario based FALs. The FALs 


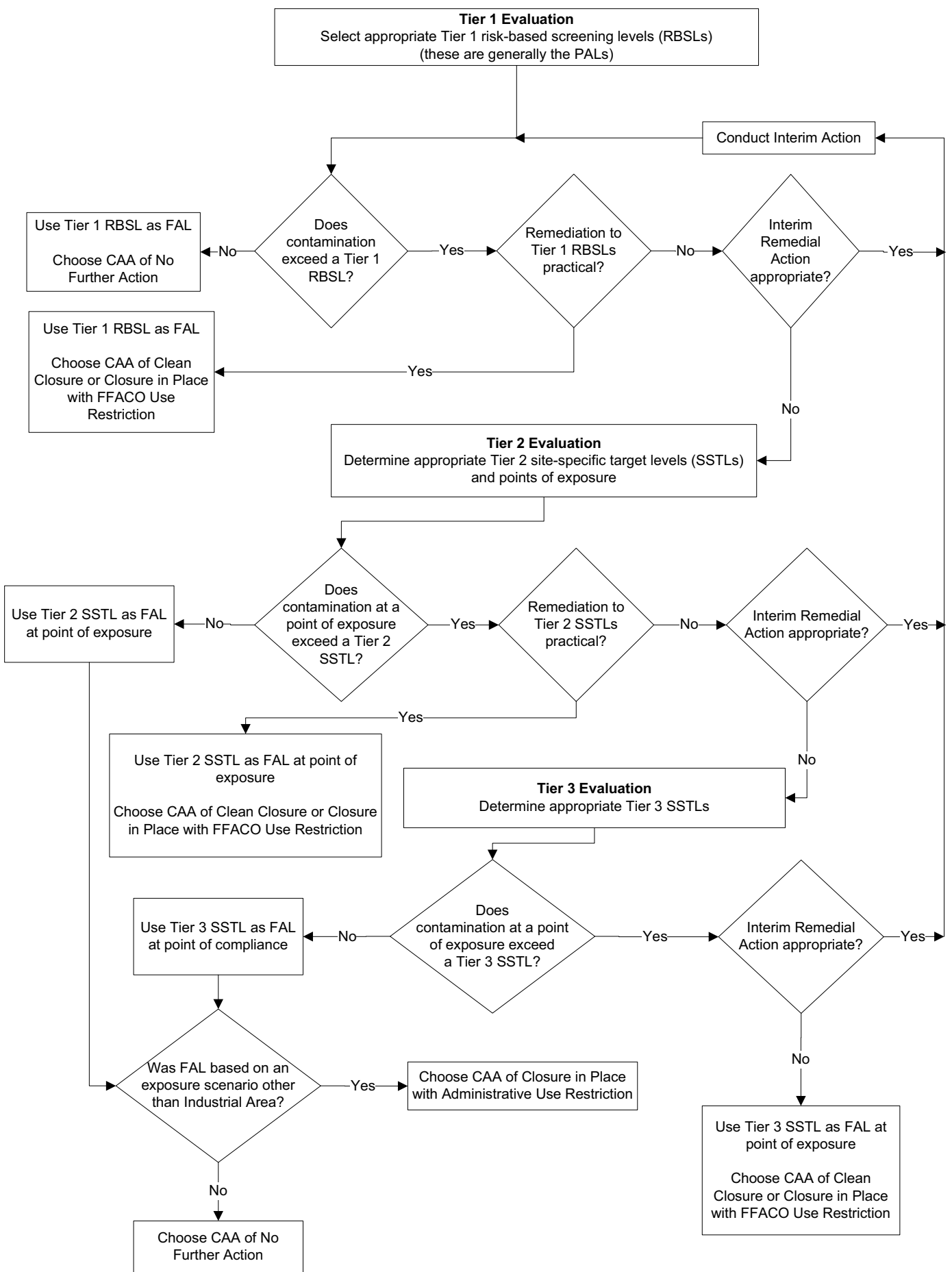

(ASTM, 1995)

Figure 3-3

Risk-Based Corrective Action Decision Process 
(along with the basis for their selection) will be proposed in the CADD, where they will be compared to laboratory results in the evaluation of potential corrective actions.

\subsubsection{Chemical PALs}

Except as noted herein, the chemical PALs are defined as the U.S. Environmental Protection Agency (EPA) Region 9 Regional Screening Levels for chemical contaminants in industrial soils (EPA, 2011a). Background concentrations for RCRA metals will be used instead of screening levels when natural background concentrations exceed the screening level, as is often the case with arsenic on the NNSS. Background is considered the mean plus two standard deviations of the mean for sediment samples collected by the Nevada Bureau of Mines and Geology throughout the Nevada Test

and Training Range (formerly the Nellis Air Force Range) (NBMG, 1998; Moore, 1999). For detected chemical COPCs without established screening levels, the protocol used by EPA Region 9 in establishing screening levels (or similar) will be used to establish PALs. If used, this process will be documented in the CADD.

\subsubsection{Radionuclide PALs}

The PAL for radioactive contaminants is a TED of 25 mrem/yr, based upon the Industrial Area exposure scenario. The Industrial Area exposure scenario is described in the Soils Risk-Based Corrective Action Evaluation Process (NNSA/NSO, 2012b). For primary releases, the TED is calculated as the sum of external dose and internal dose. External dose is determined directly from TLD measurements. Internal dose is determined by comparing analytical results from soil samples to residual radioactive material guidelines (RRMGs) that were established using the Residual Radioactive (RESRAD) computer code (Yu et al., 2001). The RRMGs presented in Table 3-3 are radionuclide-specific values for radioactivity in surface soils. The RRMG is the value, in picocuries per gram (pCi/g) of surface soil, for a particular radionuclide that would result in an internal dose of $25 \mathrm{mrem} / \mathrm{yr}$ to a receptor (under the appropriate exposure scenario) independent of any other radionuclide (assuming that no other radionuclides contribute dose).

In the RESRAD calculation, several input parameters are not specified so that site-specific information can be used. The default and site-specific input parameters used in the RESRAD calculation of RRMGs for each exposure scenario are listed in Attachment A-1 of Appendix A. 
Table 3-3

RRMG Values

\begin{tabular}{|c|c|c|c|}
\hline \multirow{2}{*}{ Radionuclide } & \multicolumn{3}{|c|}{ Exposure Scenario (pCi/g) } \\
\hline & Industrial Area & $\begin{array}{c}\text { Remote Work } \\
\text { Area }\end{array}$ & $\begin{array}{c}\text { Occasional Use } \\
\text { Area }\end{array}$ \\
\hline Am-241 & 2,816 & 16,120 & 45,550 \\
\hline Co-60 & 551,300 & $7,229,000$ & $74,210,000$ \\
\hline Cs-137 & 140,900 & $1,955,000$ & $27,560,000$ \\
\hline Eu-152 & $1,177,000$ & $13,240,000$ & $81,740,000$ \\
\hline Eu-154 & 846,900 & $9,741,000$ & $63,530,000$ \\
\hline Eu-155 & $5,588,000$ & $66,450,000$ & $475,100,000$ \\
\hline $\mathrm{Nb}-94$ & $3,499,000$ & $39,660,000$ & $249,200,000$ \\
\hline Pu-238 & 2,423 & 13,880 & 39,220 \\
\hline Pu-239/240 & 2,215 & 12,680 & 35,820 \\
\hline Sr-90 & 59,470 & 807,500 & $9,949,000$ \\
\hline Th-232 & 2,274 & 13,410 & 38,520 \\
\hline U-234 & 19,600 & 137,900 & 447,000 \\
\hline U-235 & 20,890 & 149,600 & 492,200 \\
\hline U-238 & 21,200 & 155,400 & 336,100 \\
\hline
\end{tabular}

\subsection{DQO Process Discussion}

This section contains a summary of the DQO process that is presented in Appendix A. The DQO process is a strategic planning approach based on the scientific method that is designed to ensure that the data collected will provide sufficient and reliable information to identify, evaluate, and technically defend the recommendation of viable corrective actions (e.g., no further action, clean closure, or closure in place).

As presented in Section 4.1, it is assumed that TED within the DCBs (i.e., the HCA region within the northern CA and the HCA region within the southern CA) exceed the FAL. Figure 3-4 shows the DCBs associated with CAU 550. For these areas, the DQO decisions are resolved and corrective action is required. The DQO decisions will be resolved for the areas outside the DCBs. 


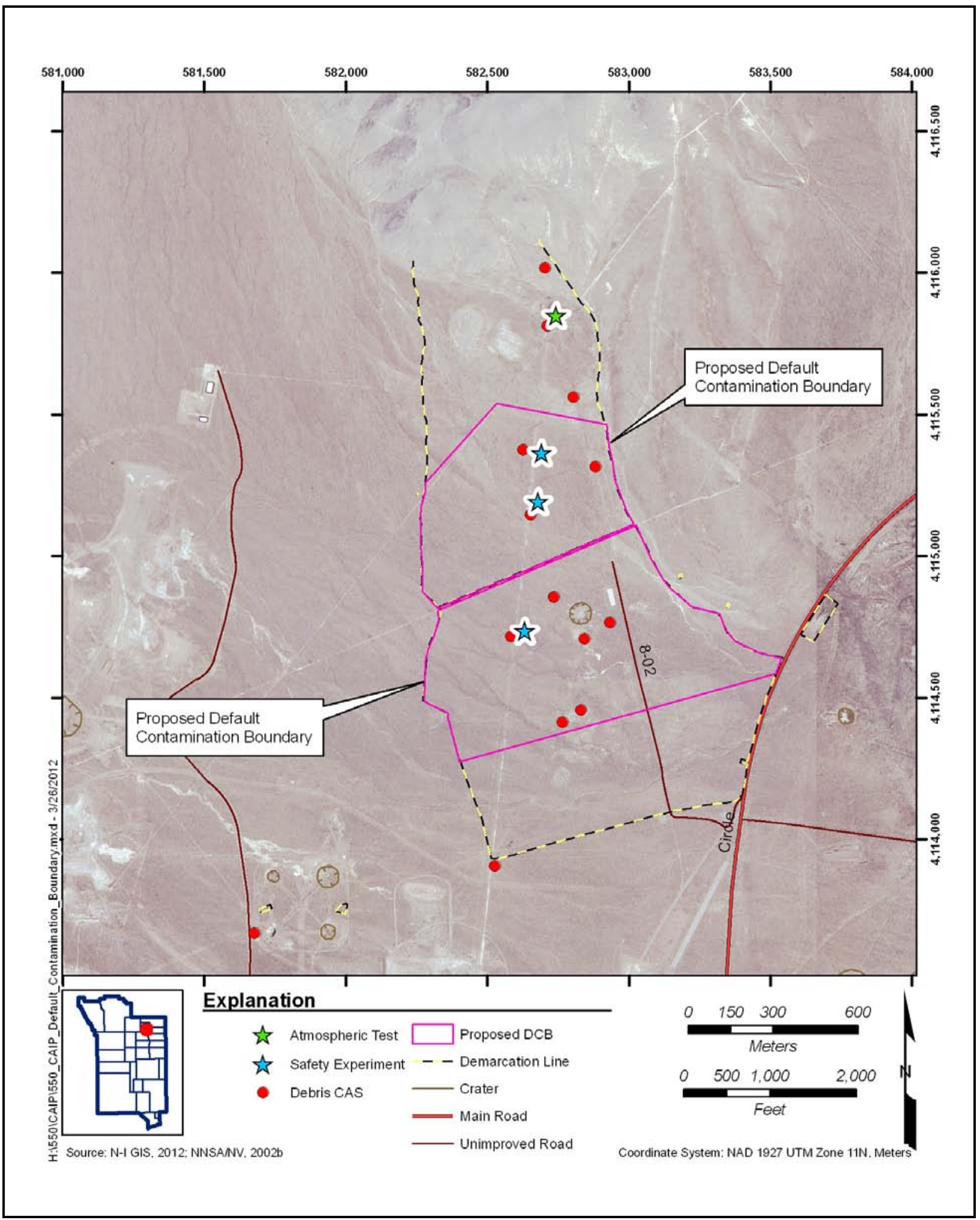

Figure 3-4

CAU 550, DCBs 
As presented in Section 1.1.2, the DQOs address two types of potential contaminant release scenarios. The primary releases will be investigated through a combination of probabilistic and judgmental sampling, and the other releases will be investigated through judgmental sampling. Therefore, discussions related to these two release scenarios are presented separately.

The DQO strategy for CAU 550 was developed at a meeting on January 31, 2012. The DQOs were developed to identify data needs, clearly define the intended use of the environmental data, and design a data collection program that will satisfy these purposes. During the DQO discussions for this CAU, the informational inputs or data needs to resolve problem statements and decision statements were documented.

The problem statement for CAU 550 is as follows: "Existing information on the nature and extent of potential contamination is insufficient to evaluate and recommend CAAs for the CASs in CAU 550.” To address this problem statement, resolution of the following decision statements is required:

- Decision I. "Is any COC present in environmental media within the CAS?" If a COC is detected, then Decision II must be resolved.

- Decision II. “Is sufficient information available to evaluate potential CAAs?” Sufficient information is defined to include the following:

- The lateral and vertical extent of COC contamination

- The information needed to determine potential remediation waste types

- The information needed to evaluate the feasibility of remediation alternatives

The presence of a COC would require a corrective action. A corrective action may also be necessary if there is a potential for wastes (i.e., potential source material [PSM]) that are present at a site to introduce COCs into site environmental media. Several conservative assumptions were made to evaluate the potential for wastes to introduce a COC to the surrounding environmental media. These assumptions are detailed in Section A.3.1.

For the primary release scenario, it is unknown whether COCs are present outside the DCBs and Decision I sampling for the primary release scenario will be conducted. If COCs are identified, Decision II must be resolved for the primary releases at CAU 550. 
For the other release scenario, Decision I samples will be submitted to analytical laboratories to determine the presence of COCs. The specific analyses for samples from other releases will be selected dependent upon the type and nature of the identified release. Decision II samples for both release scenarios will be submitted as necessary to define the extent of unbounded COCs. In addition, samples will be submitted for analyses, as needed, to support waste management or health and safety decisions.

For the laboratory data, the data quality indicators (DQIs) of precision, accuracy, representativeness, completeness, comparability, and sensitivity needed to satisfy DQO requirements are discussed in Section 6.2. Laboratory data will be assessed in the CADD to confirm or refute the CSM and determine whether the DQO data needs were met.

Analytical methods and target minimum detectable concentrations (MDCs) for each CAU 550 COPC are provided in Tables 3-4 and 3-5. The criteria for precision and accuracy listed in Tables 3-4 and 3-5 may vary from information in the Industrial Sites QAPP as a result of the laboratory used or updated/new methods (NNSA/NV, 2002a). 
Table 3-4

Analytical Requirements for Radionuclides for CAU 550

\begin{tabular}{|c|c|c|c|c|c|}
\hline Analysis $^{a}$ & $\begin{array}{l}\text { Medium or } \\
\text { Matrix }\end{array}$ & $\begin{array}{c}\text { Analytical } \\
\text { Method }\end{array}$ & $M^{\prime b}$ & $\begin{array}{c}\text { Laboratory } \\
\text { Precision }\end{array}$ & $\begin{array}{c}\text { Laboratory } \\
\text { Accuracy }\end{array}$ \\
\hline \multicolumn{6}{|c|}{ Gamma-Emitting Radionuclides } \\
\hline \multirow[b]{2}{*}{$\begin{array}{c}\text { Gamma } \\
\text { Spectroscopy }\end{array}$} & Aqueous & EPA $901.1^{\mathrm{c}}$ & \multirow[b]{2}{*}{$10 \%$ of $R R M G s^{d}$} & RPD & \multirow[b]{2}{*}{$\begin{array}{c}\text { LCS Recovery } \\
(\% \mathrm{R}) \\
80-120^{\mathrm{g}}\end{array}$} \\
\hline & Non-aqueous & GA-01-R ${ }^{h}$ & & $\begin{array}{c}20 \% \text { (aqueous) }^{\mathrm{e}} \\
\mathrm{ND} \\
-2<\mathrm{ND}<2^{\mathrm{f}}\end{array}$ & \\
\hline \multicolumn{6}{|c|}{ Other Radionuclides } \\
\hline Isotopic U & All & $U-02-R C^{h}$ & \multirow{11}{*}{$10 \%$ of RRMGs ${ }^{d}$} & \multirow{11}{*}{$\begin{array}{c}\text { RPD } \\
35 \% \text { (non-aqueous) }^{\mathrm{e}} \\
20 \% \text { (aqueous) }^{\mathrm{e}}\end{array}$} & \multirow{3}{*}{$\begin{array}{c}\text { Chemical Yield } \\
\text { Recovery }(\% R) \\
30-105^{i}\end{array}$} \\
\hline \multirow{2}{*}{ Isotopic Pu } & Aqueous & Pu-10-RCh & & & \\
\hline & Non-aqueous & $\mathrm{Pu}-02-\mathrm{RC}^{\mathrm{h}}$ & & & \\
\hline \multirow{2}{*}{ Isotopic Am } & Aqueous & Am-03-RCh & & & \multirow{4}{*}{$\begin{array}{c}\text { LCS Recovery } \\
(\% \mathrm{R}) \\
80-120^{\mathrm{i}}\end{array}$} \\
\hline & Non-aqueous & Am-01-RCh & & & \\
\hline \multirow{2}{*}{ Sr-90 } & Aqueous & EPA $905.0^{c}$ & & & \\
\hline & Non-aqueous & $\mathrm{Sr}-02-\mathrm{RC}^{\mathrm{h}}$ & & & \\
\hline & Aqueous & EPA $900.0^{c}$ & & & \multirow{4}{*}{$\begin{array}{c}\text { MS Recovery } \\
(\% \mathrm{R}) \\
\text { Lab-specific } \\
\text { LCS Recovery } \\
(\% \mathrm{R}) \\
80-120^{\mathrm{i}}\end{array}$} \\
\hline & Non-aqueous & SM $7110 B^{k}$ & & & \\
\hline \multirow[b]{2}{*}{ Tritium } & Aqueous & EPA $906.0^{c}$ & & & \\
\hline & Non-aqueous & $\begin{array}{l}\text { Laboratory } \\
\text { Procedure }\end{array}$ & & & \\
\hline
\end{tabular}

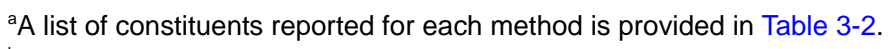

${ }^{\mathrm{b}}$ The MDC is the minimum concentration of a constituent in accordance with Standard Methods ${ }^{\mathrm{k}}$.

'Prescribed Procedures for Measurement of Radioactivity in Drinking Water (EPA, 1980).

${ }^{\mathrm{d}}$ The RRMG is the value, in picocuries per gram of surface soil, for a particular radionuclide that would result in a dose of $25 \mathrm{mrem} / \mathrm{IA}-\mathrm{yr}$ (e.g., the PAL).

'Sampling and Analysis Plan Guidance and Template (EPA, 2000).

${ }^{\mathrm{f}}$ Evaluation of Radiochemical Data Usability (Paar and Porterfield, 1997).

${ }^{9}$ Test Methods for Evaluating Solid Waste, Physical/Chemical Methods (EPA, 2011b).

${ }^{\mathrm{h}}$ The Procedures Manual of the Environmental Measurements Laboratory (DOE, 1997).

'Professional judgment and other industry acceptance criteria are used.

jAccuracy criteria are developed in-house using approved laboratory standard operating procedures in accordance with industry standards and the N-I Statement of Work requirements (NNES, 2009).

kStandard Methods for the Examination of Water and Wastewater (Clesceri et al., 1998).

'Laboratory standard operating procedures in accordance with industry standards and the N-I Statement of Work requirements (NNES, 2009).

LCS = Laboratory control sample

MS = Matrix spike

ND $=$ Normalized difference
$\mathrm{N}-\mathrm{I}=$ Navarro-Intera, LLC

$\mathrm{RPD}=$ Relative percent difference

$\% \mathrm{R}=$ Percent recovery 
Table 3-5

Analytical Requirements for Chemicals for CAU 550

\begin{tabular}{|c|c|c|c|c|c|}
\hline Analysis $^{a}$ & $\begin{array}{l}\text { Medium or } \\
\text { Matrix }\end{array}$ & $\begin{array}{c}\text { Analytical } \\
\text { Method }\end{array}$ & $\mathrm{MDC}^{\mathrm{b}}$ & Laboratory Precision & $\begin{array}{l}\text { Laboratory } \\
\text { Accuracy }\end{array}$ \\
\hline \multicolumn{6}{|c|}{ Organics } \\
\hline VOCs & All & $8260^{c}$ & $<$ FALS & Lab-specific $^{d}$ & Lab-specific $^{d}$ \\
\hline TCLP VOCs & Leachate & $1311 / 8260^{c}$ & $\begin{array}{c}<\text { Regulatory } \\
\text { Levels }\end{array}$ & Lab-specific $^{d}$ & Lab-specific $^{d}$ \\
\hline SVOCs & All & $8270^{c}$ & $<$ FALs & Lab-specific $^{d}$ & Lab-specific $^{d}$ \\
\hline TCLP SVOCS & Leachate & $1311 / 8270^{c}$ & $\begin{array}{c}<\text { Regulatory } \\
\text { Levels }\end{array}$ & Lab-specific $^{d}$ & Lab-specific $^{d}$ \\
\hline \multicolumn{6}{|c|}{ Inorganics } \\
\hline $\begin{array}{l}\text { RCRA Metals, } \\
\text { Beryllium }\end{array}$ & All & $6010 / 6020^{c}$ & \multirow{3}{*}{$<$ FALs } & $\begin{array}{c}\text { RPD } \\
35 \% \text { (non-aqueous) }\end{array}$ & $\begin{array}{c}\text { MS Recovery } \\
(\% \mathrm{R})\end{array}$ \\
\hline \multirow{2}{*}{ Mercury } & Aqueous & $7470^{c}$ & & $20 \%$ (aqueous) $^{\mathrm{e}}$ & $75-125^{c}$ \\
\hline & Non-aqueous & $7471^{\mathrm{c}}$ & & \multirow{2}{*}{$\begin{array}{l}\text { Absolute Difference } \\
\pm 2 \times \text { RL (non-aqueous) } \\
\pm 1 \times \text { RL (aqueous) }\end{array}$} & \multirow{2}{*}{$\begin{array}{c}\text { LCS Recovery } \\
(\% \mathrm{R}) \\
80-120^{\mathrm{c}}\end{array}$} \\
\hline TCLP Metals & Leachate & $1311 / 6010 / 7470^{c}$ & $\begin{array}{c}<\text { Regulatory } \\
\text { Levels }\end{array}$ & & \\
\hline
\end{tabular}

${ }^{\mathrm{a} A}$ list of constituents reported for each method is provided in Table 3-2.

${ }^{\mathrm{b}} \mathrm{T}$ he MDC is the minimum concentration of a constituent in accordance with SW-846 ${ }^{\mathrm{c}}$.

${ }^{\mathrm{C} T e s t}$ Methods for Evaluating Solid Waste, Physical/Chemical Methods (EPA, 2011b).

dPrecision and accuracy criteria are developed in-house using approved laboratory standard operating procedures in accordance with industry standards and the N-I Statement of Work requirements (NNES, 2009).

eSampling and Analysis Plan Guidance and Template (EPA, 2000).

'USEPA Contract Laboratory Program National Functional Guidelines for Inorganic Data Review (EPA, 2004).

$\mathrm{RL}=$ Reporting limit

TCLP $=$ Toxicity Characteristic Leaching Procedure 


\subsection{Field Investigation}

This section contains a description of the activities to be conducted to gather and document information from the CAU 550 field investigation.

\subsection{Technical Approach}

The information necessary to satisfy the DQO data needs will be generated for CAU 550 by collecting and analyzing samples generated during the CAI. However, the Study Group 1 and Study Group 2 investigations will not include the areas within the northern CA and southern CA that exceed the criteria for an HCA. This is based on the potential for a receptor in these areas to become contaminated and transport this removable contamination. DCBs have been established at these locations, and corrective actions are required. For Study Group 4 locations (distributed both inside and outside the DCB), information will be generated during the CAI to resolve DQO decisions.

The presence and nature of contamination for primary releases will be evaluated using a combination of judgmental and probabilistic approaches. The sample plots will be selected and evaluated judgmentally, and the samples collected within the sample plots will be collected and evaluated probablistically. Other release samples will be located and sample results evaluated based on judgmental criteria.

If it is determined that a COC is present at any study group, that study group will be further addressed by determining the extent of contamination before evaluating CAAs.

For probabilistic sampling of radiological contamination, DQO decisions will be based on the 95 percent UCL of the average TED for each sample plot. For judgmental sampling, DQO decisions will be based on a direct comparison of sample results to the FAL.

The TED will be determined by summing internal and external dose measurements at each sample location. Sample results for individual radionuclides will be used to calculate internal dose using the 
RRMGs presented in Section 3.3.2. The internal dose associated with any specific radionuclide would be established using the following equation:

$$
\text { Internal dose }(\mathrm{mrem} / \mathrm{yr})=[\text { Analytical result }(\mathrm{pCi} / \mathrm{g}) / \mathrm{RRMG}] \text { x } 25 \mathrm{mrem} / \mathrm{yr}
$$

When more than one radionuclide is present, the internal dose will be calculated as the sum of the internal doses for each radionuclide.

External dose will be determined by collecting in situ measurements using a TLD. The TLD will be installed at the approximate center of the sample plot at a height of $1 \mathrm{~m}$ and be left in place for approximately 2,000 hours (equivalent to an annual industrial worker exposure). Each TLD contains three elements from which external dose measurements will be reported. The 95 percent UCL of the average TED for each plot will be the sum of the 95 percent UCL of the TLD element results for external dose and the 95 percent UCL of the sample results for internal dose.

Modifications to the investigative strategy may be required should unexpected field conditions be encountered at any study group. Significant modifications must be justified and documented before implementation. If an unexpected condition indicates that conditions are significantly different from the CSM, the activity will be rescoped and the identified decision makers will be notified.

\subsection{Field Activities}

Field activities at CAU 550 include site preparation, sample location selection, sample collection, and demobilization.

\subsubsection{Site Preparation Activities}

Site preparation activities to be conducted before the start of environmental sampling may include relocating or removing surface debris, equipment, and structures; constructing hazardous waste accumulation areas (HWAAs) and site exclusion zones; providing sanitary facilities; constructing decontamination facilities; and moving staged equipment. 
Before mobilization for collecting investigation samples, the following preparatory activities will also be conducted:

- $\quad$ Perform radiological surveys within Study Group 3.

- Install project-specific environmental monitoring TLDs (see Section 4.2.3 for additional information).

- Perform visual surveys at Study Group 4 to identify any staining, discoloration, disturbance of native soils, or any other indication of potential contamination.

\subsubsection{Sample Location Selection}

Rationale for selecting areas for sampling is discussed in the following sections.

All soil samples collected at each sample plot and all TLDs placed at each sample plot will be sampled as described in Section 4.2.3.

\subsubsection{Study Group 1}

As presented in Section 4.1, it is assumed that TED within the DCBs (i.e., the regions within the northern CA and southern CA that exceed HCA criteria) requires corrective action.

For Study Group 1, Decision I will be evaluated by measuring TED at a sample plot established within the area of the highest gamma values as determined from the PRM-470 radiological survey. This will be done in an effort to find the location of maximum TED. If the 95 percent UCL of the TED at the Decision I sample plot associated with Study Group 1 is less than the FAL, then no further action is required. Otherwise, Decision II will be resolved using TLDs from other locations across the grid. The potential Decision I sample plot location is depicted on Figure A.8-1 along with all of the Decision I and Decision II TLD locations.

The TED rates at each TLD location where soil samples are not collected will be estimated by adding an estimate of internal dose of the respective study group to the TLD results. The conservative estimate of internal dose for each of these locations will be calculated based on a ratio of internal dose to external dose. This ratio will be conservatively established from the measured internal and external doses at the sample plot within each study group with the maximum internal dose rate (see equation 
below). Use of this ratio will overestimate internal dose (and therefore TED) at all locations with lower dose rates. The TED for each of these TLD locations will be calculated as the total of the external dose measured by the TLD and the internal dose estimated using internal/external dose ratio from the selected sample plot.

$$
I N T_{\text {inferred at location } x}=\frac{I n t_{\text {location of max internal dose }}}{T L D_{\text {location of max internal dose }}} \times T L D_{\text {location } x}
$$

\subsubsection{Study Group 2}

As presented in Section 4.1, it is assumed that TED within the DCBs (i.e., the HCA region within the northern CA and the HCA region within the southern CA) exceeds the FAL.

For Study Group 2, Decision I will be evaluated by measuring TED at sample plots established within two individual locations outside the DCB most likely to exceed the FAL. The first sample location (north of the DCB) will be selected in the area of the highest 2002 KIWI values outside the DCB, and the second sample location (southwest of the DCB) will be selected in the area of the highest 2002 americium signature value outside the DCB (N-I, 2011). The final locations most representative of the highest TED will be determined in the field with the FIDLER. No additional TLDs are planned to be placed as part of the primary release investigation at Study Group 2. If the results of the Decision I samples at Study Group 2 indicate contamination present that exceeds the FALs, then a Decision II sampling strategy will be presented to and agreed upon by the stakeholders. The Decision I sample plot locations are depicted on Figure A.8-2.

\subsubsection{Study Group 3}

Within Study Group 3, Decision I will be evaluated by measuring TED at individual sample locations. Soil samples will be collected to determine internal dose with TLDs co-located to measure external dose. A ground-based KIWI survey was conducted in 2002 in the area of Study Group 3. PRM-470 and FIDLER surveys were also conducted during the 2011 preliminary investigations indicating migration outside the DCB. A FIDLER survey will be conducted to identify elevated readings to select a minimum of two sample locations per each of the three wash segments identified in the DQOs and depicted in Figure A.8-5. This survey will be more comprehensive to provide denser coverage throughout the wash segments and will include the bank/barrier area adjacent to Circle 
Road. A sampling location will be established at the two most elevated sediment accumulation areas outside the DCB within each of the three wash segments down to the edge of Circle Road. A TLD will be placed at each sample location.

Additionally, the depositional area will be sampled at the single most-elevated location as was identified based upon the 2002 americium flyover, and the FIDLER and KIWI ground surveys.

Additional sedimentation areas will be sampled until at least two consecutive sedimentation areas are found that do not contain a COC.

\subsubsection{Study Group 4}

For the Study Group 4 releases at CAU 550, a judgmental sampling approach will be used to investigate the likelihood of the soil containing a COC. Biasing factors such as stains, presence of lead bricks and broken lead-acid batteries, and wastes suspected of containing hazardous or radiological components will be used to select the most appropriate samples.

If a COC is present at any Study Group 4 sample location, Decision II sampling will be conducted to define the extent of contamination where COCs have been confirmed. Extent (Decision II) sampling locations at each CAS will be selected based on the CSM, biasing factors, field-survey results, existing data, and the outer boundary sample locations where COCs are detected. In general, extent sample locations will be arranged in a triangular pattern around areas containing a COC at distances based on site conditions, COC concentrations, process knowledge, and biasing factors. If COCs extend beyond extent locations, additional Decision II samples will be collected from locations farther from the source.

If a spatial boundary is reached, the CSM is shown to be inadequate, or the Site Supervisor determines that extent sampling needs to be reevaluated, then work will be temporarily suspended, NDEP will be notified, and the investigation strategy will be reevaluated. A minimum of one analytical result less than the action level from each lateral and vertical direction will be required to define the extent of COC contamination. The lateral and vertical extent of COCs will only be established based on validated laboratory analytical results (i.e., not field screening). 
The Task Manager or Site Supervisor may modify the number, location, and spacing of step-outs as warranted by site conditions to achieve DQO criteria stipulated in Appendix A. Where sampling locations are modified, the justification for these modifications will be documented in the CADD.

\subsubsection{Sample Collection}

The CAU 550 sampling program will consist of the following activities:

- $\quad$ Collect and analyze samples from locations as described in Section 4.2.2.

- $\quad$ Collect required QC samples.

- Collect waste management samples as necessary.

- Collect external dose measurements by hanging TLDs at the sample plots, or collect instrument dose readings at extent locations.

- Collect soil samples from locations outside the influence of releases from the CAS, if necessary.

- Perform radiological characterization surveys of construction materials and debris as necessary for disposal purposes.

- $\quad$ Record Global Positioning System (GPS) coordinates for each environmental sample location.

To determine internal dose for Study Groups 1 and 2, a probabilistic sampling approach will be implemented for collecting composite samples within the sample plots. Each composite sample will consist of soil collected from the surface to a depth of $5 \mathrm{~cm}$ at nine randomly located subsample locations within the plot. For each composite sample, the first location will be selected randomly; the remaining eight subsample locations will be established on a systematic triangular grid (see Section A.8.0). External dose will be sampled from a TLD installed at the approximate center of the sample plot at a height of $1 \mathrm{~m}$ and be left in place for approximately 2,000 hours (equivalent to an annual industrial worker exposure).

At each Study Group 3 location, a sample will be collected from each 5-cm depth interval until native material is encountered. Each sample will be screened with an alpha/beta contamination meter. The surface sample will submitted for analysis. Additionally, if the field-screening level (FSL) for any 
depth sample exceeds the FSL of the surface sample, then the depth sample with the highest screening value at each sample location will be submitted for analysis. If the FSL is not exceeded in any depth sample, only the surface sample will be submitted for analysis.

Decision I samples will be collected from 0 to $5 \mathrm{~cm}$ bgs at each Study Group 4 location based on biasing factors. If biasing factors are still present in soils below locations where Decision I samples were collected, subsurface samples will also be collected by augering, backhoe excavation, direct-push techniques, or drilling, as appropriate. Subsurface soil samples will be collected at depth intervals selected by the Site Supervisor based on biasing factors to a depth where the biasing factors are no longer present.

\subsubsection{Sample Management}

The laboratory requirements (i.e., MDCs, precision, and accuracy) to be used when analyzing the COPCs are presented in Tables 3-4 and 3-5. The analytical program is presented in Table 3-1. All sampling activities and QC requirements for field and laboratory environmental sampling will be conducted in compliance with the Industrial Sites QAPP (NNSA/NV, 2002a) and other applicable, approved procedures.

\subsection{Site Restoration}

Upon completion of CAI and waste management activities, the following actions will be implemented before closure of the site Real Estate/Operations Permit (REOP):

- All equipment, wastes, debris, and materials associated with the CAI will be removed from the site.

- All CAI-related signage and fencing (unless part of a corrective action) will be removed from the site.

- $\quad$ Site will be inspected to ensure restoration activities have been completed. 


\subsection{Waste Management}

Waste generated during the CAU 550 field investigation will be managed in accordance with all applicable DOE orders, federal and state regulations, and agreements and permits between DOE and NDEP. Wastes will be characterized based on these regulations using process knowledge, field-screening results (FSRs), and analytical results from investigation and waste samples. Waste types that may be generated during the CAI include industrial, hazardous, hydrocarbon, Toxic Substances Control Act (TSCA) regulated (e.g., PCBs, asbestos), low-level radioactive, or mixed wastes.

Disposable sampling equipment, personal protective equipment (PPE), and rinsate are considered potentially contaminated waste only by virtue of contact with potentially contaminated media (e.g., soil) or potentially contaminated debris (e.g., lead). These wastes may be characterized based on associated environmental sample results, waste characterization results, FSRs, or process knowledge.

Chemicals were not known to be used or present at this CAU in a manner that would generate listed hazardous waste; therefore, wastes will be characterized based on their chemical characteristics. The waste will be managed and disposed of accordingly.

Conservative estimates of total waste contaminant concentrations may be made based on the mass of the waste, the amount of contaminated media contained in the waste, and the maximum concentration of contamination found in the media.

The following sections discuss how the field investigation will be conducted to minimize the generation of waste, what waste streams are expected to be generated, and how IDW will be managed.

\subsection{Waste Minimization}

The CAI will be conducted in a manner that will minimize the generation of wastes using process knowledge, segregation, visual examination, and/or field screening (e.g., radiological survey and swipe results) to avoid cross-contaminating uncontaminated media or uncontaminated IDW that 
would otherwise be characterized and disposed of as industrial waste. As appropriate, media and debris will be returned to their original location. To limit unnecessary generation of hazardous or mixed waste, hazardous materials will not be used during the CAI unless required and approved by Environmental Compliance and Health and Safety. Other waste minimization practices will include, as appropriate, avoiding contact with contaminated materials, performing dry decontamination or wet decontamination over source locations, and carefully segregating waste streams.

\subsection{Potential Waste Streams}

The following is a list of common waste streams that may be generated during the field investigation and that may require management and disposal:

\subsection{IDW Management}

The onsite management of IDW will be determined based on regulations associated with the particular waste type (e.g., industrial, low-level), or the combination of waste types. The following subsections describe how specific waste types will be managed.

\subsubsection{Industrial Waste}

Industrial solid waste, if generated, will be collected, managed, and disposed of in accordance with the solid waste regulations and the permits for operation of the NNSS Solid Waste Disposal Sites. The most commonly generated industrial solid waste includes disposable sampling equipment and PPE that will be collected in plastic bags, and marked in accordance with requirements. This waste, and other waste generated such as debris or soil that is characterized as industrial waste, may be placed in the roll-off box located adjacent to Building 23-153 in Mercury or in another approved container (e.g., drum).

\subsubsection{Hazardous Waste}

Suspected hazardous waste, if generated, will be containerized and managed in waste accumulation areas in accordance with 40 Code of Federal Regulations (CFR) 262.34 (CFR, 2011a). 


\subsubsection{Hydrocarbon Waste}

Suspected hydrocarbon solid waste, if generated, will be managed on site in a drum or other appropriate container until fully characterized and in accordance with the State of Nevada regulations (NDEP, 2006).

\subsubsection{Polychlorinated Biphenyls}

The management of PCBs is governed by TSCA and its implementing regulations at 40 CFR 761 (CFR, 2011b), and agreements between EPA and NDEP. PCB contamination may be found as a sole contaminant or in combination with any of the types of waste discussed in this document. For example, PCBs may be a co-contaminant in soil that contains a RCRA “characteristic” waste (PCB/hazardous waste), or in soil that contains radioactive wastes (PCB/radioactive waste), or even in mixed waste (PCB/radioactive/hazardous waste). The IDW will initially be evaluated using analytical results for media samples from the CAI. If any type of PCB waste is generated, it will be managed in accordance with 40 CFR 761 (CFR, 2011b) as well as State of Nevada requirements (NAC, 2008b), guidance, and agreements with NNSA/NSO.

\subsubsection{Low-Level Waste}

Low-level radioactive waste, if generated, will be managed in accordance with the contractor-specific waste certification program plan, DOE orders, and the requirements of the current version of the Nevada National Security Site Waste Acceptance Criteria (NNSSWAC) (NNSA/NSO, 2012a). Potential radioactive waste containers will be staged and managed at a designated radioactive material area (RMA).

\subsubsection{Mixed Low-Level Waste}

Mixed waste, if generated, will be managed in accordance with the RCRA requirements (CFR, 2011a), agreements between NNSA/NSO and the State of Nevada, and DOE requirements for radioactive waste. Waste characterized as mixed will not be stored for a period of time that exceeds the RCRA requirements unless subject to agreements between NNSA/NSO and the State of Nevada. Mixed waste with hazardous waste constituent concentrations below Land Disposal Restrictions may be disposed of at the NNSS Area 5 RWMS if the waste meets the requirements of the NNSSWAC 
(NNSA/NSO, 2012a) and the NNSS NDEP permit for a Hazardous Waste Management Facility NV HW0101 [NDEP, 2011]). Mixed waste constituent concentrations exceeding Land Disposal Restrictions will be transferred to the management and operating contractor for treatment and disposal. 


\subsection{Quality Assurance/Quality Control}

The overall objective of the characterization activities described in this CAIP is to collect accurate and defensible data to support the selection and implementation of a closure alternative for study groups in CAU 550. The data from the TLD measurements will also meet rigorous data quality requirements. The TLDs will be obtained from, and measured by, the Environmental Technical Services group at the NNSS. This group is responsible for a routine environmental monitoring program at the NNSS. The program includes a campaign of TLDs that are emplaced at pre-established locations across the NNSS for the monitoring of external dose. The TLDs are replaced and read quarterly. Details of this campaign can be found in the Nevada Test Site Environmental Report 2006 (Wills, 2007). The TLDs will be submitted to the Environmental Technical Services group for inclusion in their routine quarterly read of the NNSS environmental monitoring TLDs. The TLDs will be analyzed using automated TLD readers that are calibrated and maintained by the National Security Technologies, LLC, Radiological Control Department in accordance with existing QC procedures for TLD processing. A summary of the routine environmental monitoring TLD QC efforts and results can be found in Section 5.2.1 of the Nevada Test Site Environmental Report 2006. Certification is maintained through the DOE Laboratory Accreditation Program for dosimetry.

The determination of the external dose component of the TED by TLDs was determined to be the most accurate method because of the following factors:

1. The TLDs will be exposed at the sample plots for the 2,000 hours of exposure time used for the Industrial Area exposure scenario. This eliminates errors in reading dose-rate meter scale graduations and needle fluctuations that would be magnified when as-read meter values are multiplied from units of "per-hour” to 2,000 hours.

2. The use of a TLD to determine an individual's external dose is the standard in radiation safety and serves as the "legal dose of record" when other measurements are available. Specifically, 10 CFR Part 835.402 (CFR, 2012) indicates that personal dosimeters must be provided to monitor individual exposures and that the monitoring program that uses the dosimeters must be accredited in accordance with a DOE Laboratory Accreditation Program. 
Sections 6.1 and 6.2 discuss the collection of required QC samples in the field and QA requirements for soil samples.

\subsection{QC Sampling Activities}

Field QC samples will be collected in accordance with established procedures. Field QC samples are collected and analyzed to aid in determining the validity of environmental sample results. The number of required QC samples depends on the types and number of environmental samples collected. As determined in the DQO process, the minimum frequency of collecting and analyzing QC samples for this investigation is as follows:

\section{- Radiological samples}

- Field duplicates (1 per 20 environmental samples, or 1 per study group per matrix if less than 20 collected)

- Laboratory QC samples (1 per 20 environmental samples, or 1 per study group per matrix if less than 20 collected)

\section{- Chemical samples (if collected)}

- Trip blanks (1 per sample cooler containing VOC environmental samples)

- Equipment rinsate blanks (1 per sampling event for each type of decontamination procedure)

- Source blanks (1 per lot of uncharacterized source material that contacts sampled media)

- Field duplicates (1 per 20 environmental samples, or 1 per study group per matrix if less than 20 collected)

- Field blanks (1 per study group)

- Laboratory QC samples (1 per 20 environmental samples, or 1 per study group per matrix if less than 20 collected)

Additional QC samples may be submitted based on site conditions at the discretion of the Task Manager or Site Supervisor. Field QC samples must be analyzed using the same analytical procedures implemented for associated environmental samples. Additional details regarding field QC samples are available in the Industrial Sites QAPP (NNSA/NV, 2002a). 


\subsection{Laboratory/Analytical QA}

As stated in the DQOs (see Appendix A), and except where noted, laboratory analytical quality data will be used for making DQO decisions. Rigorous QA/QC will be implemented for all laboratory samples, including documentation, data verification and validation of analytical results, and an assessment of DQIs as they relate to laboratory analysis.

\subsubsection{Data Validation}

Data verification and validation will be performed in accordance with the Industrial Sites QAPP (NNSA/NV, 2002a), except where otherwise stipulated in this CAIP. All chemical and radiological laboratory data from samples that are collected and analyzed will be evaluated for data quality in accordance with company-specific procedures. The data will be reviewed to ensure that all required samples were appropriately collected and analyzed, and that the results met data validation criteria. Validated data, including estimated data (i.e., J-qualified), will be assessed to determine whether the data meet the DQO requirements of the investigation and the performance criteria for the DQIs. The results of this assessment will be documented in the CADD. If the DQOs were not met, corrective actions will be evaluated, selected, and implemented (e.g., refine CSM or resample to fill data gaps).

\subsubsection{Data Quality Indicators}

DQIs are qualitative and quantitative descriptors used in interpreting the degree of acceptability or utility of data. DQIs are used to evaluate the entire measurement system and laboratory measurement processes (i.e., analytical method performance) as well as to evaluate individual analytical results (i.e., parameter performance). The quality and usability of data used to make DQO decisions will be assessed based on the following DQIs:

- Precision

- Accuracy/bias

- Representativeness

- Completeness

- Comparability

- Sensitivity

Table 6-1 provides the established analytical method/measurement system performance criteria for each of the DQIs and the potential impacts to the decision if the criteria are not met. The following 
subsections discuss each of the DQIs that will be used to assess the quality of laboratory data. The criteria for precision and accuracy in Tables 3-4 and 3-5 may vary from corresponding information in the Industrial Sites QAPP as a result of changes in analytical methodology and laboratory contracts (NNSA/NV, 2002a).

Table 6-1

Laboratory and Analytical Performance Criteria for CAU 550 DQIs

\begin{tabular}{|c|c|c|}
\hline DQI & Performance Metric & $\begin{array}{l}\text { Potential Impact on Decision } \\
\text { If Performance Metric Not Met }\end{array}$ \\
\hline Precision & $\begin{array}{l}\text { At least } 80 \% \text { of the sample results for each } \\
\text { measured contaminant are not qualified for } \\
\text { precision based on the criteria for each } \\
\text { analytical method-specific and } \\
\text { laboratory-specific criteria presented in } \\
\text { Section } 6.2 .3 \text {. }\end{array}$ & $\begin{array}{l}\text { The affected analytical results from each } \\
\text { affected study group will be assessed to } \\
\text { determine whether there is sufficient } \\
\text { confidence in analytical results to use the data } \\
\text { in making DQO decisions. }\end{array}$ \\
\hline Accuracy & $\begin{array}{l}\text { At least } 80 \% \text { of the sample results for each } \\
\text { measured contaminant are not qualified for } \\
\text { accuracy based on the method-specific and } \\
\text { laboratory-specific criteria presented in } \\
\text { Section } 6.2 .4 \text {. }\end{array}$ & $\begin{array}{l}\text { The affected analytical results from each } \\
\text { affected study group will be assessed to } \\
\text { determine whether there is sufficient } \\
\text { confidence in analytical results to use the data } \\
\text { in making DQO decisions. }\end{array}$ \\
\hline Representativeness & $\begin{array}{l}\text { Samples contain contaminants at } \\
\text { concentrations present in the environmental } \\
\text { media from which they were collected. }\end{array}$ & $\begin{array}{l}\text { Analytical results will not represent true site } \\
\text { conditions. Inability to make appropriate } \\
\text { DQO decisions. }\end{array}$ \\
\hline $\begin{array}{c}\text { Decision I } \\
\text { Completeness }\end{array}$ & $\begin{array}{l}80 \% \text { of the CAS-specific COPCs have } \\
\text { valid results. }\end{array}$ & $\begin{array}{l}\text { Cannot support/defend decision on whether } \\
\text { cOCs are present. }\end{array}$ \\
\hline $\begin{array}{c}\text { Decision II } \\
\text { Completeness }\end{array}$ & $\begin{array}{l}100 \% \text { of COCs used to define extent have } \\
\text { valid results. }\end{array}$ & $\begin{array}{l}\text { Extent of contamination cannot be } \\
\text { accurately determined. }\end{array}$ \\
\hline Comparability & $\begin{array}{l}\text { Sampling, handling, preparation, analysis, } \\
\text { reporting, and data validation are performed } \\
\text { using standard methods and procedures. }\end{array}$ & $\begin{array}{l}\text { Inability to combine data with data obtained } \\
\text { from other sources and/or inability to compare } \\
\text { data to regulatory action levels. }\end{array}$ \\
\hline Sensitivity & $\begin{array}{l}\text { Minimum detectable concentrations are less } \\
\text { than or equal to respective FALs. }\end{array}$ & $\begin{array}{l}\text { Cannot determine whether COCs are present } \\
\text { or migrating at levels of concern. }\end{array}$ \\
\hline
\end{tabular}

The TLDs will be analyzed using automated TLD readers that are calibrated and maintained in accordance with existing QC procedures for TLD processing (Section 6.0) by a laboratory that is certified through the DOE Laboratory Accreditation Program for dosimetry. The data from this system meet rigorous data quality requirements and will be assessed for the listed DQIs before inclusion in the CAU 550 datset. Therefore, a separate evaluation of the TLD data against the DQIs will not be conducted. 


\subsubsection{Precision}

Precision is a measure of the repeatability of the analysis process from sample collection through analysis results and is used to assess the variability between two equal samples.

Determinations of precision will be made for field duplicate samples and laboratory duplicate samples. Field duplicate samples will be collected simultaneously with samples from the same source under similar conditions in separate containers. The duplicate sample will be treated independently of the original sample in order to assess field impacts and laboratory performance on precision through a comparison of results. Laboratory precision is evaluated as part of the required laboratory internal QC program to assess performance of analytical procedures. The laboratory sample duplicates are an aliquot, or subset, of a field sample generated in the laboratory. They are not a separate sample but a split, or portion, of an existing sample. Typically, laboratory duplicate QC samples may include matrix spike duplicate (MSD) and LCS duplicate samples for organic, inorganic, and radiological analyses.

Precision is a quantitative measure used to assess overall analytical method and field-sampling performance as well as the need to "flag" (qualify) individual parameter results when corresponding QC sample results are not within established control limits.

The criteria used for the assessment of inorganic chemical precision when both results are greater than or equal to 5x reporting limit (RL) are 20 and 35 percent for aqueous and soil samples, respectively. When either result is less than $5 x \mathrm{RL}$, control limits of $\pm 1 \mathrm{x} R \mathrm{R}$ and $\pm 2 \mathrm{x} R \mathrm{R}$ for aqueous and soil samples, respectively, are applied to the absolute difference.

The criteria used for the assessment of organic chemical precision are based on professional judgment using laboratory-defined control limits.

The criteria used for the assessment of radiological precision when both results are greater than or equal to 5x MDC are 20 and 35 percent for aqueous and soil samples, respectively. When either result is less than $5 x$ MDC, the ND should be between -2 and +2 for aqueous and soil samples. The parameters to be used for assessment of precision for duplicates are listed in Table 3-5. 
Any values outside the specified criteria do not necessarily result in the qualification of analytical data. It is only one factor in making an overall judgment about the quality of the reported analytical results. The performance metric for assessing the DQI of precision on DQO decisions (Table 6-1) is that at least 80 percent of sample results for each measured contaminant are not qualified due to duplicates exceeding the criteria. If this performance criterion is not met, an assessment will be conducted in the CADD on the impacts to DQO decisions specific to affected contaminants at specific CASs.

\subsubsection{Accuracy}

Accuracy is a measure of the closeness of an individual measurement to the true value. It is used to assess the performance of laboratory measurement processes.

Accuracy is determined by analyzing a reference material of known parameter concentration or by reanalyzing a sample to which a material of known concentration or amount of parameter has been added (spiked). Accuracy will be evaluated based on results from three types of spiked samples: MS, LCS, and surrogates (organics). The LCS is analyzed with the field samples using the same sample preparation, reagents, and analytical methods used for the samples. One LCS will be prepared with each batch of samples for analysis by a specific measurement.

The criteria used for the assessment of inorganic chemical accuracy are 75 to 125 percent for MS recoveries and 80 to 120 percent for LCS recoveries. For organic chemical accuracy, MS and LCS laboratory-specific percent recovery criteria developed and generated in-house by the laboratory in accordance with approved laboratory procedures are applied. The criteria used for the assessment of radiochemical accuracy are 80 to 120 percent for LCS and MS recoveries.

Any values outside the specified criteria do not necessarily result in the qualification of analytical data. It is only one factor in making an overall judgment about the quality of the reported analytical results. Factors beyond laboratory control, such as sample matrix effects, can cause the measured values to be outside the established criteria. Therefore, the entire sampling and analytical process may be evaluated when determining the usability of the affected data. 
The performance metric for assessing the DQI of accuracy on DQO decisions (Table 6-1) is that at least 80 percent of the sample results for each measured contaminant are not qualified for accuracy. If this performance criterion is not met, an assessment will be conducted in the CADD on the impacts to DQO decisions specific to affected contaminants and study groups.

\subsubsection{Representativeness}

Representativeness is the degree to which sample characteristics accurately and precisely represent characteristics of a population or an environmental condition (EPA, 2002). Representativeness is ensured by carefully developing the CAI sampling strategy during the DQO process such that false negative and false positive decision errors are minimized. The criteria listed in DQO Step 6 (Specify Performance or Acceptance Criteria) are as follows:

- For Decision I judgmental sampling, having a high degree of confidence that the sample locations selected will identify COCs if present anywhere within the study group.

- For Decision I probabilistic sampling, having a high degree of confidence that the sample locations selected will represent contamination of the study group.

- Having a high degree of confidence that analyses conducted will be sufficient to detect any COCs if present in the samples.

- For Decision II, having a high degree of confidence that the sample locations selected will identify the extent of COCs.

These are qualitative measures that will be used to assess measurement system performance for representativeness. The assessment of this qualitative criterion will be presented in the CADD.

\subsubsection{Completeness}

Completeness is defined as generating sufficient data of the appropriate quality to satisfy the data needs identified in the DQOs. For judgmental sampling, completeness will be evaluated using both a quantitative measure and a qualitative assessment. The quantitative measurement to be used to evaluate completeness is presented in Table 6-1 and is based on the percentage of measurements made that are judged to be valid. 
For the judgmental sampling approach, the completeness goal is 80 percent. If this goal is not achieved, the dataset will be assessed for potential impacts on making DQO decisions. For the probabilistic sampling approach, the completeness goal is a calculated minimum sample size required to produce a valid statistical comparison of the sample mean to the FAL.

The qualitative assessment of completeness is an evaluation of the sufficiency of information available to make DQO decisions. This assessment will be based on meeting the data needs identified in the DQOs and will be presented in the CADD. Additional samples will be collected if it is determined that the available information is not sufficient to resolve DQO decisions.

\subsubsection{Comparability}

Comparability is a qualitative parameter expressing the confidence with which one dataset can be compared to another (EPA, 2002). The criteria for the evaluation of comparability will be that all sampling, handling, preparation, analysis, reporting, and data validation were performed and documented in accordance with approved procedures that are in conformance with standard industry practices. Analytical methods and procedures approved by DOE will be used to analyze, report, and validate the data. These methods and procedures are in conformance with applicable methods used in industry and government practices. An evaluation of comparability will be presented in the CADD.

\subsubsection{Sensitivity}

Sensitivity is the capability of a method or instrument to discriminate between measurement responses representing different levels of the variable of interest (EPA, 2002). If this criterion is not achieved, the affected data will be assessed for usability and potential impacts on meeting site characterization objectives. This assessment will be presented in the CADD.

As presented in Section 3.4, the evaluation criterion for this parameter will be that the analytical methods must be sufficient to detect contamination that is present in the samples at concentrations less than or equal to the corresponding FALs. The target MDCs for each COPC are provided in Tables 3-4 and 3-5. 
Although the data quality for TLD measurements is assessed via the routine environmental monitoring program (Section 6.0), the sensitivity evaluation criterion for TLD measurements is 50 percent of the FAL (i.e., 12.5 net mrem/yr). 


\subsection{Duration and Records Availability}

\subsection{Duration}

Field and analytical activities will require approximately 160 days to complete.

\subsection{Records Availability}

Historical information and documents referenced in this plan are retained in the NNSA/NSO project files in Las Vegas, Nevada, and can be obtained through written request to the NNSA/NSO Soils Activity Lead. This document is available in the DOE public reading facilities located in Las Vegas and Carson City, Nevada, or by contacting the appropriate DOE Soils Activity Lead. 


\subsection{References}

AEC, see Atomic Energy Commission.

ARL/SORD, see Air Resources Laboratory/Special Operations and Research Division.

ASTM, see ASTM International.

Air Resources Laboratory/Special Operations and Research Division. 2011. “Nevada Test Site (NTS) Climatological Rain Gauge Network.” As accessed at http://www.sord.nv.doe.gov/home_climate_rain.htm on 27 February 2012.

ASTM International. 1995 (reapproved 2002). Standard Guide for Risk-Based Corrective Action Applied at Petroleum Release Sites, ASTM E1739 - 95(2002). West Conshohocken, PA.

Atomic Energy Commission. 1958. Albuquerque Operations. Report of the Test Manager - Operation HardTack, Phase II, August - October 1958.

BN, see Bechtel Nevada.

Bechtel Nevada. 1999a. An Aerial Radiological Survey of the Nevada Test Site, DOE/NV/11718--324. Prepared for U.S. Department of Energy, Nevada Operations Office. Las Vegas, NV: Remote Sensing Laboratory.

Bechtel Nevada. 1999b. A Series of Low-Altitude Aerial Radiological Surveys of Selected Regions within the Areas 3, 5, 8, 9, 11, 18, and 25 at the Nevada Test Site, DOE/NV/11718--362. Prepared by D.P. Colton for the U.S. Department of Energy, Nevada Operations Office. Las Vegas, NV: Remote Sensing Laboratory.

Bechtel Nevada. 2002. Demarcation Activities at SMOKY and T-7c Sites Nevada Test Site FY 2002. Las Vegas, NV.

Bechtel Nevada. 2004. Engineering Plan for NST Legacy Rehabilitation Area-8 Circle Road, ENGR-C-135, Rev. 0. 8 July. Las Vegas, NV.

Buchheit, Jr., R., and C. Marianno. 2005. "Update of Technology for Use with FIDLER Detectors.” In Radiation Protection Management, Vol. 22(4): pp. 19-22.

CFR, see Code of Federal Regulations.

Clesceri, L.S., A.E. Greenberg, and A.D. Eaton, eds. 1998. Standard Methods for the Examination of Water and Wastewater, 20th edition. Published by American Public Health Association, American Water Works Association, and Water Environmental Federation. 
Code of Federal Regulations. 2011a. Title 40 CFR, Parts 260 to 282, "Hazardous Waste Management System.” Washington, DC: U.S. Government Printing Office.

Code of Federal Regulations. 2011b. Title 40 CFR, Part 761, "Polychlorinated Biphenyls (PCBs) Manufacturing, Processing, Distribution in Commerce, and Use Prohibitions.” Washington, DC: U.S. Government Printing Office.

Code of Federal Regulations. 2012. Title 10 CFR, Part 835, “Occupational Radiation Protection.” Washington, DC: U.S. Government Printing Office.

DOE, see U.S. Department of Energy.

DOE/NV, see U.S. Department of Energy, Nevada Operations Office.

DRI, see Desert Research Institute.

Desert Research Institute. 1988. CERCLA Preliminary Assessment of DOE's Nevada Operations Office Nuclear Weapons Testing Areas. April. Las Vegas, NV.

EPA, see U.S. Environmental Protection Agency.

ERDA, see Energy Research and Development Administration.

Energy Research and Development Administration. 1977. Final Environmental Impact Statement, Nevada Test Site, Nye County, Nevada, ERDA-1551. Washington, DC.

FFACO, see Federal Facility Agreement and Consent Order.

Federal Facility Agreement and Consent Order. 1996 (as amended March 2010). Agreed to by the State of Nevada; U.S. Department of Energy, Environmental Management; U.S. Department of Defense; and U.S. Department of Energy, Legacy Management. Appendix VI, which contains the Soils Sites Strategy, was last modified May 2011, Revision No. 4.

Frizzell, V.A., and J. Shulters. 1990. Geologic Map of the Nevada Test Site, Southern Nevada, Map I-2046. Denver, CO: U.S. Geological Survey.

Gilbert, R.O., E.H. Essington, D.N. Brady, P.G. Doctor, and L.L Eberhardt. 1977. "Statistical Activities during 1976 and the Design and Initial Analysis of Nuclear Site Studies.” In Transuranics in Desert Ecosystems, NVO-181. pp. 331-366. November. Las Vegas, NV: U.S. Department of Energy, Nevada Operations Office.

Gray, K.J., D.S. Shafer, K. Self, C. Martin, and R. McArthur. 2007. Radionuclide Inventory and Distribution Program (RIDP) Database, Rev. 2. April. Las Vegas, NV: Desert Research Institute, Water Resources Center. 
Hevesi, J.A., A.L. Flint, and L.E. Flint. 2003. Simulation of Net Infiltration and Potential Recharge Using a Distributed-Parameter Watershed Model of the Death Valley Region, Nevada and California, Water-Resources Investigations Report 03-4090. Sacramento, CA: U.S. Geological Survey.

Kwicklis, E.M., A.V. Wolfsberg, P.H. Stauffer, M.A. Walvoord, and M. Sulley. 2006. Numerical Evaluation of Liquid and Vapor Fluxes at the Nevada Test Site Area 3 Radioactive Waste Management Site Using Hydrologic Data and Natural Environmental Tracers, LA-UR-06-1212. Los Alamos, NM: Los Alamos National Laboratory.

Laczniak, R.J., J.C. Cole, D.A. Sawyer, and D.A. Trudeau. 1996. Summary of Hydrogeologic Controls on Ground-Water Flow at the Nevada Test Site, Nye County, Nevada, Water-Resources Investigations Report 96-4109. Carson City, NV: U.S. Geological Survey.

McArthur, R.D., and J.F. Kordas. 1983. Radionuclide Inventory and Distribution Program: The Galileo Area, DOE/NV/10162-14; Publication No. 45035. Las Vegas, NV: Desert Research Institute, Water Resources Center.

McArthur, R.D., and J.F. Kordas. 1985. Nevada Test Site Radionuclide Inventory and Distribution Program: Report \#2. Areas 2 and 4, DOE/NV/10162-20; Publication No. 45041. Las Vegas, NV: Desert Research Institute, Water Resources Center.

McArthur, R.D., and S.W. Mead. 1987. Nevada Test Site Radionuclide Inventory and Distribution Program: Report \#3. Areas 3, 7, 8, 9, and 10, DOE/NV/10384-15; Publication No. 45056. Las Vegas, NV: Desert Research Institute, Water Resources Center.

Moore, J., Science Applications International Corporation. 1999. Memorandum to M. Todd (SAIC) titled "Background Concentrations for NTS and TTR Soil Samples," 3 February. Las Vegas, NV: IT Corporation.

NAC, see Nevada Administrative Code.

NBMG, see Nevada Bureau of Mines and Geology.

NDEP, see Nevada Division of Environmental Protection.

N-I, see Navarro-Intera, LLC.

N-I GIS, see Navarro-Intera Geographic Information Systems.

NNES, see Navarro Nevada Environmental Services, LLC.

NNSA/NSO, see U.S. Department of Energy, National Nuclear Security Administration Nevada Site Office. 
NNSA/NV, see U.S. Department of Energy, National Nuclear Security Administration Nevada Operations Office.

Navarro-Intera Geographic Information Systems. 2012. ESRI ArcGIS Software.

Navarro-Intera, LLC. 2010. Written communication. Subject: “UGTA Borehole Index Database.” Las Vegas, NV.

Navarro-Intera, LLC. 2011. Data transfer to M. Knop from NSTec regarding KIWI and aerial radiological surveys, 4 November. Las Vegas, NV.

Navarro Nevada Environmental Services, LLC. 2009. Statement of Work for Analytical Laboratories, Section C. Las Vegas, NV.

Nevada Administrative Code. 2008a. NAC 445A.227, “Contamination of Soil: Order by Director for Corrective Action; Factors To Be Considered in Determining Whether Corrective Action Required.” Carson City, NV. As accessed at http://www.leg.state.nv.us/nac on 6 March 2012.

Nevada Administrative Code. 2008b. NAC 445A.22705, "Contamination of Soil: Evaluation of Site by Owner or Operator; Review of Evaluation by Division.” Carson City, NV. As accessed at http://www.leg.state.nv.us/nac on 6 March 2012.

Nevada Bureau of Mines and Geology. 1998. Mineral and Energy Resource Assessment of the Nellis Air Force Range, Open-File Report 98-1. Reno, NV.

Nevada Division of Environmental Protection. 2006 (as amended August 2000). Class III Solid Waste Disposal Site for Hydrocarbon Burdened Soils, Area 6 of the NTS, Permit SW 13-097-02, Rev. 7. Carson City, NV.

Nevada Division of Environmental Protection. 2011. Nevada Division of Environmental Protection RCRA Permit for a Hazardous Waste Management Facility, Rev.2, Permit Number NEV HW0101. Las Vegas, NV.

Paar, J.G., and D.R. Porterfield. 1997. Evaluation of Radiochemical Data Usability, ES/ER/MS-5. April. Oak Ridge, TN: U.S. Department of Energy.

REECO, see Reynolds Electrical \& Engineering Co., Inc.

Reynolds Electrical \& Engineering Co., Inc. 1957. Report on Decontamination of Area T2c, 23-29 July. Radiological Safety Division, Nevada Test Site, NV.

Riedhauser, S.R. 1999. A Radiological Characterization of the Kiwi-I Vehicle, DOE/NV/11718--298. Las Vegas, NV: Bechtel Nevada, Remote Sensing Laboratory.

Shaw, see Shaw Environmental, Inc. 
SNJV, see Stoller-Navarro Joint Venture.

Shaw Environmental, Inc. 2003. Written communication. Subject: Preliminary Assessment: Site Reference Summary for CAU 550, Drums, Batteries, and Lead Materials, Nevada Test Site, Vol. I. Las Vegas, NV.

Shott, G.J., V. Yucel, M.J. Sully, L.E. Barker, S.E. Rawlinson, and B.A. Moore. 1997. Performance Assessment/Composite Analysis for the Area 3 Radioactive Waste Management Site at the Nevada Test Site, Nye County, Nevada, Rev. 2.0. Las Vegas, NV.

Stoller Navarro Joint Venture. 2006. Phase I Hydrologic Data for the Groundwater Flow and Contaminant Transport Model of Corrective Action Unit 97: Yucca Flat/Climax Mine, Nevada Test Site, Nye County, Nevada, Rev. 0, S-N/99205--077. Las Vegas, NV.

TSA Systems, see TSA Systems, Ltd.

Tamura, T. 1977. "Plutonium Distribution in a Desert Pavement-Desert Mound Soil System in Area 11.” In Environmental Plutonium on the Nevada Test Site and Environs, NVO-171. June. Las Vegas, NV: Energy Research and Development Administration, Nevada Applied Ecology Group.

TSA Systems, Ltd. 2005. PRM-470CGN Operations Manual, Doc. \#5200, Rev. A. Longmont, CO.

U.S. Department of Energy. 1997. The Procedures Manual of the Environmental Measurements Laboratory, HASL-300, 28th Ed., Vol. I. February. New York, NY.

U.S. Department of Energy, National Nuclear Security Administration Nevada Operations Office. 2002a. Industrial Sites Quality Assurance Project Plan, Rev. 3, DOE/NV--372--REV. 3. Las Vegas, NV.

U.S. Department of Energy, National Nuclear Security Administration Nevada Operations Office. 2002b. Nevada Test Site Orthophoto Site Atlas, DOE/NV/11718--604. Aerial photos acquired Summer 1998. Prepared by Bechtel Nevada. Las Vegas, NV.

U.S. Department of Energy, National Nuclear Security Administration Nevada Site Office. 2005. Nevada Test Site Guide, DOE/NV-715, Rev. 1. Las Vegas, NV.

U.S. Department of Energy, National Nuclear Security Administration Nevada Site Office. 2012a. Nevada National Security Site Waste Acceptance Criteria, DOE/NV-325-Rev. 9. Las Vegas, NV.

U.S. Department of Energy, National Nuclear Security Administration Nevada Site Office. $2012 \mathrm{~b}$. Soils Risk-Based Corrective Action Evaluation Process, Rev. 0, DOE/NV--1475. Las Vegas, NV. 
U.S. Department of Energy, Nevada Operations Office. 1992. Remedial Investigation and Feasibility Study for the Plutonium Contaminated Soils at Nevada Test Site, Nellis Air Force Range and Tonopah Test Range. April. Las Vegas, NV.

U.S. Department of Energy, Nevada Operations Office. 1996. Final Environmental Impact Statement for the Nevada Test Site and Off-Site Locations in the State of Nevada, DOE/EIS 0243. Las Vegas, NV.

U.S. Department of Energy, Nevada Operations Office. 1998. Nevada Test Site Resource Management Plan, DOE/NV--518. Las Vegas, NV.

U.S. Department of Energy, Nevada Operations Office. 2000a. United States Nuclear Tests, July 1945 through September 1992, DOE/NV--209-Rev 15. Las Vegas, NV.

U.S. Department of Energy, Nevada Operations Office. 2000b. Contaminated Land Areas Report, Volume I, December 2000, DOE/NV/11718--418-VOL.1. Las Vegas, NV.

U.S. Environmental Protection Agency. 1980. Prescribed Procedures for Measurement of Radioactivity in Drinking Water, EPA 600/4-80-032. Cincinnati, OH: Environmental Monitoring and Support Laboratory Office of Research and Development.

U.S. Environmental Protection Agency. 2000. Sampling and Analysis Plan Guidance and Template, R9QA/002.1. As accessed at http://www.epa.gov/region09/qa/projplans.html on 21 February 2012.

U.S. Environmental Protection Agency. 2002. Guidance for Quality Assurance Project Plans, EPA QA/G5, EPA/240/R-02/009. Washington, DC: Office of Environmental Information.

U.S. Environmental Protection Agency. 2004. USEPA Contract Laboratory Program National Functional Guidelines for Inorganic Data Review, OSWER 9240.1-45/EPA 540-R-04-004. October. Washington, DC: Office of Superfund Remediation and Technology Innovation.

U.S. Environmental Protection Agency. 2011a. Pacific Southwest, Region 9: Regional Screening Levels (Formerly PRGs), Screening Levels for Chemical Contaminants. As accessed at http://www.epa.gov/region9/superfund/prg on 21 February 2012. Prepared by EPA Office of Superfund and Oak Ridge National Laboratory.

U.S. Environmental Protection Agency. 2011b. SW-846, Test Methods for Evaluating Solid Waste, Physical/Chemical Methods. As accessed at http://www.epa.gov/epawaste/hazard/testmethods/sw846 on 21 February 2012.

Wills, C.A. 2007. Nevada Test Site Environmental Report 2006, DOE/NV 25946--259. Prepared for the U.S. Department of Energy, National Nuclear Security Administration Nevada Site Office. Las Vegas, NV: National Security Technologies, LLC. 
Yu, C., A.J. Zielen, J.-J. Cheng, D.J. LePoire, E. Gnanapragasam, S. Kamboj, J. Arnish, A. Wallo III, W.A. Williams, and H. Peterson. 2001. User's Manual for RESRAD Version 6, ANL/EAD-4. Argonne, IL: Argonne National Laboratory, Environmental Assessment Division. (Version 6.5 released in October 2009.)

Yucel, V., National Security Technologies, LLC. 2009. Personal communication to R.L. Kidman (N-I) regarding PET data, 30 April. Las Vegas, NV. 


\section{Appendix A}

\section{Data Quality Objectives}


The DQO process described in this appendix is a seven-step strategic systematic planning method used to plan data collection activities and define performance criteria for the CAU 550, Smoky Contamination Area, field investigation. The DQOs are designed to ensure that the data collected will provide sufficient and reliable information to identify, evaluate, and technically defend recommended corrective actions (i.e., no further action, closure in place, or clean closure). Existing information about the nature and extent of contamination at the study groups in CAU 550 is insufficient to evaluate and select preferred corrective actions; therefore, a CAI will be conducted.

The CAU 550 CAI will be based on the DQOs presented in this appendix as developed by NDEP and NNSA/NSO representatives. The seven steps of the DQO process presented in Sections A.2.0 through A.8.0 were developed in accordance with Guidance on Systematic Planning Using the Data Quality Objectives Process (EPA, 2006).

The DQO process presents a combination of probabilistic and judgmental sampling approaches. In general, the procedures used in the DQO process provide the following:

- A method to establish performance or acceptance criteria, which serve as the basis for designing a plan for collecting data of sufficient quality and quantity to support the goals of a study.

- Criteria that will be used to establish the final data collection design, such as

- the nature of the problem that has initiated the study and a conceptual model of the environmental hazard to be investigated;

- the decisions or estimates that need to be made, and the order of priority for resolving them;

- $\quad$ the type of data needed; and

- an analytic approach or decision rule that defines the logic for how the data will be used to draw conclusions from the study findings.

- Acceptable quantitative criteria on the quality and quantity of the data to be collected, relative to the ultimate use of the data. 
- A data collection design that will generate data meeting the quantitative and qualitative criteria specified. A data collection design specifies the type, number, location, and physical quantity of samples and data, as well as the QA and QC activities that will ensure that sampling design and measurement errors are managed sufficiently to meet the performance or acceptance criteria specified in the DQOs. 


\section{A.2.0 Step 1 - State the Problem}

Step 1 of the DQO process defines the problem that requires study, identifies the planning team, and develops a conceptual model of the environmental hazard to be investigated.

The problem statement for CAU 550 is as follows: "Existing information on the nature and extent of potential contamination is insufficient to evaluate and recommend CAAs for the study groups in CAU 550.”

\section{A.2.1 Planning Team Members}

The DQO planning team consists of representatives from NDEP and NNSA/NSO. The DQO planning team met on January 31, 2012, for the DQO meeting.

\section{A.2.2 Conceptual Site Model}

The CSM is used to organize and communicate information about site characteristics. It reflects the best interpretation of available information at a point in time. The CSM is a primary vehicle for communicating assumptions about release mechanisms, potential migration pathways, or specific constraints. It provides a summary of how and where contaminants are expected to move and what impacts such movement may have. It is the basis for assessing how contaminants could reach receptors both in the present and future. The CSM describes the most probable scenario for current conditions at each site and defines the assumptions that are the basis for identifying appropriate sampling strategy and data collection methods. An accurate CSM is important as it serves as the basis for all subsequent inputs and decisions throughout the DQO process.

The CSM was developed for CAU 550 using information from the physical setting, potential contaminant sources, release information, historical background information, knowledge from similar sites, and physical and chemical properties of the potentially affected media and COPCs.

The CSM consists of the following:

- Potential contaminant releases, including media subsequently affected 
- Release mechanisms (the conditions associated with the release)

- Potential contaminant source characteristics, including contaminants suspected to be present and contaminant-specific properties

- Site characteristics, including physical, topographical, and meteorological information

- Migration pathways and transport mechanisms that describe the potential for migration and where the contamination may be transported

- The locations of points of exposure where individuals or populations may come in contact with a COC associated with a study group

- Routes of exposure where contaminants may enter the receptor

If additional elements are identified during the CAI that are outside the scope of the CSM, the situation will be reviewed and a recommendation will be made as to how to proceed. In such cases, NDEP will be notified and given the opportunity to comment on, or concur with, the recommendation.

The applicability of the CSM to each study group is summarized in Table A.2-1 and discussed below. Table A.2-1 provides information on CSM elements that will be used throughout the remaining steps of the DQO process. Figure A.2-1 depicts a representation of the conceptual pathways to receptors from CAU 550 sources. Figure A.2-2 depicts a graphical representation of the CSM.

Table A.2-1

CSM Description of Elements for Each CAU 550 Group

(Page 1 of 2)

\begin{tabular}{||c|c|c|c|c||}
\hline Group Identifier & Study Group 1 & Study Group 2 & Study Group 3 & Study Group 4 \\
\hline Group Description & $\begin{array}{c}\text { Atmospheric } \\
\text { Test }\end{array}$ & $\begin{array}{c}\text { Safety } \\
\text { Experiments }\end{array}$ & Washes & Debris \\
\hline \hline Site Status & \multicolumn{3}{|c|}{ Sites are inactive and/or abandoned } \\
\hline Exposure Scenario & \multicolumn{3}{|c|}{ Occasional Use/Nuclear Test Zone } \\
\hline $\begin{array}{c}\text { Sources of Potential } \\
\text { Soil Contamination }\end{array}$ & $\begin{array}{c}\text { Fallout and soil activation from } \\
\text { nuclear detonations }\end{array}$ & $\begin{array}{c}\text { Leaking containers and surface } \\
\text { disposal of discarded equipment } \\
\text { and materials }\end{array}$ \\
\hline $\begin{array}{c}\text { Location of } \\
\text { Contamination/ } \\
\text { Release Point }\end{array}$ & $\begin{array}{c}\text { Deposited material from nuclear } \\
\text { detonations and contaminated } \\
\text { surface soil }\end{array}$ & $\begin{array}{c}\text { Surface and subsurface soil at or } \\
\text { near location(s) of debris and } \\
\text { within washes }\end{array}$ \\
\hline
\end{tabular}


Table A.2-1

CSM Description of Elements for Each CAU 550 Group

(Page 2 of 2)

\begin{tabular}{|c|c|c|c|c|}
\hline Group Identifier & Study Group 1 & Study Group 2 & Study Group 3 & Study Group 4 \\
\hline Group Description & $\begin{array}{l}\text { Atmospheric } \\
\text { Test }\end{array}$ & $\begin{array}{l}\text { Safety } \\
\text { Experiments }\end{array}$ & Washes & Debris \\
\hline Amount Released & \multicolumn{4}{|c|}{ Unknown } \\
\hline Affected Media & \multicolumn{4}{|c|}{$\begin{array}{l}\text { Surface and shallow subsurface soil; debris, such as concrete, steel, } \\
\text { and wood }\end{array}$} \\
\hline $\begin{array}{l}\text { Potential } \\
\text { Contaminants }\end{array}$ & \multicolumn{3}{|c|}{ Unburned fuel, activation and fission products } & Unknown \\
\hline $\begin{array}{l}\text { Transport } \\
\text { Mechanisms }\end{array}$ & \multicolumn{4}{|c|}{$\begin{array}{l}\text { Surface water runoff may provide for the transportation of some } \\
\text { contaminants within or outside the boundaries of the CAS, through } \\
\text { ephemeral drainages near the CASs. Infiltration of precipitation through } \\
\text { subsurface media serves as a minor driving force for migration of } \\
\text { contaminants. Mechanical displacement. }\end{array}$} \\
\hline Migration Pathways & \multicolumn{4}{|c|}{$\begin{array}{l}\text { Lateral transport is expected to dominate over vertical transport due to the } \\
\text { relatively large PET value as compared to the annual precipitation rate. } \\
\text { Depth to uppermost aquifer precludes groundwater as significant pathway. }\end{array}$} \\
\hline $\begin{array}{l}\text { Lateral and Vertical } \\
\text { Extent of } \\
\text { Contamination }\end{array}$ & \multicolumn{4}{|c|}{$\begin{array}{l}\text { Contamination, if present, is expected to be contiguous to the release } \\
\text { points. Concentrations are expected to decrease with distance and depth } \\
\text { from the source. Lateral and vertical extent of COC contamination is } \\
\text { assumed to be within the spatial boundaries. }\end{array}$} \\
\hline Exposure Pathways & \multicolumn{4}{|c|}{$\begin{array}{l}\text { The potential for contamination exposure is limited to industrial and } \\
\text { construction workers, and military personnel conducting training. These } \\
\text { human receptors may be exposed to COPCs through oral ingestion or } \\
\text { inhalation of, or dermal contact (absorption) with soil and/or debris due } \\
\text { to inadvertent disturbance of these materials, or irradiation by } \\
\text { radioactive materials. }\end{array}$} \\
\hline
\end{tabular}

\section{A.2.2.1 Release Sources}

To facilitate site investigation and the evaluation of DQO decisions for different CSM components, the releases at each study group were classified into one of the following categories:

- Primary releases. This release category is specific to the atmospheric deposition of radionuclide contamination onto the soil surface that has not been displaced through excavation or migration. The contamination associated with the primary releases is limited to the top $5 \mathrm{~cm}$ of soil. Atmospheric releases of radionuclides that have been distributed at the NNSS from nuclear testing have been found to be concentrated in the upper $5 \mathrm{~cm}$ of undisturbed soil (McArthur and Kordas, 1983 and 1985; Gilbert et al., 1977; Tamura, 1977). Therefore, for the purposes of this CAIP, surface is defined as the upper $5 \mathrm{~cm}$ of soil. 


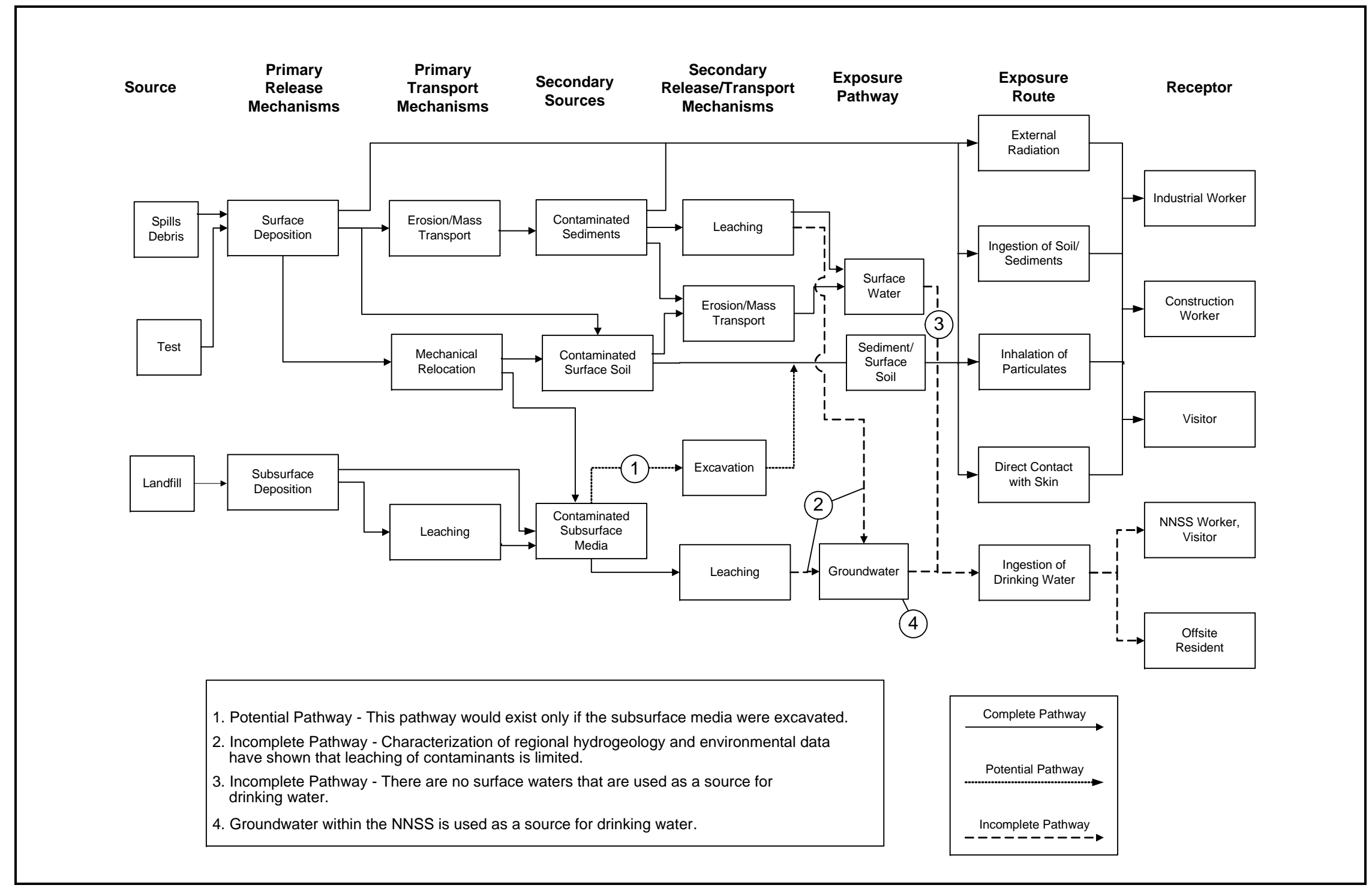

Figure A.2-1

CSM Diagram

\section{UNCONTROLLED When Printed}




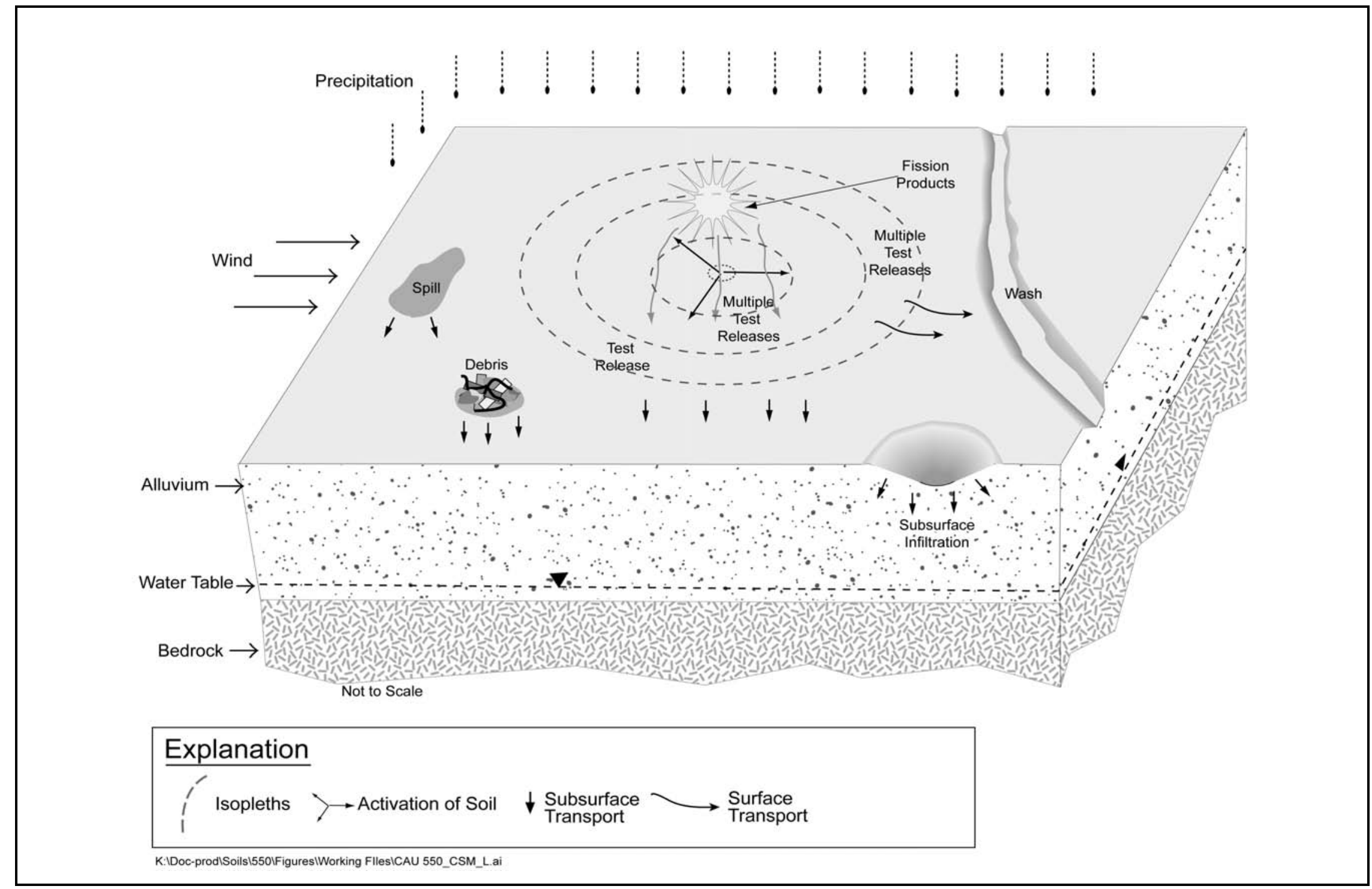

Figure A.2-2

CSM for CAU 550 CASs 
- Other releases. This release category includes any radionuclide contamination from test activities that is not atmospheric deposition of radionuclides. This includes radionuclide contaminants that were initially deposited onto the soil surface (as in the primary release category) but have been displaced through subsequent activities. This category also includes radionuclides that were deposited under mechanisms other than atmospheric deposition (such as radionuclides being driven into the soil by high explosives at each of the GZ areas). This includes any other chemical or radiological contamination that may be discovered during the investigation through the identification of biasing factors that are not a part of a previously identified release.

The following identifies the primary release sources (DOE/NV, 2000) specific to CAU 550:

\section{Study Group 1}

- T-2C, the Smoky source (CAS 08-23-04), was a weapons-related test with a yield of $44 \mathrm{kt}$ detonated from a tower at $700 \mathrm{ft}$ agl on August 31, 1957. The potential releases are classified as primary releases and are addressed as Study Group 1.

\section{Study Group 2}

- T-8A, the Oberon source (CAS 08-23-06), was a zero-yield safety experiment detonated from a tower at $25 \mathrm{ft}$ agl on October 22, 1958. The potential releases are classified as primary releases and are addressed as Study Group 2.

- $\quad$ T-8B, the Ceres source (CAS 08-23-03), was a safety experiment with yield of 0.7 tons detonated from a tower at $25 \mathrm{ft}$ agl on October 26, 1958. The potential releases are classified as primary releases and are addressed as Study Group 2.

- $\quad$ T-8C, the Titania source (CAS 08-23-07), was a safety experiment with yield of 0.2 tons detonated from a tower at $25 \mathrm{ft}$ agl on October 30, 1958. The potential releases are classified as primary releases and are addressed as Study Group 2.

The following identifies the other release sources specific to CAU 550:

\section{Study Group 3}

- Contaminant sources translocated through stormwater deposits in areas where water slows down and sediment deposits. These areas are within washes flowing through CAU 550 and the depositional area, and are addressed as Study Group 3. 


\section{Study Group 4}

- CASs 08-01-01, 08-22-05, 08-22-07, 08-22-08, 08-22-09, 08-24-03, 08-24-04, 08-24-07, 08-24-08, 08-26-01, 10-22-17, 10-22-18, 10-22-19, 10-22-20, and 10-24-10 contain various types of debris (e.g., lead-acid batteries, lead bricks, drums) present on the ground surface. These items have the potential to release contamination to the soil and are addressed as Study Group 4.

The most likely locations of the contamination and releases to the environment are the soils directly below or adjacent to the CSM's surface and subsurface components (i.e., soils impacted by fallout and other releases).

\section{A.2.2.2 Potential Contaminants}

The group-specific COPCs are based on a conservative evaluation of possible site activities identified during the planning process through the review of site history, process knowledge, personal interviews, past investigation efforts (where available), and inferred activities associated with the study groups. Additional COPCs for other releases may be discovered during the investigation. Specific COPCs (and subsequently the analyses requested) will be determined for other potential releases based on the nature of the potential release (e.g., hydrocarbon stain, lead bricks). The list of COPCs is intended to encompass all significant contaminants that could potentially be present at each study group. Significant contaminants are defined as contaminants that are present at concentrations exceeding the PAL. The COPCs applicable to environmental samples from each of the CAU 550 study groups are listed in Table A.2-2. Table A.2-3 lists the analytical methods required for these COPCs, while Table A.2-4 lists all the analytes that are reported by the analytical laboratory for each of the analytical methods.

\section{A.2.2.3 Contaminant Characteristics}

Contaminant characteristics include, but are not limited to, solubility, density, and adsorption potential. In general, contaminants with low solubility, high affinity for media, and high density can be expected to be found relatively close to release points. Contaminants with small particle size, high solubility, low density, and/or low affinity for media are found farther from release points or in low areas where evaporation of ponding will concentrate dissolved contaminants. 
Table A.2-2

Contaminants of Potential Concern ${ }^{\mathrm{a}}$

\begin{tabular}{|c|c|c|c|}
\hline COPCs & Study Groups 1 and 2 & Study Group 3 & Study Group 4 \\
\hline \multicolumn{4}{|c|}{ Inorganic COPCs } \\
\hline Lead & -- & -- & $X$ \\
\hline \multicolumn{4}{|c|}{ Radionuclide COPCs } \\
\hline U-234 & $\mathrm{x}$ & $\mathrm{X}$ & -- \\
\hline$U-235 / 236$ & $x$ & $x$ & -- \\
\hline $\mathrm{U}-238$ & $\mathrm{X}$ & $x$ & -- \\
\hline Pu-238 & $x$ & $x$ & -- \\
\hline Pu-239/240 & $X$ & $x$ & -- \\
\hline Pu-241 & $x$ & $x$ & -- \\
\hline Cs-137 & $x$ & $x$ & -- \\
\hline Am-241 & $x$ & $x$ & -- \\
\hline Eu-152/154/155 & $x$ & $x$ & -- \\
\hline
\end{tabular}

${ }^{a}$ The COPCs are the constituents that, based on process knowledge and historical documentation, are likely to be present.

$X=$ COPC associated with this study group

-- = COPC not associated with this study group

Table A.2-3

Analytical Methods

(Page 1 of 2)

\begin{tabular}{|c|c|c|c|c|}
\hline Analytical Method & $\begin{array}{l}\text { Study } \\
\text { Group } 1\end{array}$ & $\begin{array}{l}\text { Study } \\
\text { Group } 2\end{array}$ & $\begin{array}{l}\text { Study } \\
\text { Group } 3\end{array}$ & $\begin{array}{c}\text { Study } \\
\text { Group } 4^{\mathrm{a}}\end{array}$ \\
\hline \multicolumn{5}{|c|}{ Organic COPCs } \\
\hline PCBs & -- & -- & -- & $x$ \\
\hline SVOCs & -- & -- & -- & $x$ \\
\hline VOCs & -- & -- & -- & $x$ \\
\hline \multicolumn{5}{|c|}{ Inorganic COPCs } \\
\hline RCRA Metals & -- & -- & -- & $x$ \\
\hline Total Beryllium & -- & -- & -- & $x$ \\
\hline
\end{tabular}


Table A.2-3

\section{Analytical Methods}

(Page 2 of 2)

\begin{tabular}{|c|c|c|c|c|}
\hline Analytical Method & \multicolumn{1}{|c|}{$\begin{array}{c}\text { Study } \\
\text { Group 1 }\end{array}$} & $\begin{array}{c}\text { Study } \\
\text { Group 2 }\end{array}$ & $\begin{array}{c}\text { Study } \\
\text { Group 3 }\end{array}$ & $\begin{array}{c}\text { Study } \\
\text { Group 4 }^{\mathrm{a}}\end{array}$ \\
\hline \hline \multicolumn{5}{|c|}{ Radionuclide COPCs } \\
\hline Gamma Spectroscopy & $\mathrm{x}$ & $\mathrm{x}$ & $\mathrm{x}$ & $\mathrm{X}^{\mathrm{b}}$ \\
\hline Isotopic U & $\mathrm{x}$ & $\mathrm{x}$ & $\mathrm{x}$ & -- \\
\hline Isotopic Pu & $\mathrm{x}$ & $\mathrm{x}$ & $\mathrm{x}$ & -- \\
\hline Isotopic Am & $\mathrm{x}$ & $\mathrm{x}$ & $\mathrm{x}$ & -- \\
\hline
\end{tabular}

${ }^{a}$ The analytical methods may be required based on the nature of the potential release.

${ }^{\mathrm{b}}$ Results of gamma analysis will be used to determine whether further isotopic analysis is warranted.

$X=$ Required analytical method

$--=$ Not required

The radionuclide contaminants in CAU 550 are all moderately to highly adsorbed on the alluvial materials present in CAU 550. A summary of the inherent vertical migration potential of these contaminants through the vadose zone due to their adsorption properties is presented in Table A.2-5. This table also presents the contaminant sorption coefficients $\left(\mathrm{K}_{\mathrm{d}}\right)$ along with the equivalent retardation factor (based on an average bulk density of 1.5 grams per milliliter and porosity of 0.3 ) (SNJV 2007). Based on these properties and the maximum estimated recharge rate of $50 \mathrm{~m}$ in 1,000 years (Section 3.1.4), the major radionuclide contaminants at CAU 550 are estimated to migrate no more than $1 / 10$ of a meter in 1,000 years except for uranium, which could migrate up to $8 \mathrm{~m}$ in 1,000 years.

The migration potential of radionuclides released from a nuclear detonation was demonstrated in a long-term radionuclide migration study of an underground nuclear test. A well installed into the groundwater $91 \mathrm{~m}$ away from the Cambric test GZ (and much closer to the nearest extent of the test cavity) was continuously pumped from 1975 to 1991 in order to draw radionuclides from the detonation cavity. The May 1965 Cambric test released a yield of 750 tons at a depth of $294 \mathrm{~m}$ below the land surface and 73 m below the water table (DOE/NV, 2000; Hoffman and Daniels, 1984). No radionuclides associated with nuclear fission tests (including the major contributing radionuclides plutonium, uranium, cesium, europium, strontium, or cobalt) other than tritium and krypton (which are considered to be conservative tracers in groundwater, as they do not interact with the 
Table A.2-4

Analytes Reported by Analytical Methods

\begin{tabular}{|c|c|c|c|c|c|c|}
\hline \multicolumn{2}{|c|}{ VOCs } & \multicolumn{2}{|c|}{ SVOCs } & PCBs & Metals & Radionuclides \\
\hline $\begin{array}{l}\text { 1,1,1,2-Tetrachloroethane } \\
\text { 1,1,1-Trichloroethane } \\
\text { 1,1,2,2-Tetrachloroethane } \\
\text { 1,1,2-Trichloroethane } \\
\text { 1,1-Dichloroethane } \\
\text { 1,1-Dichloroethene } \\
\text { 1,2,4-Trichlorobenzene } \\
\text { 1,2,4-Trimethylbenzene } \\
\text { 1,2-Dibromo-3-chloropropane } \\
\text { 1,2-Dichlorobenzene } \\
\text { 1,2-Dichloroethane } \\
\text { 1,2-Dichloropropane } \\
\text { 1,3,5-Trimethylbenzene } \\
\text { 1,3-Dichlorobenzene } \\
\text { 1,4-Dichlorobenzene } \\
\text { 1,4-Dioxane } \\
\text { 2-Butanone } \\
\text { 2-Chlorotoluene } \\
\text { 2-Hexanone } \\
\text { 4-Isopropyltoluene } \\
\text { 4-Methyl-2-pentanone } \\
\text { Acetone } \\
\text { Acetonitrile } \\
\text { Allyl chloride } \\
\text { Benzene } \\
\text { Bromodichloromethane } \\
\text { Bromoform } \\
\text { Bromomethane } \\
\text { Carbon disulfide }\end{array}$ & $\begin{array}{l}\text { Carbon tetrachloride } \\
\text { Chlorobenzene } \\
\text { Chloroethane } \\
\text { Chloroform } \\
\text { Chloromethane } \\
\text { Chloroprene } \\
\text { cis-1,2-Dichloroethene } \\
\text { Dibromochloromethane } \\
\text { Dichlorodifluoromethane } \\
\text { Ethyl methacrylate } \\
\text { Ethylbenzene } \\
\text { Isobutyl alcohol } \\
\text { Isopropylbenzene } \\
\text { Methacrylonitrile } \\
\text { Methyl methacrylate } \\
\text { Methylene chloride } \\
\text { n-Butylbenzene } \\
\text { n-Propylbenzene } \\
\text { sec-Butylbenzene } \\
\text { Styrene } \\
\text { tert-Butylbenzene } \\
\text { Tetrachloroethene } \\
\text { Toluene } \\
\text { Total xylenes } \\
\text { Trichloroethene } \\
\text { Trichlorofluoromethane } \\
\text { Vinyl acetate } \\
\text { Vinyl chloride }\end{array}$ & $\begin{array}{l}\text { 2,3,4,6-Tetrachlorophenol } \\
\text { 2,4,5-Trichlorophenol } \\
\text { 2,4,6-Trichlorophenol } \\
\text { 2,4-Dimethylphenol } \\
\text { 2,4-Dinitrotoluene } \\
\text { 2-Chlorophenol } \\
\text { 2-Methylnaphthalene } \\
\text { 2-Methylphenol } \\
\text { 2-Nitrophenol } \\
\text { 3-Methylphenol }{ }^{a} \text { (m-cresol) } \\
\text { 4-Methylphenol }{ }^{a} \text { (p-cresol) } \\
\text { 4-Chloroaniline } \\
\text { 4-Nitrophenol } \\
\text { Acenaphthene } \\
\text { Acenaphthylene } \\
\text { Aniline } \\
\text { Anthracene } \\
\text { Benzo(a)anthracene } \\
\text { Benzo(a)pyrene } \\
\text { Benzo(b)fluoranthene } \\
\text { Benzo(g,h,i)perylene } \\
\text { Benzo(k)fluoranthene } \\
\text { Benzoic acid } \\
\text { Benzyl alcohol } \\
\text { Bis(2-ethylhexyl)phthalate } \\
\text { Butyl benzyl phthalate } \\
\text { Carbazole } \\
\text { Chrysene } \\
\text { Di-n-butyl phthalate }\end{array}$ & $\begin{array}{l}\text { Di-n-octyl phthalate } \\
\text { Dibenzo(a,h)anthracene } \\
\text { Dibenzofuran } \\
\text { Diethyl phthalate } \\
\text { Dimethyl phthalate } \\
\text { Fluoranthene } \\
\text { Fluorene } \\
\text { Hexachlorobenzene } \\
\text { Hexachlorobutadiene } \\
\text { Hexachloroethane } \\
\text { Indeno(1,2,3-cd)pyrene } \\
\text { n-Nitroso-di-n-propylamine } \\
\text { Naphthalene } \\
\text { Nitrobenzene } \\
\text { Pentachlorophenol } \\
\text { Phenanthrene } \\
\text { Phenol } \\
\text { Pyrene } \\
\text { Pyridine }\end{array}$ & $\begin{array}{l}\text { Aroclor } 1016 \\
\text { Aroclor } 1221 \\
\text { Aroclor } 1232 \\
\text { Aroclor } 1242 \\
\text { Aroclor } 1248 \\
\text { Aroclor } 1254 \\
\text { Aroclor } 1260 \\
\text { Aroclor } 1268\end{array}$ & \begin{tabular}{|l} 
Arsenic \\
Barium \\
Beryllium \\
Cadmium \\
Chromium \\
Lead \\
Mercury \\
Selenium \\
Silver
\end{tabular} & \begin{tabular}{|l} 
Isotopic Analyses \\
Am-241 \\
Pu-238 \\
Pu-239/240 \\
U-234 \\
U-235 \\
U-238 \\
\\
\\
Gamma-Emitting \\
Ac-228 \\
Am-241 \\
Co-60 \\
Cs-137 \\
Eu-152 \\
Eu-154 \\
Eu-155 \\
K-40 \\
Nb-94 \\
Pb-212 \\
Pb-214 \\
Th-234 \\
TI-208 \\
U-235
\end{tabular} \\
\hline
\end{tabular}

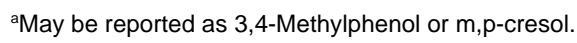

geologic media through which the water moves) were detected in the pumped groundwater during the 29 years of pumping (Bryant, 1992; Hoffman and Daniels, 1984). This test demonstrated the relative immobility of the fission radionuclides under conditions of very high mass flow (more than 1.5 billion gallons of water pumped) in a saturated matrix. Under unsaturated conditions (such as surface soil with atmospheric deposition from nuclear test releases), infiltrating water percolating through the vadose zone provides a small fraction of the migration potential (mass flow is less than $3 \mathrm{~cm}$ of recharge per year). Therefore, it can be assumed that while the major fission radionuclides are relatively immobile in saturated conditions with an artificial gradient (i.e., under pumping conditions), they will be even less mobile under unsaturated conditions with limited net infiltration of precipitation. 
Table A.2-5

\section{Vertical Migration Potential through the Vadose of the Major Radionuclide Contaminants}

\begin{tabular}{|c|c|c|c||}
\hline Coc & $\begin{array}{c}\text { Approximate Range } \\
\text { of } \mathbf{K}_{\mathbf{d}} \text { Values } \\
(\mathbf{m L} / \mathbf{g})\end{array}$ & $\begin{array}{c}\text { Equivalent } \\
\text { Retardation Factor }\end{array}$ & $\begin{array}{c}\text { Migration Distance } \\
\text { in 1,000 years } \\
(\mathbf{m})\end{array}$ \\
\hline \hline Uranium & $1-10$ & $6-50$ & $1-8$ \\
\hline Plutonium & $100-10,000$ & $500-50,000$ & $0.001-0.1$ \\
\hline Europium & $1,000-100,000$ & $5,000-500,000$ & $0.0001-0.01$ \\
\hline Thorium & $100-10,000$ & $500-50,000$ & $0.001-0.1$ \\
\hline Cesium & $1,000-10,000$ & $5,000-50,000$ & $0.001-0.01$ \\
\hline Americium & $10,000-100,000$ & $50,000-500,000$ & $0.0001-0.001$ \\
\hline
\end{tabular}

$\mathrm{mL} / \mathrm{g}=$ Milliliters per gram

Based on this evidence, the major radionuclide potential contaminants (plutonium, americium, and cesium) are classified as adsorbing radionuclides with low solubilities that are located within unsaturated media. Therefore, these contaminants are expected to be found relatively close to release points.

\section{A.2.2.4 Site Characteristics}

Site characteristics are defined by the interaction of physical, topographical, and meteorological attributes and properties. Topographical and meteorological properties and attributes include slope stability, precipitation frequency and amounts, precipitation runoff pathways, drainage channels and ephemeral streams, and PET. Meteorological data are presented in Section 2.1.

Local topography around CAU 550 is relatively flat, with distinct hills to the north and moderate sloping hills towards the southeast. The soil in and around CAU 550 is made up of sand- to cobble-sized alluvium of various lithologies. Some of the ground was cleared during pre-test installations, but vegetation has grown back and is now relatively uniform across the CAU. The general direction of precipitation runoff flow from Smoky is to the southeast into a series of ephemeral channels that generally flow to the south into the Yucca Flat dry lake. 
Several washes cut through the CAs with general flow-direction to the southeast. These washes coalesce into a wash system that intermittently transports sediment across the south-southeastern boundary of the site into a depositional area on the east side of Circle Road (BN, 2004). Sediment has also been deposited throughout the channels and collects in sediment accumulation areas within the wash channels upgradient from Circle Road.

\section{A.2.2.5 Migration Pathways and Transport Mechanisms}

Migration pathways include the lateral migration of potential contaminants across surface soils/sediments and vertical migration of potential contaminants through subsurface soils. Contaminants present in ephemeral washes are subject to much higher transport rates than contaminants present in other surface areas. These ephemeral washes are generally dry but are subject to infrequent stormwater flows. These stormwater flow events provide an intermittent mechanism for both vertical and lateral transport of contaminants. Contaminated sediments entrained by these stormwater events would be carried by the streamflow to locations where the flowing water loses energy and the sediments drop out. These locations are readily identifiable as sedimentation areas. No perennial streamflow exists in the region. Any streamflow in the area flows in natural flow paths that combine with intermittent washes to the east continuing south into the Yucca Flat dry lake. Other migration pathways for contamination from the sites include windborne material and materials displaced from maintenance activities (e.g., moved during road maintenance). Contaminants may also be moved through mechanical disturbance due to maintenance or construction activities at the site. Specifically, this can include activities such as decontamination and demolition of facilities, investigation and resolution of CASs, and disassembly and removal of equipment and support structures.

Migration is influenced by the chemical characteristics of the contaminants (presented in Section A.2.2.3) and the physical characteristics of the vadose material (presented in Section A.2.2.4). In general, the contaminants that are reasonably expected to be present at CAU 550 (i.e., plutonium, americium, and cesium) have low solubilities and high affinity for media. The physical characteristics of the vadose material generally include medium and high adsorbive capacities, low moisture contents (i.e., available water-holding capacity), and relatively long 
distances to groundwater (e.g., groundwater at 2,128 ft bgs). Based on these physical and chemical factors, contamination is expected to be found relatively close to release points.

Infiltration and percolation of precipitation serve as a driving force for downward migration of contaminants. However, due to high PET (annual PET at the Area 3 RWMS has been estimated at 61.7 in. [Yucel, 1999]) and limited precipitation at Station BJY (6.26 in./yr [ARL/SORD, 2011]), percolation of infiltrated precipitation at the NNSS does not provide a significant mechanism for vertical migration of contaminants to groundwater (DOE/NV, 1992).

Subsurface migration pathways at CAU 550 are expected to be predominately vertical, although spills or leaks at the ground surface may also have limited lateral migration before infiltration. The depth of infiltration (shape of the subsurface contaminant plume) will be dependent upon the type, volume, and duration of the discharge as well as the presence of relatively impermeable layers that could modify vertical or lateral transport pathways, both on the ground surface (e.g., concrete) and in the subsurface (e.g., caliche layers).

\section{A.2.2.6 Exposure Scenarios}

Human receptors may be exposed to COPCs through oral ingestion or inhalation of, or dermal contact (absorption) with soil or debris due to inadvertent disturbance of these materials, or external irradiation by radioactive materials. The land-use and exposure scenarios for the CAU 550 study groups are listed in Table A.2-6. These are based on current and future land use at the NNSS. CAU 550 is located at a remote location without any site improvements and where no regular work is performed. There is still the possibility, however, that site workers could occupy these locations on an occasional and temporary basis, such as a military exercise. Therefore, the current site usage at CAU 550 is conservatively represented by the Occasional Use Area exposure scenario. 
Table A.2-6

Land-Use and Exposure Scenarios

\begin{tabular}{|c|c|c|}
\hline $\begin{array}{l}\text { Group of } \\
\text { CASs }\end{array}$ & $\begin{array}{l}\text { Record of Decision } \\
\text { Land-Use Zone }\end{array}$ & Exposure Scenario \\
\hline \multirow{3}{*}{ All } & \multirow{3}{*}{$\begin{array}{l}\text { Nuclear and High Explosives Test } \\
\text { This area is designated within the } \\
\text { Nuclear Test Zone for additional } \\
\text { underground nuclear weapons tests } \\
\text { and outdoor high-explosive tests. This } \\
\text { zone includes compatible defense and } \\
\text { nondefense research, development, } \\
\text { and testing activities. }\end{array}$} & $\begin{array}{l}\text { Industrial Area } \\
\text { Worker will be exposed to the site full time ( } 250 \text { days per year, } \\
8 \text { hours per day for } 25 \text { years). Active powered buildings with } \\
\text { toilets are present at the site. }\end{array}$ \\
\hline & & $\begin{array}{l}\text { Remote Work Area } \\
\text { Worker will be exposed to the site part time (up to } 336 \text { hours } \\
\text { per year for } 25 \text { years). Site structures are present for shelter } \\
\text { and comfort of the worker. }\end{array}$ \\
\hline & & $\begin{array}{l}\text { Occasional Use Area } \\
\text { Worker will be exposed to the site occasionally (up to } 80 \text { hours } \\
\text { per year for } 5 \text { years). Site structures are not present for shelter } \\
\text { and comfort of the worker. }\end{array}$ \\
\hline
\end{tabular}




\section{A.3.0 Step 2 - Identify the Goal of the Study}

Step 2 of the DQO process states how environmental data will be used in meeting objectives and solving the problem, identifies study questions or decision statement(s), and considers alternative outcomes or actions that can occur upon answering the question(s).

\section{A.3.1 Decision Statements}

The Decision I statement is as follows: "Is any COC present in environmental media within the study group?” For judgmental sampling design, any analytical result for a COPC above the FAL will result in that COPC being designated as a COC. For the probabilistic (unbiased) sampling design, any COPC that has a 95 percent UCL of the average concentration above the FAL will result in that COPC being designated as a COC. A COC may also be defined as a contaminant that, in combination with other like contaminants, is determined to jointly pose an unacceptable risk based on a multiple contaminant analysis (NNSA/NSO, 2012). If a COC is detected, then Decision II must be resolved.

The Decision II statement is as follows: "If a COC is present, is sufficient information available to evaluate potential CAAs?” Sufficient information is defined to include the following:

- The lateral and vertical extent of COC contamination

- The information needed to predict potential remediation waste types and volumes

- The information needed to evaluate the feasibility of remediation alternatives (bioassessment if natural attenuation or biodegradation is considered, and geotechnical data if construction or evaluation of barriers is considered)

For radiological contaminants, the presence of a COC is defined as the condition where the most exposed worker has the potential to receive a TED of at least $25 \mathrm{mrem} / \mathrm{yr}$.

A corrective action will be determined for any site containing a COC. For the primary release scenario, the DQO process resulted in an assumption that corrective action is required within the areas exhibiting HCA conditions. Therefore, DCBs were established to include these areas (Section 3.4). Figure 3-4 shows the DCBs. For the primary release scenario, Decision I will be resolved for the area outside the DCBs. 
For the other release scenario, Decision I samples will be submitted to analytical laboratories to determine the presence of COCs, and Decision II samples will be submitted to define the extent of unbounded COCs. In addition, samples will be submitted for analyses, as needed, to support waste management or health and safety decisions.

A corrective action may also be required if a waste present within a study group contains contaminants that, if released, could cause the surrounding environmental media to contain a COC. Such a waste would be considered PSM. To evaluate wastes for the potential to result in the introduction of a COC to the surrounding environmental media, the conservative assumption was made that any physical waste containment would fail at some point and release the contaminants to the surrounding media. The following will be used as the criteria for determining whether a waste is PSM:

- A waste, regardless of concentration or configuration, may be assumed to be PSM and handled under a corrective action.

- Based on process knowledge and/or professional judgment, some waste may be assumed not to be PSM if it is clear that it could not result in soil contamination exceeding a FAL.

- If assumptions about the waste cannot be made, then the waste material will be sampled, and the results will be compared to FALs based on the following criteria:

- For non-liquid wastes, the concentration of any chemical contaminant in soil (after degradation of the waste and release of contaminants into soil) would be equal to the mass of the contaminant in the waste divided by the mass of the waste. If the resulting soil concentration exceeds the FAL, then the waste would be considered to be PSM.

- For non-liquid wastes, the dose resulting from radioactive contaminants in soil (after degradation of the waste and release of contaminants into soil) would be calculated using the activity of the contaminant in the waste divided by the mass of the waste (for each radioactive contaminant) and calculating the combined resulting dose using the RESRAD code (Murphy, 2004). If the resulting soil concentration exceeds the FAL, then the waste would be considered to be PSM.

- For liquid wastes, the resulting concentration of contaminants in the surrounding soil would be calculated based on the concentration of contaminants in the waste and the liquid-holding capacity of the soil. If the resulting soil concentration exceeds the FAL, then the liquid waste would be considered to be PSM. 
A COC may also be defined as a contaminant that, in combination with other like contaminants, is determined to jointly pose an unacceptable risk (NNSA/NSO, 2012).

If sufficient information is not available to evaluate potential CAAs, then site conditions will be reevaluated and additional samples will be collected (as long as the scope of the investigation is not exceeded and any CSM assumption has not been shown to be incorrect).

\section{A.3.2 Alternative Actions to the Decisions}

This section identifies actions that may be taken to solve the problem depending on the possible outcomes of the investigation.

\section{A.3.2.1 Alternative Actions to Decision I}

If no COC associated with a release from the study group is detected, then further assessment of the study group is not required. If a COC associated with a release from the study group is detected, then the extent of COC contamination will be determined, and additional information required to evaluate potential CAAs will be collected.

\section{A.3.2.2 Alternative Actions to Decision II}

If the lateral and vertical extent of COC contamination have not been defined by bounding sample results, then additional bounding samples will be collected. If sample analytical results are not sufficient to predict potential remediation waste types, then additional waste characterization samples will be collected. If available information is not sufficient to evaluate the potential for COC migration, then additional information will be collected. If sufficient information is not available to evaluate potential CAAs, then additional samples will be collected. Otherwise, collection of additional information is not required. 


\section{A.4.0 Step 3 - Identify Information Inputs}

Step 3 of the DQO process identifies the information needed, determines sources for information, and identifies sampling and analysis methods that will allow reliable comparisons with FALs.

\section{A.4.1 Information Needs}

To resolve Decision I (determine whether a COC is present at a study group) for the areas outside the DCBs, samples will be collected and analyzed following these two criteria:

- Samples must either (a) be collected in areas most likely to contain a COC (judgmental sampling) or (b) properly represent contamination at the study group (probabilistic sampling).

- $\quad$ The analytical suite selected must be sufficient to identify any COCs present in the samples.

To resolve Decision II for primary release contamination outside the DCBs, TED rates need to be established at locations that bound the FAL dose rate and provide sufficient information to establish a high (greater than 0.8) correlation to radiation survey isopleths. A boundary will then be determined around the radiation survey isopleth the correlates to the 25-mrem/yr FAL.

To resolve Decision II for other release contamination outside the DCBs (determine whether sufficient information is available to evaluate potential CAAs at each study group), samples need to be collected and analyzed to meet the following criteria:

- Samples must be collected in areas contiguous to the contamination but where contaminant concentrations are below FALs.

- Samples of the waste or environmental media must provide sufficient information to determine potential remediation waste types.

- Samples of the waste must provide sufficient information to determine whether they contain PSM.

- The analytical suites selected must be sufficient to detect contaminants at concentrations equal to or less than their corresponding FALs. 
Decision II sampling will not be conducted for the drainage sedimentation areas (other release). If a COC is present in the sediment, the entire volume of the sediment will be assumed to contain the COC and will require corrective action.

\section{A.4.2 Sources of Information}

Information to satisfy Decision I and Decision II will be generated by collecting environmental samples. These samples will be submitted to analytical laboratories meeting the quality criteria stipulated in the Industrial Sites QAPP (NNSA/NV, 2002a). The TLDs will be submitted to the Environmental Technical Services group at the NNSS, which is certified by the DOE Laboratory Accreditation Program for dosimetry. Only validated data from analytical laboratories will be used to make DQO decisions. Sample collection and handling activities will follow standard procedures.

\section{A.4.2.1 Sample Locations}

Design of the sampling approaches for the CAU 550 CASs must ensure that the data collected are sufficient for selection of the CAAs (EPA, 2002b). To meet this objective, the samples collected from each site should either be from locations that most likely contain a COC, if present (judgmental), or from locations that properly represent overall contamination at the study group (probabilistic). These sample locations, therefore, can be selected by means of either (a) biasing factors used in judgmental sampling (e.g., radiation survey anomalies, a stain, broken lead-acid batteries, spilled substance) or (b) randomly using a probabilistic sampling design. The implementation of a judgmental approach for sample location selection, and of a probabilistic sampling approach, for CAU 550 are discussed in Section A.8.0.

\section{A.4.2.2 Analytical Methods}

Analytical methods are available to provide the data needed to resolve the decision statements. The analytical methods and laboratory requirements (e.g., detection limits, precision, and accuracy) for soil samples are provided in Tables 3-4 and 3-5. 


\section{A.5.0 Step 4 - Define the Boundaries of the Study}

Step 4 of the DQO process defines the target population of interest and its relevant spatial boundaries, specifies temporal and other practical constraints associated with sample/data collection, and defines the sampling units on which decisions or estimates will be made.

\section{A.5.1 Target Populations of Interest}

The population of interest to resolve Decision I ("Is any COC present in environmental media within the study group?”) is contaminant concentrations exceeding a FAL at any location or area within the site. The populations of interest to resolve Decision II ("If a COC is present, is sufficient information available to evaluate potential CAAs?”) are as follows:

- For the primary release, TED and corresponding radiation survey values from locations where TED varies from above the FAL to below the FAL.

- For other releases, COC concentrations for each one of a set of locations bounding contamination in lateral and vertical directions

- Investigation waste and potential remediation waste characteristics

\section{A.5.2 Spatial Boundaries}

Spatial boundaries are the maximum lateral and vertical extent of expected contamination that can be supported by the CSM. Decision II spatial boundaries are as follows:

- Vertical. Primary release: $5 \mathrm{~cm}$ below original ground surface

- Vertical. Other release: $15 \mathrm{ft}$ bgs

- Lateral. Primary and other release: $2 / 3 \mathrm{mi}$ from GZ

Contamination found beyond these boundaries may indicate a flaw in the CSM and may require reevaluation of the CSM before the investigation can continue. Each study group is considered geographically independent, and intrusive activities are not intended to extend into the boundaries of neighboring CASs. 


\section{A.5.3 Practical Constraints}

Practical constraints (e.g., activities by other organizations at the NNSS, utilities, threatened or endangered animals and plants, unstable or steep terrain, and/or access restrictions) may affect the ability to investigate this site.

\section{A.5.4 Define the Sampling Units}

The scale of decision making in Decision I is defined as the study group. Any COC detected at any location within the CAS will cause the determination that the study group is contaminated and needs further evaluation. The scale of decision making for Decision II is defined as a contiguous area contaminated with any COC originating from the study group. Resolution of Decision II requires this contiguous area to be bounded laterally and vertically. 


\section{A.6.0 Step 5 - Develop the Analytic Approach}

Step 5 of the DQO process specifies appropriate population parameters for making decisions, defines action levels, and generates an "If ... then ... else" decision rule that involves it.

\section{A.6.1 Population Parameters}

Population parameters are defined for judgmental and probablistic sampling designs in the following sections. Population parameters are the parameters compared to action levels.

\section{A.6.1.1 Judgmental Sampling Design}

For chemical sample results, the population parameter is the observed concentration of each contaminant from each individual analytical sample. For radiological sample results, it is the calculated TED for each sample. Each sample result will be compared to the FALs to determine the appropriate resolution to Decision I and Decision II. A single sample result for any contaminant exceeding a FAL would cause a determination that a COC is present within the study group (for Decision I), or that the COC is not bounded (for Decision II).

\section{A.6.1.2 Probabilistic Sampling Design}

For probabilistic sampling results, the population parameter is the true TED over the area of the sample plot. Resolution of DQO decisions associated with the probabilistic sampling design requires determining, with a specified degree of confidence, whether the true TED at the site in question exceeds the FAL. Because a calculated TED is an estimate of the true (unknown) TED, it is uncertain how well the calculated TED represents the true TED. If the calculated TED were significantly different from the true TED, a decision based on the calculated TED could result in a decision error. To reduce the probability of making a false negative decision error, a conservative estimate of the true TED is used to compare to the FAL instead of the calculated TED. This conservative estimate (overestimation) of the true TED will be calculated as the 95 percent UCL of the average TED values. By definition, there will be a 95 percent probability that the true TED is less than the 95 percent UCL of the calculated TED. 
The computation of appropriate UCLs depends upon the data distribution, the number of samples, the variability of the dataset, and the skewness associated with the dataset. A statistical package will be used to determine the appropriate probability distribution (e.g., normal, lognormal, gamma) and/or a suitable nonparametric distribution-free method and then to compute appropriate UCLs. To ensure that the appropriate UCL computational method is used, the sample data will be tested for goodness-of-fit to all parametric and nonparametric UCL computation methods described in Calculating the Upper Confidence Limits for Exposure Point Concentrations at Hazardous Waste Sites (EPA, 2002a).

Computation of an appropriate UCL for each of the calculated TED averages requires the following:

- A minimum number of samples are collected.

- The data originate from a symmetric, but not necessarily normally distributed, population.

- The estimation of the variability is reasonable and representative of the population being sampled.

- The population values are not spatially correlated.

\section{A.6.2 Action Levels}

The PALs presented in this section are to be used for site screening purposes. They are not necessarily intended to be used as cleanup action levels or FALs. However, they are useful in screening out contaminants that are not present in sufficient concentrations to warrant further evaluation and, therefore, streamline the consideration of remedial alternatives. The RBCA process used to establish FALs is described in the Soils Risk-Based Corrective Action Evaluation Process (NNSA/NSO, 2012). This process conforms with NAC 445A.227, which lists the requirements for sites with soil contamination (NAC, 2008a). For the evaluation of corrective actions, NAC 445A.22705 (NAC, 2008b) requires the use of ASTM Method E1739 (ASTM, 1995) to "conduct an evaluation of the site, based on the risk it poses to public health and the environment, to determine the necessary remediation standards or to establish that corrective action is not necessary." For the evaluation of corrective actions, the FALs are established as the necessary remedial standard. 
This RBCA process defines three tiers (or levels) of evaluation involving increasingly sophisticated analyses:

- Tier 1 evaluation. Sample results from source areas (highest concentrations) are compared to action levels based on generic (non-site-specific) conditions (i.e., the PALs established in the CAIP). The FALs may then be established as the Tier 1 action levels, or the FALs may be calculated using a Tier 2 evaluation.

- Tier 2 evaluation. Conducted by calculating Tier 2 SSTLs using site-specific information as inputs to the same or similar methodology used to calculate Tier 1 action levels. The Tier 2 SSTLs are then compared to individual sample results from reasonable points of exposure (as opposed to the source areas as is done in Tier 1) on a point-by-point basis. Total concentrations of TPH will not be used for risk-based decisions under Tier 2 or Tier 3. Rather, the individual chemicals of concern will be compared to the SSTLs.

- Tier 3 evaluation. Conducted by calculating Tier 3 SSTLs on the basis of more sophisticated risk analyses using methodologies described in Method E1739 that consider site-, pathway-, and receptor-specific parameters.

The comparison of laboratory results to FALs and the evaluation of potential corrective actions will be included in the CADD. The FALs will be defined (along with the basis for their definition) in the CADD.

\section{A.6.2.1 Chemical PALs}

Except as noted herein, the chemical PALs are defined as the Region 9 Regional Screening Levels for chemical contaminants in industrial soils (EPA, 2011). Background concentrations for RCRA metals will be used instead of screening levels when natural background concentrations exceed the screening level (e.g., arsenic on the NNSS). Background is considered the average concentration plus two standard deviations of the average concentration for sediment samples collected by the Nevada Bureau of Mines and Geology throughout the Nevada Test and Training Range (formerly the Nellis Air Force Range) (NBMG, 1998; Moore, 1999). For detected chemical COPCs without established screening levels, the protocol used by EPA Region 9 in establishing screening levels (or similar) will be used to establish PALs. If used, this process will be documented in the CADD. 


\section{A.6.2.2 Radionuclide PALs}

The PAL for radioactive contaminants is a TED of $25 \mathrm{mrem} / \mathrm{yr}$, based upon the Industrial Area exposure scenario. The Industrial Area exposure scenario is described in the Soils Risk-Based Corrective Action Evaluation Process (NNSA/NSO, 2012). For primary releases, the TED is calculated as the sum of external dose and internal dose. External dose is determined directly from TLD measurements. Internal dose is determined by comparing analytical results from soil samples to RRMGs that were established using the RESRAD computer code (Yu et al., 2001). The RRMGs presented in Table A.6-1 are radionuclide-specific values for radioactivity in surface soils. The RRMG is the value, in picocuries per gram of surface soil, for a particular radionuclide that would result in an internal dose of $25 \mathrm{mrem} / \mathrm{yr}$ to a receptor (under the appropriate exposure scenario) independent of any other radionuclide (assuming that no other radionuclides contribute dose). The internal dose associated with any specific radionuclide would be established using the following equation:

Internal dose $(\mathrm{mrem} / \mathrm{yr})=[$ Analytical result $(\mathrm{pCi} / \mathrm{g}) / \mathrm{RRMG}]$ x $25 \mathrm{mrem} / \mathrm{yr}$

When more than one radionuclide is present, the internal dose will be calculated as the sum of the internal doses for each radionuclide. In the RESRAD calculation, several input parameters are not specified so that site-specific information can be used. The default and site-specific input parameters used in the RESRAD calculation of RRMGs for each exposure scenario are listed in Attachment A-1.

Table A.6-1

RRMG Values

(Page 1 of 2)

\begin{tabular}{||c|c|c|c||}
\hline \multirow{2}{*}{ Radionuclide } & \multicolumn{3}{|c|}{ Exposure Scenario (pCi/g) } \\
\cline { 2 - 4 } & Industrial Area & $\begin{array}{c}\text { Remote Work } \\
\text { Area }\end{array}$ & $\begin{array}{c}\text { Occasional Use } \\
\text { Area }\end{array}$ \\
\hline \hline Am-241 & 2,816 & 16,120 & 45,550 \\
\hline Co-60 & 551,300 & $7,229,000$ & $74,210,000$ \\
\hline Cs-137 & 140,900 & $1,955,000$ & $27,560,000$ \\
\hline Eu-152 & $1,177,000$ & $13,240,000$ & $81,740,000$ \\
\hline Eu-154 & 846,900 & $9,741,000$ & $63,530,000$ \\
\hline Eu-155 & $5,588,000$ & $66,450,000$ & $475,100,000$ \\
\hline
\end{tabular}


Table A.6-1

\section{RRMG Values}

(Page 2 of 2)

\begin{tabular}{||c|c|c|c||}
\hline \multirow{2}{*}{ Radionuclide } & \multicolumn{3}{|c|}{ Exposure Scenario (pCi/g) } \\
\cline { 2 - 4 } & Industrial Area & $\begin{array}{c}\text { Remote Work } \\
\text { Area }\end{array}$ & $\begin{array}{c}\text { Occasional Use } \\
\text { Area }\end{array}$ \\
\hline \hline $\mathrm{Nb}-94$ & $3,499,000$ & $39,660,000$ & $249,200,000$ \\
\hline $\mathrm{Pu}-238$ & 2,423 & 13,880 & 39,220 \\
\hline $\mathrm{Pu}-239 / 240$ & 2,215 & 12,680 & 35,820 \\
\hline $\mathrm{Sr}-90$ & 59,470 & 807,500 & $9,949,000$ \\
\hline $\mathrm{Th}-232$ & 2,274 & 13,410 & 38,520 \\
\hline $\mathrm{U}-234$ & 19,600 & 137,900 & 447,000 \\
\hline $\mathrm{U}-235$ & 20,890 & 149,600 & 492,200 \\
\hline $\mathrm{U}-238$ & 21,200 & 155,400 & 336,100 \\
\hline
\end{tabular}

\section{A.6.3 Decision Rules}

The decision rules applicable to both Decision I and Decision II are as follows:

- If COC contamination is inconsistent with the CSM or extends beyond the spatial boundaries identified in Section A.5.2, then work will be suspended and the investigation strategy will be reconsidered, else the decision will be to continue sampling.

The decision rules for Decision I are as follows:

- If the population parameter of any COPC in the Decision I population of interest (defined in Step 4) exceeds the corresponding FAL, then that contaminant is identified as a COC, and Decision II samples will be collected, else no further investigation is needed for that COPC in that population.

- If a COC exists at any study group, then a corrective action will be determined, else no further action will be necessary.

- If a waste is present that, if released, has the potential to cause the future contamination of site environmental media, then a corrective action will be determined, else no further action will be necessary. 
The decision rules for Decision II are as follows:

- If the population parameter (the observed concentration of any COC) in the Decision II population of interest (defined in Step 4) exceeds the corresponding FAL or potential remediation wastes have not been adequately defined, then additional samples will be collected to complete the Decision II evaluation, else the extent of the COC contamination has been defined.

- If valid analytical results are available for the waste characterization samples defined in Section A.8.0, then the decision will be that sufficient information exists to determine potential remediation waste types and evaluate the feasibility of remediation alternatives, else collect additional waste characterization samples. 


\section{A.7.0 Step 6 - Specify Performance or Acceptance Criteria}

Step 6 of the DQO process defines the decision hypotheses, specifies controls against false rejection and false acceptance decision errors, examines consequences of making incorrect decisions from the test, and places acceptable limits on the likelihood of making decision errors.

\section{A.7.1 Decision Hypotheses}

The baseline condition (i.e., null hypothesis) and alternative condition for Decision I are as follows:

- Baseline condition. A COC is present.

- Alternative condition. A COC is not present.

The baseline condition (i.e., null hypothesis) and alternative condition for Decision II are as follows:

- Baseline condition. The extent of a COC has not been defined.

- Alternative condition. The extent of a COC has been defined.

Decisions and/or criteria have false negative or false positive errors associated with their determination. The impact of these decision errors and the methods that will be used to control these errors are discussed in the following subsections. In general terms, confidence in DQO decisions based on judgmental sampling results will be established qualitatively by the following:

- Developing a CSM (based on process knowledge) that is agreed to by stakeholder participants during the DQO process.

- Testing the validity of the CSM based on investigation results.

- Evaluating the quality of data based on DQI parameters.

\section{A.7.2 False Negative Decision Error}

The false negative decision error would mean deciding that a COC is not present when it actually is (Decision I), or deciding that the extent of a COC has been defined when it has not (Decision II). In both cases, the potential consequence is an increased risk to human health and environment. 


\section{A.7.2.1 False Negative Decision Error for Judgmental Sampling}

In judgmental sampling, the selection of the number and location of samples is based on knowledge of the feature or condition under investigation and on professional judgment (EPA, 2002b).

Judgmental sampling conclusions about the target population depend upon the validity and accuracy of professional judgment.

The false negative decision error (where consequences are more severe) for judgmental sampling designs is controlled by meeting these criteria:

- For Decision I, having a high degree of confidence that the sample locations selected will identify COCs if present anywhere within the study group. For Decision II, having a high degree of confidence that the sample locations selected will identify the extent of COCs.

- Having a high degree of confidence that analyses conducted will be sufficient to detect any COCs present in the samples.

- Having a high degree of confidence that the dataset is of sufficient quality and completeness.

To satisfy the first criterion, Decision I samples must be collected in areas most likely to be contaminated by COCs (supplemented by unbiased samples where appropriate). Decision II samples must be collected in areas that represent the lateral and vertical extent of contamination (above FALs). The following characteristics must be considered to control decision errors for the first criterion:

- Source and location of release

- Chemical nature and fate properties

- $\quad$ Physical transport pathways and properties

- Hydrologic drivers

These characteristics were considered during the development of the CSM and selection of sampling locations. The field-screening methods and biasing factors listed in Section A.4.2.1 will be used to further ensure that appropriate sampling locations are selected to meet these criteria. Radiological survey instruments and field-screening equipment will be calibrated and checked in accordance with the manufacturer's instructions and approved procedures. The CADD will present an assessment on the DQI of representativeness that samples were collected from those locations that best represent the populations of interest as defined in Section A.5.1. 
To satisfy the second criterion, Decision I soil samples will be analyzed for the chemical and radiological parameters listed in Section 3.2. Decision II soil samples will be analyzed for those chemical and radiological parameters that identified unbounded COCs. The DQI of sensitivity will be assessed for all analytical results to ensure that all sample analyses had measurement sensitivities (detection limits) that were less than or equal to the corresponding FALs. If this criterion is not achieved, the affected data will be assessed (for usability and potential impacts on meeting site characterization objectives) in the CADD.

To satisfy the third criterion, the entire dataset of soil sample results, as well as individual soil sample results, will be assessed against the DQIs of precision, accuracy, comparability, and completeness as defined in the Industrial Sites QAPP (NNSA/NV, 2002a) and in Section 6.2.2. The DQIs of precision and accuracy will be used to assess overall analytical method performance as well as to assess the need to potentially “flag” (qualify) individual contaminant results when corresponding QC sample results are not within the established control limits for precision and accuracy. Data qualified as estimated for reasons of precision or accuracy may be considered to meet the analyte performance criteria based on an assessment of the data. The DQI for completeness will be assessed to ensure that all data needs identified in the DQO have been met. The DQI of comparability will be assessed to ensure that all analytical methods used are equivalent to standard EPA methods so that results will be comparable to regulatory action levels that have been established using those procedures. Strict adherence to established procedures and QA/QC protocol protects against false negatives. Site-specific DQIs are discussed in more detail in Section 6.2.2.

To provide information for the assessment of the DQIs of precision and accuracy, the following QC samples will be collected as required by the Industrial Sites QAPP (NNSA/NV, 2002a):

- Field duplicates (minimum of 1 per matrix per 20 environmental samples)

- Laboratory QC samples (minimum of 1 per matrix per 20 environmental samples, or 1 per study group per matrix if less than 20 collected)

\section{A.7.2.2 False Negative Decision Error for Probabilistic Sampling}

The false negative decision error rate goal was established by the DQO meeting participants at 5 percent. Upon validation of the analytical results, statistical parameters will be calculated for each 
significant COPC identified at each site. Protection against a false negative decision error is contingent upon the following:

- Population distribution

- Sample size

- Actual variability

- Measurement error

Control of the false negative decision error for probabilistic sampling designs is accomplished by ensuring that the following requirements are met for each of the significant COPCs:

- The population distributions fit the applied UCL determination method.

- A sufficient sample size was collected.

- The actual standard deviation is calculated.

- Analyses conducted were sufficient to detect contamination exceeding FALs.

\section{A.7.3 False Positive Decision Error}

The false positive decision error would mean deciding that a COC is present when it is not, or a COC is unbounded when it is not, resulting in increased costs for unnecessary sampling and analysis.

False positive results are typically attributed to laboratory and/or sampling/handling errors that could cause cross contamination. To control against cross contamination, decontamination of sampling equipment will be conducted in accordance with established and approved procedures, and only clean sample containers will be used. To determine whether a false positive analytical result may have occurred, the following QC samples will be collected as required by the Industrial Sites QAPP (NNSA/NV, 2002a):

- $\quad$ Trip blanks (1 per sample cooler containing VOC environmental samples)

- Equipment blanks (1 per sampling event)

- $\quad$ Source blanks (1 per uncharacterized source lot per lot)

- Field blanks (minimum of 1 per study group, additional if field conditions change)

For probabilistic sampling, false positive decision error rate goal was established by the DQO meeting participants at 0.20 (or 20 percent probability). Protection against this decision error is also afforded by the controls listed in Section A.7.2 for probabilistic sampling designs. 


\section{A.8.0 Step 7 - Develop the Plan for Obtaining Data}

Step 7 of the DQO process selects and documents a design that will produce data that exceeds performance or acceptance criteria. Judgmental sampling schemes will be implemented to select sample plot locations for the primary releases. Probabilistic sampling schemes will be implemented to select the sample locations within each of the sample plots. Judgmental sampling will also be used to investigate any other releases as described in Section A.2.2.1. Investigation results will be compared to FALs to determine the need for corrective action. PSM sample results will be evaluated against the PSM criteria listed in Section A.3.1 to determine the need for corrective action.

\section{A.8.1 Primary Releases Sample Location Selection and Sampling}

A judgmental sampling design will be implemented for locating Decision I sample plots for the primary release scenario (Study Groups 1 and 2). These sample plot locations will be determined judgmentally based on the highest results of the radiological aerial and ground-based surveys. This will be done in an effort to find locations where the internal dose contributes the greatest amount to TED.

CAS 08-23-04 (Smoky) will be investigated individually as Study Group 1, while CASs 08-23-03, 08-23-06, and 08-23-07 (Oberon, Ceres, and Titania) will collectively be investigated as Study Group 2.

\section{A.8.1.1 Study Group 1 Sample Plot and TLD Locations}

For Study Group 1, Decision I will be evaluated outside the DCB by measuring TED at a sample plot established within the area of the highest gamma values as determined from the PRM-470 radiological survey. This will be done in an effort to find the location of maximum TED. If the 95 percent UCL of the TED at the Decision I sample plot associated with Study Group 1 is less than the FAL, then no further action is required. Otherwise, Decision II will be resolved using approximately 50 TLDs from other locations established in the DQOs. Internal dose at each TLD location will be applied based on the internal/external ratio obtained at the Decision I location (Section 4.2.2.1). The Decision I sample plot potential location is depicted on Figure A.8-1 along with all of the Decision I and Decision II TLD potential locations. 


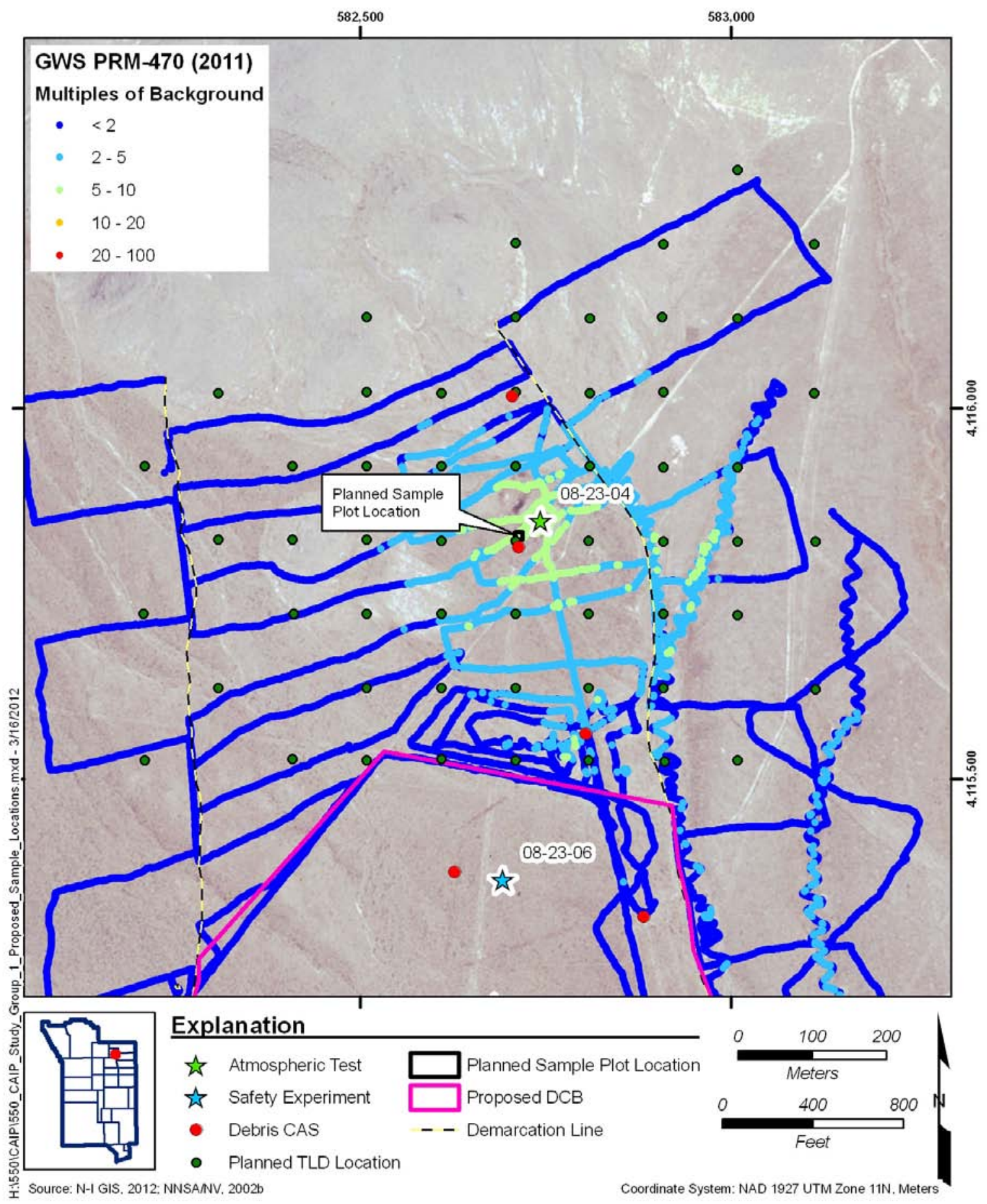

Figure A.8-1

Sample Layout for Study Group 1 


\section{A.8.1.2 Study Group 2 Sample Plot and TLD Locations}

For Study Group 2, Decision I will be evaluated by measuring TED at sample plots established within two individual locations outside the DCB most likely to exceed the FAL. The first sample location (north of the DCB) will be selected in the area of the highest 2002 KIWI value outside the DCB, and the second sample location (southwest of the DCB) will be selected in the area of the highest 2002 americium signature value outside the DCB (N-I, 2011). The final locations most representative of the highest TED will be determined in the field with the FIDLER. No additional TLDs are planned to be placed as part of the primary release investigation at Study Group 2. If the results of the Decision I samples at Study Group 2 indicate contamination present that exceeds the FALs, then a Decision II sampling strategy will be presented to and agreed upon by NNSA/NSO and NDEP. The Decision I sample plot and TLD locations are depicted on Figure A.8-2.

\section{A.8.1.3 Sampling of Sample Plots}

The probabilistic sampling scheme will be implemented to select sample locations within the sample plots and evaluate the analytical results. For each sample collected within the sample plot, randomly selected subsample locations will be chosen based on a random start, triangular pattern (see Figure A.8-3 for an example of this sampling scheme). If sufficient sample material cannot be collected at a specified location (due to rock, caliche, or buried concrete), the Site Supervisor will establish the location at the nearest place that a surface sample can be obtained.

Statistical methods that generate site characteristics will be used to establish internal dose estimates that represent the sample plot as a whole. Composite samples will be collected at each sample plot in the following manner:

- At least four composite samples will be collected from each established sample plot.

- Each composite sample will be comprised of nine aliquots taken from randomly selected locations within each plot. These locations will be predetermined using a random start with a triangular grid pattern.

- Samples will be sieved to eliminate material (e.g., Trinity glass) greater than 0.25 -in. diameter that cannot effectively be inhaled or ingested.

- The entire volume of the composited material collected will be submitted to the laboratory for analysis. 


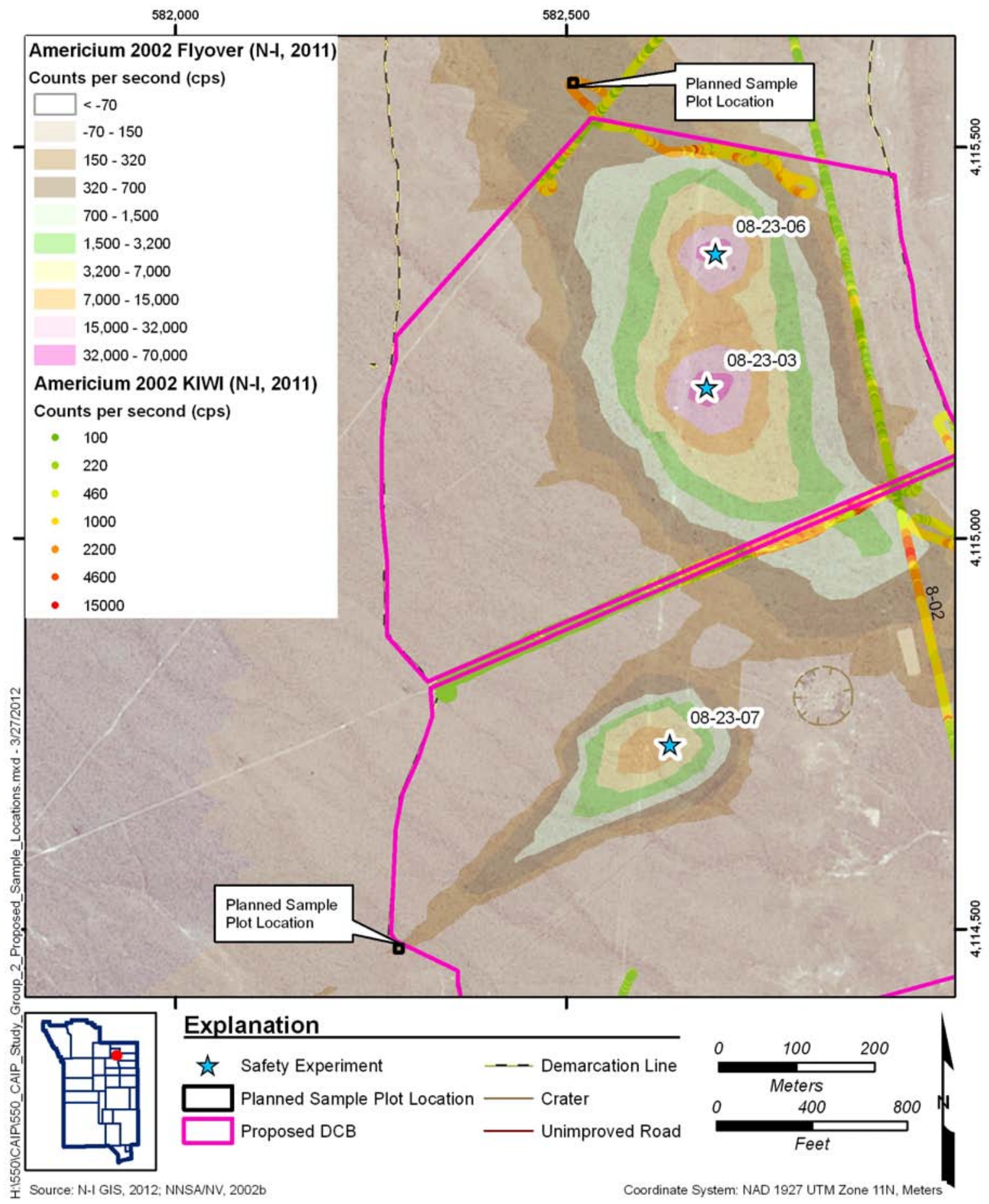

Figure A.8-2

Sample Layout for Study Group 2 


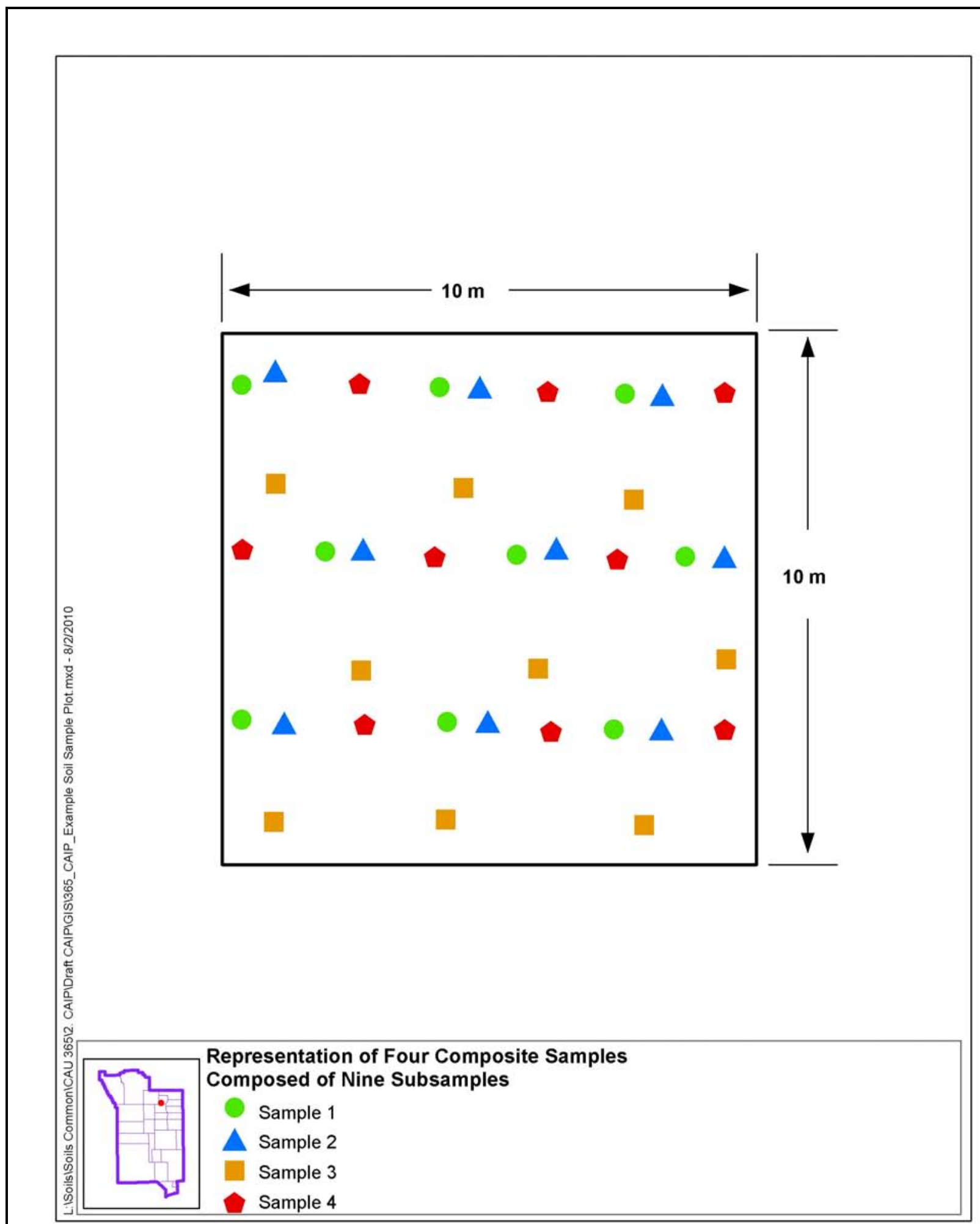

Figure A.8-3

Example Sample Plot 
An example of the predetermined sample locations at one plot is shown in Figure A.8-3.

As determination of the minimum sample size cannot be accomplished until after the data have been generated, the sufficiency of the number of samples collected will be evaluated. This will be evaluated based on TED results (composed of individual internal dose rates associated with each of the four composite samples added to the external dose rates from the TLD elements). The minimum number of samples required for each sample plot was calculated for both the internal (soil samples) and external (TLD elements) dose samples. The minimum sample size was calculated using the following EPA sample size formula (EPA, 2006):

$$
\mathrm{n} \geq \frac{\mathrm{s}^{2}\left(\mathrm{z}_{.95}+\mathrm{z}_{.80}\right)^{2}}{(\mu-\mathrm{C})^{2}}+\frac{\left(\mathrm{z}_{.95}\right)^{2}}{2}
$$

where

$$
\begin{aligned}
& \mathrm{s}=\text { standard deviation } \\
& \mathrm{z}_{.95}=\mathrm{z} \text { score associated with the false negative rate of } 5 \text { percent } \\
& \mathrm{z}_{.80}=\mathrm{z} \text { score associated with the false positive rate of } 20 \text { percent } \\
& \mu=\text { dose level where false positive decision is not acceptable }(12.5 \mathrm{mrem} / \mathrm{yr}) \\
& \mathrm{C}=\text { FAL }(25 \mathrm{mrem} / \mathrm{yr})
\end{aligned}
$$

The use of this formula requires the input of basic statistical values associated with the sample data. Data from a minimum of three samples is required to calculate these statistical values and as such, the least possible number of samples required to apply the formula is three. Therefore, in instances where the formula resulted in a value less than three, three is adopted as the minimum number of samples required.

All calculations for the determination of sample size sufficiency will be provided in the CADD. If the criteria established in this section result in a determination that the minimum sample size was not met for a plot, one of the following actions may be taken:

- Additional composite sample(s) may be collected.

- Conservatively assume that the TED for the plot exceeds the FAL.

If these criteria cannot be met, justifications for use of the resulting TED without meeting the criteria will be made in the CADD. 


\section{A.8.1.4 External Dose Sampling}

External dose will be determined by collecting in situ measurements using TLDs. The TLD measurements will be taken at a height of $1 \mathrm{~m}$ ( $3.3 \mathrm{ft})$. For sample plots, the TLDs will be located in the approximate center of the plot.

The TLD placement and processing will follow the protocols established in Nevada Test Site Routine Radiological Environmental Monitoring Plan (BN, 2003). The TLDs will be in place for a targeted total exposure time of 2,000 hours, or the resulting data will be adjusted to be equivalent to an exposure time of 2,000 hours.

Estimates of external dose, in mrem/IA-yr, will be presented as net values (e.g., a background has been subtracted from the raw result). Naturally occurring terrestrial and cosmic radiation (i.e., background) will be registered on a TLD. These background radiation values can be comparable to the value of the FAL. Therefore, the FAL is only applicable to radiation dose from man-made sources at the NNSS and is a value in excess of what would be present if there were no nuclear activities at the site.

The value for the natural background dose to be subtracted from the TLD results will be obtained from an area determined to be unaffected by man-made activities at the NNSS. Ten such areas are identified in Section 5.0 of the Nevada Test Site Environmental Report 2006 (Wills, 2007) and are routinely monitored for external radiation exposure via environmental monitoring TLDs. Specific background TLDs will be placed for CAU 550 at locations shown in Figure A.8-4.

The project-specific TLDs are subjected to the same QA checks as the routine NNSS environmental monitoring TLDs, as described in Section 6.0. The Panasonic UD-814 TLD used in the NNSS environmental monitoring program contains four individual elements. The readings from each element are compared as part of the routine QA checks during the TLD processing. External dose at each TLD location is then determined using the readings from TLD elements 2, 3, and 4. Element 1 is designed to measure dose to the skin and is not relevant to the determination of the external dose. 


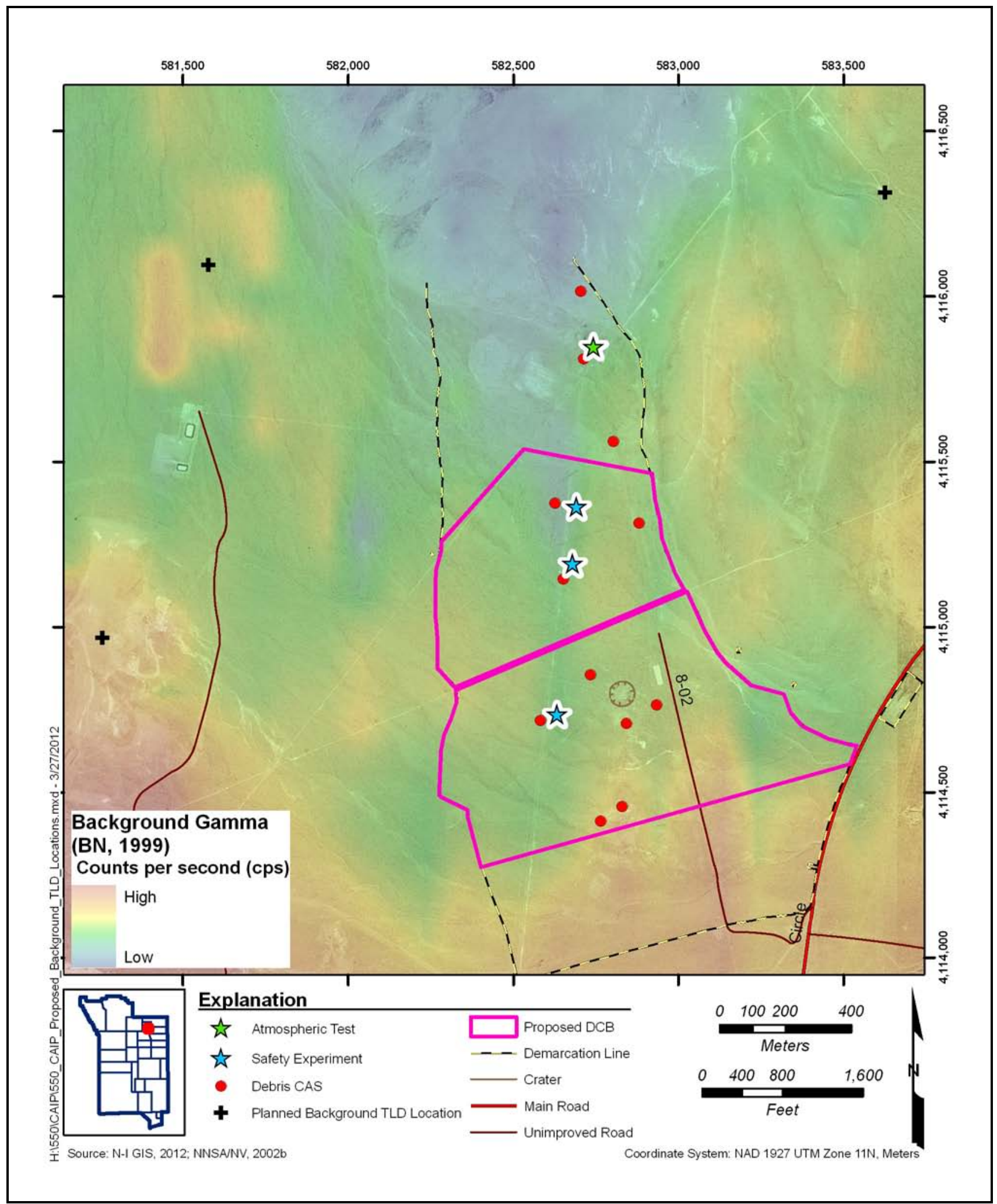

Figure A.8-4

Background TLD Layout 


\section{A.8.2 Sampling for Other Releases}

Sample locations for other releases will be determined based upon the likelihood of a contaminant release at the study group. These locations will be selected based on the identification of biasing factors during the investigation. For the investigation of other releases such as washes (Study Group 3, Washes), sample locations will be selected from sediment accumulation areas based on elevated radiological readings. For other releases related to debris left on site (Study Group 4, Debris), biasing factors such as stains, radiological survey results, and wastes suspected of containing hazardous or radiological components will be used to select the most appropriate samples from a particular location for submittal to the analytical laboratory. Additional stained soil and debris may be identified during the site characterization activities and will be investigated as appropriate.

The following factors will also be considered in selecting locations for analytical samples at CAU 550:

- Stains. Any spot or area on the soil surface that may indicate the presence of a potentially hazardous liquid. Typically, stains indicate an organic liquid, such as an oil, has reached the soil and may have spread out vertically and laterally.

- Radiological survey anomalies. Radiological survey results that are significantly higher than the surrounding area.

- Drums, containers, equipment, or debris. Materials that contain or may have contained hazardous or radioactive substances.

- Preselected areas based on process knowledge of the site. Locations for which evidence such as historical photographs, experience from previous investigations, or input from interviewee exists that a release of hazardous or radioactive substances may have occurred.

- $\quad$ Preselected areas based on process knowledge of the contaminant(s). Locations that may reasonably have received contamination, selected on the basis of the chemical and/or physical properties of the contaminant(s) in that environmental setting.

- Visual indicators such as discoloration, textural discontinuities, disturbance of native soils, or any other indication of potential contamination.

- $\quad$ Presence of debris, waste, or equipment.

- Other biasing factors. Factors not previously defined for the CAI that become evident once the investigation of the site is under way. 
For the other releases, individual sample results, rather than an average concentration, will be used to compare to FALs. Therefore, statistical methods to generate site characteristics will not be needed. Adequate representativeness of the entire target population may not be a requirement in developing a sampling design. If good prior information about the target site of interest is available, then the sampling may be designed to collect samples only from areas known to have the highest concentration levels on the target site. If the observed concentrations from these samples are below the action level, then a decision can be made that the site contains safe levels of the contaminant without the samples being truly representative of the entire area (EPA, 2006).

A biased sampling strategy will be used to target areas with the highest potential to contain a COC, if it is present anywhere in the study group. If biasing factors are present in soils below locations where Decision I samples were removed, additional Decision I soil samples will be collected at depth intervals selected by the Site Supervisor based on biasing factors to a depth where the biasing factors are no longer present. The Site Supervisor has the discretion to modify the judgmental sample locations, but only if the modified locations meet the decision needs and criteria stipulated in these DQOs.

\section{A.8.2.1 Study Group 3 Sample and TLD Locations}

Within Study Group 3 (Washes), Decision I will be evaluated by measuring TED at individual sample locations. Individual soil samples will be collected at locations to determine internal dose with TLDs co-located to measure external dose. A ground-based KIWI survey was conducted in 2002 in the area of Study Group 3. PRM-470 and FIDLER surveys were also conducted during the 2011 preliminary investigations indicating migration outside the DCB. A FIDLER survey will be conducted to identify elevated readings to select a minimum of two sample locations per each of the three wash segments identified in the DQOs depicted in Figure A.8-5. This survey will be more comprehensive to provide denser coverage throughout the wash segments and will include the bank/barrier area adjacent to Circle Road. A grab sampling location will be established at the two most elevated sediment accumulation areas outside the DCB within each of the three wash segments down to the edge of Circle Road. A TLD will also be placed at each sample location. 


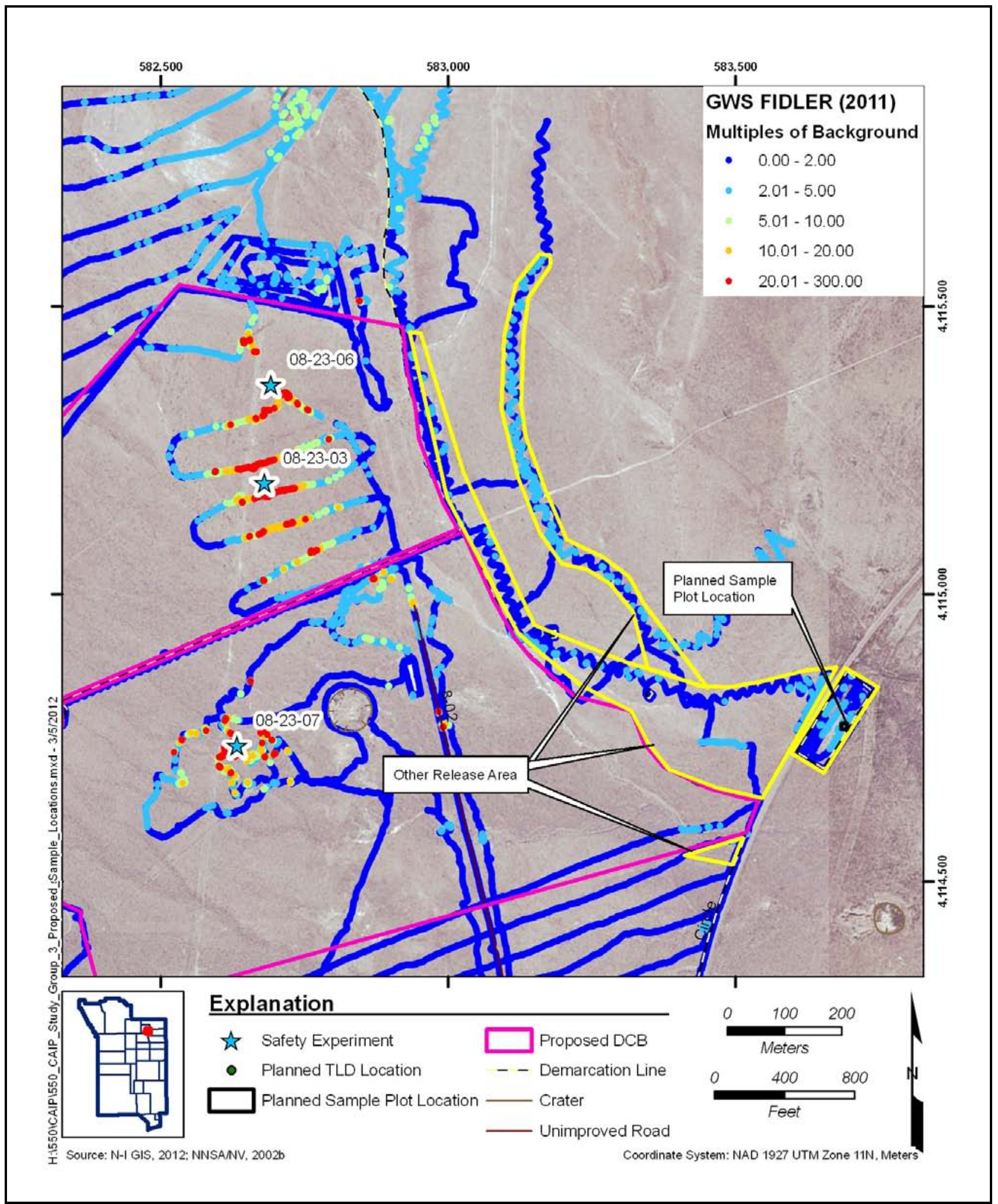

Figure A.8-5

Group 3 Investigation Areas 
Additionally, the depositional area will be sampled (soil grab sample and TLD) at the single most-elevated location, as was identified based upon the 2002 americium flyover, and the FIDLER and KIWI ground surveys.

Additional sedimentation areas will be sampled until at least two consecutive sedimentation areas are found that do not exceed the FAL.

All wash and depositional area samples will be submitted for the analyses listed under Study Group 3 in Table A.2-3.

Judgmental samples will be collected as follows:

- At each sample location within individual sediment accumulation areas selected (washes and depositional area), a sample will be collected from each 5-cm depth interval until native material is encountered.

- Each sample will be field screened with an alpha/beta contamination meter and compared to the established background FSL for the site.

- If the depth sample with the highest FSR is not significantly different (at least 20 percent difference) than the FSR of the surface sample, then only the surface sample will be submitted for analysis. If the FSR is greater than 20 percent higher than the surface sample, then both the surface sample and the depth sample with the elevated FSR will be submitted for analysis.

- If the FSL is not exceeded in any depth sample, then only the surface sample will be submitted for analysis.

It will be conservatively assumed that the highest TED from either surface or subsurface samples will be used to resolve DQO decisions. If a subsurface sample results in a higher internal dose than a surface sample, a TLD-equivalent external dose will be calculated for the subsurface sample. This will be accomplished by establishing a correlation between RESRAD-calculated external dose from surface samples and the RESRAD-calculated external dose from the subsurface samples. This surface TLD reading will be increased by this proportion to estimate a TLD-equivalent external dose for the subsurface soil. 
Information (such as sample results and the results of the radiological survey) needed to assess the potential for future migration of the $25-\mathrm{mrem} / \mathrm{yr}$ boundary will be obtained during the field investigation and addressed in the CADD.

\section{A.8.2.2 Study Group 4}

For the Study Group 4 releases at CAU 550, a judgmental sampling approach will be used to investigate the likelihood of the soil containing a COC. Biasing factors such as stains, presence of lead bricks and broken lead-acid batteries, and wastes suspected of containing hazardous or radiological components will be used to select the most appropriate samples. Specific analyses requested for these samples will be determined based on the nature of the potential release (e.g., hydrocarbon stain, lead bricks).

If a COC is present at any Study Group 4 sample location, Decision II sampling will be conducted to define the extent of contamination where COCs have been confirmed. Extent (Decision II) sampling locations at each study group will be selected based on the CSM, biasing factors, field-survey results, existing data, and the outer boundary sample locations where COCs are detected. In general, extent sample locations will be arranged in a triangular pattern around areas containing a COC at distances based on site conditions, COC concentrations, process knowledge, and biasing factors. If COCs extend beyond extent locations, additional Decision II samples will be collected from locations farther from the source.

\section{A.8.3 Evaluation of TED}

As discussed in Section A.6.1.2, the 95 percent UCL of the TED from each sample location will be used to establish the corrective action boundary. The 95 percent UCL of the TED for each sample location will be established as the sum of the 95 percent UCL of the internal dose and the 95 percent UCL of the external dose. These 95 percent UCL dose estimates will be calculated using the three external dose measurements from the TLD and the RRMG-calculated internal dose estimates from the soil samples (Section 3.3.2).

The initial corrective action boundary area will be calculated using the 95 percent UCL of the TED from each sample location and a corresponding measurement from an appropriate radiation survey. 
These paired values will be used to establish a correlation for each radiation survey and identify the radiation survey that has the best correlation to TED values. This correlation will be used to establish a radiation survey value corresponding to the 25-mrem/yr FAL (using the appropriate exposure scenario). An isopleth of this value from the radiological survey will be used as the initial corrective action boundary.

\section{A.8.4 Establishment of Final Corrective Action Boundary}

The final corrective action boundary will be established to include the DCB, the initial corrective action boundary, any additional areas that exceed the FAL and any COCs identified from the other releases. 
ARL/SORD, see Air Resources Laboratory/Special Operations and Research Division.

ASTM, see ASTM International.

Air Resources Laboratory/Special Operations and Research Division. 2011. “Nevada Test Site (NTS) Climatological Rain Gauge Network.” As accessed at http://www.sord.nv.doe.gov/home_climate_rain.htm on 27 February 2012.

ASTM International. 1995 (reapproved 2002). Standard Guide for Risk-Based Corrective Action Applied at Petroleum Release Sites, ASTM E1739 - 95(2002). West Conshohocken, PA.

BN, see Bechtel Nevada.

Bechtel Nevada. 1999. An Aerial Radiological Survey of the Nevada Test Site, DOE/NV/11718--324. Prepared for U.S. Department of Energy, Nevada Operations Office. Las Vegas, NV: Remote Sensing Laboratory.

Bechtel Nevada. 2003. Nevada Test Site Routine Radiological Environmental Monitoring Plan, DOE/NV/11718--804. Prepared for the U.S. Department of Energy, National Nuclear Security Administration, Nevada Site Office. Las Vegas, NV.

Bechtel Nevada. 2004. Engineering Plan for NST Legacy Rehabilitation Area-8 Circle Road, ENGR-C-135, Rev. 0. 8 July. Las Vegas, NV.

Bryant, E.A. 1992. The Cambric Migration Experiment, A Summary Report, LA-12335-MS. Los Alamos, NM: Los Alamos National Laboratory.

DOE, see U.S. Department of Energy.

DOE/NV, see U.S. Department of Energy, Nevada Operations Office.

EPA, see U.S. Environmental Protection Agency.

Gilbert, R.O., E.H. Essington, D.N. Brady, P.G. Doctor, and L.L Eberhardt. 1977. "Statistical Activities during 1976 and the Design and Initial Analysis of Nuclear Site Studies.” In Transuranics in Desert Ecosystems, NVO-181. pp. 331-366. November. Las Vegas, NV: U.S. Department of Energy, Nevada Operations Office.

Hoffman, D.C., and W.R. Daniels. 1984. “Assessment of the Potential for Radionuclide Migration from a Nuclear Explosion Cavity.” In Groundwater Contamination, pp. 139-146. Washington, DC: National Academy Press. 
McArthur, R.D., and J.F. Kordas. 1983. Radionuclide Inventory and Distribution Program: The Galileo Area, DOE/NV/10162-14; Publication No. 45035. Las Vegas, NV: Desert Research Institute, Water Resources Center.

McArthur, R.D., and J.F. Kordas. 1985. Nevada Test Site Radionuclide Inventory and Distribution Program: Report \#2. Areas 2 and 4, DOE/NV/10162-20; Publication No. 45041. Las Vegas, NV: Desert Research Institute, Water Resources Center.

Moore, J., Science Applications International Corporation. 1999. Memorandum to M Todd (SAIC) titled “Background Concentrations for NTS and TTR Soil Samples,” 3 February. Las Vegas, NV: IT Corporation.

Murphy, T., Bureau of Federal Facilities. 2004. Letter to R. Bangerter (NNSA/NSO) titled "Review of Industrial Sites Project Document Guidance for Calculating Industrial Sites Project Remediation Goals for Radionuclides in Soil Using the Residual Radiation (RESRAD) Computer Code,” 19 November. Las Vegas, NV.

NAC, see Nevada Administrative Code.

NBMG, see Nevada Bureau of Mines and Geology.

N-I, see Navarro-Intera, LLC.

N-I GIS, see Navarro-Intera Geographic Information Systems.

NNSA/NSO, see U.S. Department of Energy, National Nuclear Security Administration Nevada Site Office.

NNSA/NV, see U.S. Department of Energy, National Nuclear Security Administration Nevada Operations Office.

Navarro-Intera Geographic Information Systems. 2012. ESRI ArcGIS Software.

Navarro-Intera, LLC. 2011. Data transfer to M. Knop from NSTec regarding KIWI and aerial radiological surveys, 4 November. Las Vegas, NV.

Nevada Administrative Code. 2008a. NAC 445A.227, “Contamination of Soil: Order by Director for Corrective Action; Factors To Be Considered in Determining Whether Corrective Action Required.” Carson City, NV. As accessed at http://www.leg.state.nv.us/nac on 6 March 2012.

Nevada Administrative Code. 2008b. NAC 445A.22705, "Contamination of Soil: Evaluation of Site by Owner or Operator; Review of Evaluation by Division.” Carson City, NV. As accessed at http://www.leg.state.nv.us/nac on 6 March 2012. 
Nevada Bureau of Mines and Geology. 1998. Mineral and Energy Resource Assessment of the Nellis Air Force Range, Open-File Report 98-1. Reno, NV.

SNJV, see Stoller-Navarro Joint Venture.

Stoller Navarro Joint Venture. 2007. Phase I Contaminant Transport Parameters for the Groundwater Flow and Contaminant Transport Model of Corrective Action Unit 97: Yucca Flat/Climax Mine, Nevada Test Site, Nye County, Nevada, Rev. 0, S-N/99205--096. Las Vegas, NV.

Tamura, T. 1977. "Plutonium Distribution in a Desert Pavement-Desert Mound Soil System in Area 11.” In Environmental Plutonium on the Nevada Test Site and Environs, NVO-171. June. Las Vegas, NV: Energy Research and Development Administration, Nevada Applied Ecology Group.

U.S. Department of Energy, National Nuclear Security Administration Nevada Operations Office. 2002a. Industrial Sites Quality Assurance Project Plan, Nevada Test Site, Nevada, Rev. 3, DOE/NV--372. Las Vegas, NV.

U.S. Department of Energy, National Nuclear Security Administration Nevada Operations Office. 2002b. Nevada Test Site Orthophoto Site Atlas, DOE/NV/11718--604. Aerial photos acquired Summer 1998. Prepared by Bechtel Nevada. Las Vegas, NV.

U.S. Department of Energy, National Nuclear Security Administration Nevada Site Office. 2012. Soils Risk-Based Corrective Action Evaluation Process, Rev. 0, DOE/NV--1475. Las Vegas, NV.

U.S. Department of Energy, Nevada Operations Office. 1992. Remedial Investigation and Feasibility Study for the Plutonium Contaminated Soils at Nevada Test Site, Nellis Air Force Range and Tonopah Test Range. April. Las Vegas, NV.

U.S. Department of Energy, Nevada Operations Office. 2000. United States Nuclear Tests, July 1945 through September 1992, DOE/NV--209-REV 15. Las Vegas, NV.

U.S. Environmental Protection Agency. 2002a. Calculating Upper Confidence Limits for Exposure Point Concentrations at Hazardous Waste Sites, OSWER 9285.6-10. December. Washington, DC: Office of Emergency and Remedial Response.

U.S. Environmental Protection Agency. 2002b. Guidance for Quality Assurance Project Plans, EPA QA/G5, EPA/240/R-02/009. Washington, DC: Office of Environmental Information.

U.S. Environmental Protection Agency. 2006. Guidance on Systematic Planning Using the Data Quality Objectives Process, EPA QA/G-4, EPA/240/B-06/001. Washington, DC: Office of Environmental Information. 
U.S. Environmental Protection Agency. 2011. Pacific Southwest, Region 9: Regional Screening Levels (Formerly PRGs), Screening Levels for Chemical Contaminants. As accessed at http://www.epa.gov/region9/superfund/prg on 21 February 2012. Prepared by EPA Office of Superfund and Oak Ridge National Laboratory.

Wills, C.A. 2007. Nevada Test Site Environmental Report 2006, DOE/NV 25946--259. Prepared for the U.S. Department of Energy, National Nuclear Security Administration Nevada Site Office. Las Vegas, NV: National Security Technologies, LLC.

Yu, C., A.J. Zielen, J.-J. Cheng, D.J. LePoire, E. Gnanapragasam, S. Kamboj, J. Arnish, A. Wallo III, W.A. Williams, and H. Peterson. 2001. User's Manual for RESRAD Version 6, ANL/EAD-4. Argonne, IL: Argonne National Laboratory, Environmental Assessment Division. (Version 6.5 released in October 2009.)

Yucel, V., National Security Technologies, LLC. 2009. Personal communication to R.L. Kidman (N-I) regarding PET data, 30 April. Las Vegas, NV. 


\title{
Attachment A-1
}

\section{Derivation of Residual Radioactive Material Guidelines for Radionuclides in Soil}

\author{
(10 Pages)
}




\section{Introduction}

This appendix promulgates tables of Residual Radioactive Material Guidelines (RRMGs) for the Industrial Area, Remote Work Area, and Occasional Use Area exposure scenarios, for use in the evaluation of Soils Project sites. These exposure scenarios are described in the document Industrial Sites Project Establishment of Final Action Levels (NNSA/NSO, 2006). Two sets of RRMGs were calculated for each of the three exposure scenarios: one set using only the inhalation and ingestion pathways (e.g., internal dose), and one set that added the external gamma pathway (e.g., internal and external dose). The second set is needed to evaluate "other release” soil samples where thermoluminescent dosimeters (TLDs) were not emplaced to measure the external dose.

\section{Background}

The Industrial Sites Project Establishment of Final Action Levels (NNSA/NSO, 2006), provides a Nevada Division of Environmental Protection (NDEP)-approved process for the derivation of soil sampling final action levels that are congruent with the risk-based corrective action process. This document is used by the Navarro-Intera, LLC, Soils Project as well.

The Residual Radioactive (RESRAD) computer code, version 6.5 (Yu et al., 2001), and the guidance provided in NNSA/NSO (2006) were used to derive RRMGs for use in the Soils Project. The RRMGs are radionuclide-specific values for radioactivity in surface soils, expressed in units of picocuries per gram (pCi/g). A soil sample with a radionuclide concentration that is equal to the RRMG value for that radionuclide would present a potential dose of 25 millirem per year (mrem/yr) to a receptor under the conditions described in the exposure scenario. When more than one radionuclide is present, the potential dose must be evaluated by summing the fractions for each radionuclide (i.e., the measured concentration divided by the RRMG for the radionuclide). The resultant sum of the fractions value is then multiplied by 25.0 to obtain an estimate of the dose.

The RRMGs are specific to a particular exposure scenario. The dose estimates obtained from the use of RRMGs are valid only when the assumptions provided in the exposure scenario for the intended land-use hold true. In most cases at the Nevada National Security Site (NNSS), the Industrial Area exposure scenario is quite conservative and is bounding for most anticipated future land uses.

A recent revision to 10 Code of Federal Regulations (CFR) Part 835 (CFR, 2012) had adopted new, more sophisticated, dosimetric models and new dosimetric terms. Internal dose is now to be expressed in terms of the Committed Effective Dose (CED), and International Commission on Radiological Protection (ICRP) 72 dose conversion factors are to be used.

\section{Methods}

Calculations were performed using the RESRAD code, version 6.5 (Yu et al., 2001). The ICRP 72 dose conversion factors were used. The RESRAD input parameters were verified and checkprinted. 
The radionuclide niobium (Nb)-94 was previously added to the RRMGs to accommodate work in Area 25 that is related to the Nuclear Rocket Development Station (NRDS). The radionuclides silver (Ag)-108m, curium (Cm)-243, and Cm-244 were recently detected on one or more Soils Project sites, and RRMGs were calculated to demonstrate that their contribution to the total effective dose (TED) is negligible.

The RESRAD calculations have identified that for all radionuclides evaluated, with one exception: The maximum potential dose occurs at time-zero. The RRMGs provided in this memorandum do reflect those for time-zero. The exception previously mentioned is the radionuclide thorium (Th)-232, which has several daughters with short half-lives. Because the daughter activity "grows in," and because RRMGs include the contributions from daughters, the maximum potential dose for Th-232 actually occurs at 10.21 years. A RRMG for Th-232 at 10.21 years was not selected, and the RRMG for time-zero was used, for the following reasons:

- RESRAD suggests a set of RRMGs for use when the overall total dose is at its maximum. Considering the contributions from all radionuclide contaminants of potential concern (COPCs), this would be at time-zero.

- The additional dose from the in-growth of Th-232 daughters is offset by the radioactive decay of other radionuclides that would be present (e.g., cesium [Cs]-137).

- The additional dose from the in-growth of Th-232 daughters is very small when compared to the basic dose limit of $25 \mathrm{mrem} / \mathrm{yr}$. For example, if Th-232 were found at a concentration of $100 \mathrm{pCi} / \mathrm{g}$, the increase in potential dose from time-zero to 10.21 years would only be 0.52 millirem (mrem). To date, Th-232 has only been seen on Soils Project sites at environmental levels of about 1.5 to $3 \mathrm{pCi} / \mathrm{g}$.

\section{Assumptions and Default Parameters}

Appendix B to DOE/NV--1107 (NNSA/NSO, 2006) lists the RESRAD code variables (i.e., input parameters) for the three exposure scenarios. These pre-determined values were used to calculate the RRMGs, with a few exceptions as described in Table 1.

\section{$\underline{\text { Results }}$}

The RRMGs are presented in Tables 2 to 7. The abbreviation "RRMG" in each of the six tables includes a subscript to indicate the scenario and the exposure pathways that are activated. When referencing a set of RRMGs, the subscripts should be included to avoid confusion and a potential misapplication of the RRMGs. 
Table 1: RESRAD Input Parameters

\begin{tabular}{|c|c|c|c|c|c|}
\hline Item \# & $\begin{array}{l}\text { RESRAD } \\
\text { Parameter }\end{array}$ & $\begin{array}{c}\text { Industrial } \\
\text { Area }\end{array}$ & $\begin{array}{c}\text { Remote } \\
\text { Work Area }\end{array}$ & $\begin{array}{l}\text { Occasional } \\
\text { Use Area }\end{array}$ & $\begin{array}{lll}\text { Explanation } & \end{array}$ \\
\hline 1 & $\begin{array}{l}\text { Area of CZ } \\
\quad\left(\mathrm{m}^{2}\right)\end{array}$ & \multicolumn{3}{|c|}{1,000} & $\begin{array}{l}\text { Appendix B states “Site Specific.” Previously, } 100 \mathrm{~m}^{2} \text { was selected to conform to } \\
\text { the maximum area of contamination limitation in DOE Order } 458.1 \text { (DOE, 2011). } \\
\text { Going forward, } 1,000 \mathrm{~m}^{2} \text { has been selected to add conservatism and realism to the } \\
\text { RRMGs. The } 1,000 \mathrm{~m}^{2} \text { RRMGs will be applied to } 100-\mathrm{m}^{2} \text { evaluation areas. }\end{array}$ \\
\hline 2 & $\begin{array}{l}\text { Thickness of CZ } \\
\text { (m) }\end{array}$ & \multicolumn{3}{|c|}{0.05} & $\begin{array}{l}\text { Appendix B states “Site Specific.” This depth encompasses the bulk of the } \\
\text { potential contamination and includes the maximum concentration. }\end{array}$ \\
\hline 3 & Cover Depth & \multicolumn{3}{|c|}{0.00} & $\begin{array}{l}\text { Appendix B states “Site Specific.” Cover depth only affects the time delay before } \\
\text { contamination becomes available for erosion and airborne suspension. Increasing } \\
\text { the cover depth, in some cases, may lead to lower dose estimates. }\end{array}$ \\
\hline 4 & $\begin{array}{l}\text { Precipitation } \\
\text { (m/yr) }\end{array}$ & \multicolumn{3}{|c|}{0.144} & $\begin{array}{l}\text { Appendix B states “Site Specific.” The selected value is the average annual rainfall } \\
\text { as recorded at Camp Desert Rock. }\end{array}$ \\
\hline 5 & Indoor Time Fraction & [0.1712] & {$[0.0256]$} & 0 & $\begin{array}{l}\text { The stated value was } 0 \text {, conservatively assuming no time is spent indoors. The new } \\
\text { value more accurately reflects the Industrial Area scenario in which } 66 \% \text { of the time } \\
\text { is spent indoors. } \\
\qquad\left(\frac{2250 \text { hrs on }- \text { site }}{8760 \text { hrs in a year }}\right) 0.6666 \text { indoors }=0.1712 \\
\text { The same correction was made for the Remote Work Area scenario. }\end{array}$ \\
\hline 6 & $\begin{array}{l}\text { Soil Ingestion Rate } \\
\text { (g/yr) }\end{array}$ & [43.43] & 20.2 & 4.8 & $\begin{array}{l}\text { The stated value was 108, assuming that all time is spent outdoors under a } \\
480 \text {-mg/day soil ingestion rate. The new value more accurately reflects the soil } \\
\text { ingestion rate of } 193 \mathrm{mg} / \text { day when both indoor and outdoor time fractions are } \\
\text { considered. Refer to page } 14 \text { of DOE/NV--1107 (NNSA/NSO, 2006). }\end{array}$ \\
\hline 7 & $\begin{array}{l}\text { Indoor Dust } \\
\text { Filtration Factor }\end{array}$ & {$[0.4]$} & {$[0.4]$} & 1 & $\begin{array}{l}\text { This is the RESRAD default value and is appropriate as, under the Industrial Area } \\
\text { and Remote Work Area scenarios, } 66 \% \text { of the time is spent indoors. }\end{array}$ \\
\hline 8 & $\begin{array}{l}\text { Shielding Factor } \\
\text { External Gamma }\end{array}$ & [0.7] & [0.7] & 1 & $\begin{array}{l}\text { This is the RESRAD default value and is appropriate as, under the Industrial Area } \\
\text { and Remote Work Area scenarios, } 66 \% \text { of the time is spent indoors. }\end{array}$ \\
\hline 9 & $\begin{array}{l}\text { Pathway } 1- \\
\text { External Gamma }\end{array}$ & Suppressed & Suppressed & Suppressed & $\begin{array}{l}\text { In general, external dose at Soils Projects will be evaluated via TLDs or direct } \\
\text { measurement with a dose-rate meter. Soil samples and RRMGs are used to } \\
\text { determine the internal dose component only. The pathway was activated for the } \\
\text { second set of RRMGs for each scenario to allow the evaluation of biased sample } \\
\text { locations where TLDs were not emplaced. }\end{array}$ \\
\hline
\end{tabular}

Note 1: Items 1-4 above are site-specific default values that were selected for the Soils Project.

Note 2: Table B.1-1 in DOE/NV--1107 (NNSA/NSO, 2006) contains several errors. The bold and bracketed values are corrections to those values.

$\mathrm{CZ}=$ Contamination zone

g/yr $=$ Grams per year

$m=$ Meter $m^{2}=$ Square meter

$m / y r=$ Meters per year

$m g /$ day $=$ Milligrams per day

\section{UNCONTROLLED When Printed}


Table 2: Soils Project - Industrial Area Exposure Scenario - Internal Dose Only

\begin{tabular}{|c|c|}
\hline Radionuclide & $\begin{array}{c}\mathbf{R R M G}_{(\mathbf{I A}-\mathbf{I})} \\
(\mathrm{pCi} / \mathrm{g})\end{array}$ \\
\hline Ag-108m & $2.737 \mathrm{E}+06$ \\
\hline Am-241 & $2.816 \mathrm{E}+03$ \\
\hline $\mathrm{Cm}-243$ & $3.852 E+03$ \\
\hline Cm-244 & $4.735 E+03$ \\
\hline Co-60 & $5.513 \mathrm{E}+05$ \\
\hline Cs-137 & $1.409 \mathrm{E}+05$ \\
\hline Eu-152 & $1.177 \mathrm{E}+06$ \\
\hline Eu-154 & $8.469 \mathrm{E}+05$ \\
\hline Eu-155 & $5.588 \mathrm{E}+06$ \\
\hline Nb-94 & $3.499 \mathrm{E}+06$ \\
\hline Pu-238 & $2.423 \mathrm{E}+03$ \\
\hline $\mathrm{Pu}-239 / 240$ & $2.215 \mathrm{E}+03$ \\
\hline Sr-90 & $5.947 \mathrm{E}+04$ \\
\hline Th-232 & $2.274 \mathrm{E}+03$ \\
\hline $\mathrm{U}-234$ & $1.960 \mathrm{E}+04$ \\
\hline U-235 & $2.089 \mathrm{E}+04$ \\
\hline U-238 & $2.120 \mathrm{E}+04$ \\
\hline
\end{tabular}

A soil sample at this RRMG value would present an internal dose potential of 25 mrem under the Industrial Area exposure scenario. 
Table 3: Soils Project - Industrial Area Exposure Scenario - Internal \& External Dose Radionuclide RRMG $_{(\mathrm{IA}-\mathrm{IE})}$

\begin{tabular}{|c|c|}
\hline Ag-108m & $(\mathrm{pCi} / \mathrm{g})$ \\
\hline Am-241 & $9.281 \mathrm{E}+01$ \\
\hline Cm-243 & $1.503 \mathrm{E}+03$ \\
\hline Cm-244 & $3.155 \mathrm{E}+02$ \\
\hline Co-60 & $4.713 \mathrm{E}+03$ \\
\hline Cs-137 & $1.833 \mathrm{E}+01$ \\
\hline Eu-152 & $7.290 \mathrm{E}+01$ \\
\hline Eu-154 & $3.826 \mathrm{E}+01$ \\
\hline Eu-155 & $3.571 \mathrm{E}+01$ \\
\hline Nb-94 & $9.583 \mathrm{E}+02$ \\
\hline Pu-238 & $9.653 \mathrm{E}+01$ \\
\hline Pu-239/240 & $2.416 \mathrm{E}+03$ \\
\hline Sr-90 & $2.207 \mathrm{E}+03$ \\
\hline Th-232 & $7.714 \mathrm{E}+03$ \\
\hline $\mathrm{U}-234$ & $5.067 \mathrm{E}+02$ \\
\hline $\mathrm{U}-235$ & $1.865 \mathrm{E}+04$ \\
\hline $\mathrm{U}-238$ & $2.555 \mathrm{E}+02$ \\
\hline & $1.423 \mathrm{E}+03$ \\
\hline
\end{tabular}

A soil sample at this RRMG value would present a TED potential of 25 mrem under the Industrial Area exposure scenario. 
Table 4: Soils Project - Remote Work Area Exposure Scenario - Internal Dose Only

\section{Radionuclide}

\begin{tabular}{|c|c|}
\hline Ag-108m & (pCi/g) \\
\hline Am-241 & $3.389 \mathrm{E}+07$ \\
\hline
\end{tabular}

\begin{tabular}{|c|c|}
\hline $\mathrm{Cm}-243$ & $2.223 \mathrm{E}+04$ \\
\hline $\mathrm{Cm}-244$ & $2.716 \mathrm{E}+04$ \\
\hline
\end{tabular}

\begin{tabular}{|c|c|}
\hline Co-60 & $7.229 \mathrm{E}+06$ \\
\hline Cs-137 & $1.955 \mathrm{E}+06$ \\
\hline
\end{tabular}

\begin{tabular}{|l|l|}
\hline Eu-152 & $1.324 \mathrm{E}+07$ \\
\hline Eu-154 & $9.741 \mathrm{E}+06$ \\
\hline
\end{tabular}

\begin{tabular}{|c|c|}
\hline Eu-155 & $6.645 \mathrm{E}+07$ \\
\hline $\mathrm{Nb}-94$ & $3.966 \mathrm{E}+07$ \\
\hline $\mathrm{Pu}-238$ & $1.388 \mathrm{E}+04$ \\
\hline $\mathrm{Pu}-239 / 240$ & $1.268 \mathrm{E}+04$ \\
\hline
\end{tabular}

\begin{tabular}{|c|c|}
\hline Sr-90 & $1.268 \mathrm{E}+04$ \\
\hline Th-232 & $8.075 \mathrm{E}+05$ \\
\hline $\mathrm{U}-234$ & $1.341 \mathrm{E}+04$ \\
\hline $\mathrm{U}-235$ & $1.379 \mathrm{E}+05$ \\
\hline $\mathrm{U}-238$ & $1.496 \mathrm{E}+05$ \\
\hline
\end{tabular}

A soil sample at this RRMG value would present an internal dose potential of 25 mrem under the Remote Work Area exposure scenario. 
Table 5: Soils Project - Remote Work Area Exposure Scenario - Internal \& External Dose

\begin{tabular}{|c|c|}
\hline Radionuclide & $\begin{array}{c}\text { RRMG } \\
(\mathbf{p C i} / \mathrm{g})\end{array}$ \\
\hline Ag-108m & $6.204 \mathrm{E}+02$ \\
\hline Am-241 & $9.239 \mathrm{E}+03$ \\
\hline Cm-243 & $2.083 \mathrm{E}+03$ \\
\hline Cm-244 & $2.715 \mathrm{E}+04$ \\
\hline Co-60 & $1.225 \mathrm{E}+02$ \\
\hline Cs-137 & $4.874 \mathrm{E}+02$ \\
\hline Eu-152 & $2.557 \mathrm{E}+02$ \\
\hline Eu-154 & $2.387 \mathrm{E}+02$ \\
\hline Eu-155 & $6.406 \mathrm{E}+03$ \\
\hline Nb-94 & $6.452 \mathrm{E}+02$ \\
\hline Pu-238 & $1.390 \mathrm{E}+04$ \\
\hline Pu-239/240 & $1.269 \mathrm{E}+04$ \\
\hline Sr-90 & $5.522 \mathrm{E}+04$ \\
\hline Th-232 & $3.292 \mathrm{E}+03$ \\
\hline $\mathrm{U}-234$ & $1.314 \mathrm{E}+05$ \\
\hline $\mathrm{U}-235$ & $1.709 \mathrm{E}+03$ \\
\hline $\mathrm{U}-238$ & $9.572 \mathrm{E}+03$ \\
\hline
\end{tabular}

A soil sample at this RRMG value would present a TED potential of 25 mrem under the Remote Work Area exposure scenario. 
Table 6: Soils Project - Occasional Use Area Exposure Scenario - Internal Dose Only

\begin{tabular}{|c|c|}
\hline Radionuclide & $\begin{array}{c}\text { RRMG (OUA-I) } \\
\text { (pCi/g) }\end{array}$ \\
\hline Ag-108m & $2.762 \mathrm{E}+08$ \\
\hline Am-241 & $4.555 \mathrm{E}+04$ \\
\hline Cm-243 & $6.307 \mathrm{E}+04$ \\
\hline Cm-244 & $7.68 \mathrm{E}+04$ \\
\hline Co-60 & $7.421 \mathrm{E}+07$ \\
\hline Cs-137 & $2.756 \mathrm{E}+07$ \\
\hline Eu-152 & $8.174 \mathrm{E}+07$ \\
\hline Eu-154 & $6.353 \mathrm{E}+07$ \\
\hline Eu-155 & $4.751 \mathrm{E}+08$ \\
\hline Nb-94 & $2.492 \mathrm{E}+08$ \\
\hline Pu-238 & $3.922 \mathrm{E}+04$ \\
\hline Pu-239/240 & $3.582 \mathrm{E}+04$ \\
\hline Sr-90 & $9.949 \mathrm{E}+06$ \\
\hline Th-232 & $3.852 \mathrm{E}+04$ \\
\hline $\mathrm{U}-234$ & $4.470 \mathrm{E}+05$ \\
\hline $\mathrm{U}-235$ & $4.922 \mathrm{E}+05$ \\
\hline $\mathrm{U}-238$ & $3.361 \mathrm{E}+05$ \\
\hline
\end{tabular}

A soil sample at this RRMG value would present an internal dose potential of 25 mrem under the Occasional Use Area exposure scenario. 
Table 7: Soils Project - Occasional Use Area Exposure Scenario - Internal \& External Dose

\begin{tabular}{|c|c|}
\hline Radionuclide & $\begin{array}{c}\mathbf{R R M G}_{(\text {OUA-IE) }} \\
(\mathrm{pCi} / \mathrm{g})\end{array}$ \\
\hline Ag-108m & 2.087E+03 \\
\hline Am-241 & $2.797 \mathrm{E}+04$ \\
\hline $\mathrm{Cm}-243$ & $6.886 \mathrm{E}+03$ \\
\hline $\mathrm{Cm}-244$ & 7.653E+04 \\
\hline Co-60 & $4.122 \mathrm{E}+02$ \\
\hline Cs-137 & $1.640 \mathrm{E}+03$ \\
\hline Eu-152 & $8.604 \mathrm{E}+02$ \\
\hline Eu-154 & $8.031 \mathrm{E}+02$ \\
\hline Eu-155 & $2.156 \mathrm{E}+04$ \\
\hline Nb-94 & $2.171 \mathrm{E}+03$ \\
\hline Pu-238 & $3.915 E+04$ \\
\hline $\mathrm{Pu}-239 / 240$ & $3.573 E+04$ \\
\hline Sr-90 & $1.955 \mathrm{E}+05$ \\
\hline Th-232 & $1.062 \mathrm{E}+04$ \\
\hline U-234 & $4.252 \mathrm{E}+05$ \\
\hline U-235 & $5.749 \mathrm{E}+03$ \\
\hline U-238 & $3.219 \mathrm{E}+04$ \\
\hline
\end{tabular}

A soil sample at this RRMG value would present a TED potential of 25 mrem under the Occasional Use Area exposure scenario. 


\section{$\underline{\text { References }}$}

CFR, see Code of Federal Regulations.

Code of Federal Regulations. 2012. Title 10 CFR Part 835, “Occupational Radiation Protection.” Washington, DC: U.S. Government Printing Office.

DOE, see U.S. Department of Energy.

NNSA/NSO, see U.S. Department of Energy, National Nuclear Security Administration Nevada Site Office.

U.S. Department of Energy. 2011. Radiation Protection of the Public and the Environment, DOE Order 458.1, Change 2. Washington, DC: Office of Health, Safety, and Security.

U.S. Department of Energy, National Nuclear Security Administration Nevada Site Office. 2006. Industrial Sites Project Establishment of Final Action Levels, Rev. 0, DOE/NV--1107. Las Vegas, NV.

Yu, C., A.J. Zielen, J.J. Cheng, D.J. LePoire, E. Gnanapragasam, S. Kamboj, J. Arnish, A. Wallo III, W.A. Williams, and H. Peterson. 2001. User's Manual for RESRAD Version 6, ANL/EAD-4. Argonne, IL: Argonne National Laboratory, Environmental Assessment Division. (Version 6.5 released in October 2009.) 


\section{Appendix B}

\section{Project Organization}




\section{B.1.0 Project Organization}

The NNSA/NSO Soils Activity Lead is Kevin Cabble. He can be contacted at (702) 295-5000.

The identification of the project Health and Safety Officer and the Quality Assurance Officer can be found in the appropriate plan. However, personnel are subject to change, and it is suggested that the NNSA/NSO Soils Activity Lead be contacted for further information. The Task Manager will be identified in the FFACO Monthly Activity Report prior to the start of field activities. 


\section{Appendix C}

\section{Nevada Division of Environmental}

Protection Comments

(1 Page) 


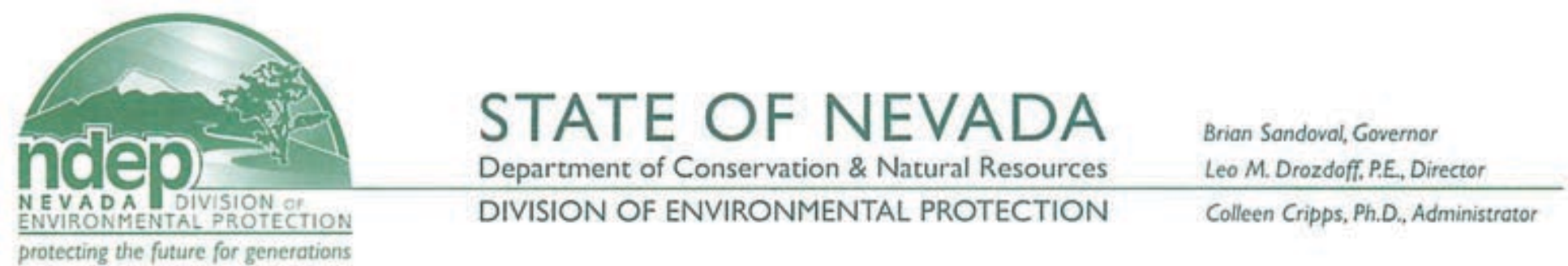

April 25, 2012

Robert F. Boehlecke

Federal Project Director

Environmental Restoration Project

National Nuclear Security Administration

Nevada Site Office

P. O. Box 98518

Las Vegas, NV 89193-8518

RE: Review of Draft Corrective Action Investigation Plan (CAIP) for Corrective Action Unit (CAU) 550: Smoky Contamination Area, Nevada National Security Site, Nevada Federal Facility Agreement and Consent Order

Dear Mr. Boehlecke,

The Nevada Division of Environmental Protection, Bureau of Federal Facilities (NDEP) staff has received and reviewed the draft CAIP for Corrective Action Unit (CAU) 550: Smoky contamination Area. NDEP's review of this document did not indicate any deficiencies.

If you have any questions regarding this matter contact me at (702) 486-2850 ext. 233

Sincerely,

\section{/s/ Jeff MacDougall}

Jeff MacDougall, Ph.D., C.P.M.

Supervisor

Bureau of Federal Facilities

THM/JJM/JW: jjm

cc: J. T. Fraher, DTRA/CXTS, Kirtland AFB, NM

N-I Central Files, MS NSF 156

NSTec Correspondence Control, MS NLV008

T. A. Lantow, ERP, NNSA/NSO, Las Vegas, NV

FFACO Group, PSG, NNSA/NSO, Las Vegas, NV 


\title{
Library Distribution List
}

\author{
$\underline{\text { Copies }}$
}

U.S. Department of Energy

1 (Uncontrolled, electronic copy)

National Nuclear Security Administration

Nevada Site Office

Technical Library

P.O. Box 98518, M/S 505

Las Vegas, NV 89193-8518

U.S. Department of Energy

1 (Uncontrolled, electronic copy)

Office of Scientific and Technical Information

P.O. Box 62

Oak Ridge, TN 37831-0062

Southern Nevada Public Reading Facility

2 (Uncontrolled, electronic copies)

c/o Nuclear Testing Archive

P.O. Box 98521, M/S 400

Las Vegas, NV 89193-8521

Manager, Northern Nevada FFACO

1 (Uncontrolled, electronic copy)

Public Reading Facility

c/o Nevada State Library \& Archives

100 N. Stewart Street

Carson City, NV 89701-4285 